University of Louisville

ThinkIR: The University of Louisville's Institutional Repository

Electronic Theses and Dissertations

\title{
$5-2011$
}

\section{The lived experience of mothering during incarceration.}

\author{
Barbara M. Jackson
}

University of Louisville

Follow this and additional works at: https://ir.library.louisville.edu/etd

\section{Recommended Citation}

Jackson, Barbara M., "The lived experience of mothering during incarceration." (2011). Electronic Theses and Dissertations. Paper 667.

https://doi.org/10.18297/etd/667

This Doctoral Dissertation is brought to you for free and open access by ThinkIR: The University of Louisville's Institutional Repository. It has been accepted for inclusion in Electronic Theses and Dissertations by an authorized administrator of ThinkIR: The University of Louisville's Institutional Repository. This title appears here courtesy of the author, who has retained all other copyrights. For more information, please contact thinkir@louisville.edu. 


\title{
THE LIVED EXPERIENCE OF MOTHERING DURING INCARCERATION
}

\author{
By
}

Barbara M. Jackson

B.S.N, Indiana University- Southeast, 2005

\begin{abstract}
A Dissertation
Submitted to the Faculty of the

In Partial Fulfillment of the Requirements

For the Degree of

Doctor of Philosophy

School of Nursing

University of Louisville

Louisville, Kentucky
\end{abstract}

School of Nursing of the University of Louisville

May 2011 
Copyright 2011 by Barbara M. Jackson

All rights reserved 



\section{THE LIVED EXPERIENCE OF MOTHERING DURING INCARCERATION}

By

Barbara M. Jackson

B.S.N., Indiana University-Southeast

A Dissertation Approved on

April 15, 2011

By the following Dissertation Committee:

Dr. Vicki Hines-Martth - Dissertation Čhair

Dr. Deborah Armstrong

Tr. Peggy El-Mallakh

Dr. J. Price Foster

Dr. Muriel Harris 


\section{DEDICATION}

This dissertation is dedicated to my husband, John, for giving me encouragement and love when the road became rough and for always being on my side, regardless. You are my champion and your support has let me succeed. Thank you for holding things together for these last few years and for giving me the freedom to pursue my goal.

To my daughters, Amanda and Cynthia, thank you for giving me a reason to forge ahead and providing me with endless hours of laughter and joy. You make me want to be a better person and a better mother and it is because of who you are as young women that I treasure being your mother.

To my dad, thank you for always believing that I could and would finish this piece of work, providing me the countdown to the finish and always giving me unwavering love and support.

To my mom, thank you for giving me the inspiration to pursue this degree and allowing me to find my own way. I cherish you as my colleague, my mother, and my friend. 


\section{ACKNOWLEDGEMENTS}

I would like to thank my dissertation chairperson, Dr. Vicki Hines-Martin. You have given me much motivation throughout this process with your enthusiasm for my research. Your optimism and confidence in my work allowed me to reach new heights. I would also like to thank Dr. Deby Armstrong for being there from the beginning of this adventure and giving me so much encouragement and support. To Drs. El-Mallakh, Harris, and Foster: thank you for your invaluable guidance with my research and dissertation. As my dissertation committee, you all have inspired me with your knowledge and freely imparted your wisdom.

I would like to thank Janet Conover, the warden at the Kentucky Correctional Institution for Women. I appreciate you opening the doors to your prison and allowing me to work with the mothers who reside at your facility. To Shannon Butrum, Procedures Officer at Kentucky Correctional Institution for Women, thank you so very much for all of the time you committed to organizing and scheduling my visits to KCIW. You have been a gracious and kind collaborator in this project and I appreciate everything you did to assist me in reaching my goal.

I would also like to express my gratitude to Dr. Jacque Reid, associate professor at the School of Nursing at Indiana University Southeast for inspiring me to work with the women at KCIW. Providing me with the opportunity to teach prenatal classes to the incarcerated women at KCIW in my undergraduate program started me on this path and I will be forever grateful for your guidance and friendship. As well, I would like to thank 
Dr. Mimi McKay, Dean at the School of Nursing at Indiana University Southeast, who along with Jacque, introduced me to conducting research with incarcerated women by allowing me to assist in collecting data for their study.

To my colleagues and friends, thank you for lending me a sympathetic ear, even when my thoughts were jumbled and my perspective was skewed, and for being my cheerleaders and showing me the love that helped guide me along the yellow brick road. 


\begin{abstract}
The Lived Experience of Mothering During Incarceration

Barbara M. Jackson
\end{abstract}

April 15. 2011

A phenomenological study of the lived experience of mothering during incarceration was conducted at a women's multi-custody level prison in Kentucky. The purpose of the study was to explore and describe the experience of mothering among incarcerated women to address the gap within this body of literature. Semi-structured interviews, observation, and field notes from 24 participants were collected and analyzed to provide an in-depth understanding of the mothering experience for the participants. Burnard's method was used for analysis of the interview data. Two major themes emerged including: Living in the fire: The lived experience of incarcerated mothers which stemmed from two sub-themes: "Mistakes were made" and the 'Here and Now' of it and "Emerging from the fire: Dreams for the future as mothers" which arose from the sub-themes "Motivated to change" and "Redefining themselves". 


\section{TABLE OF CONTENTS}

PAGE

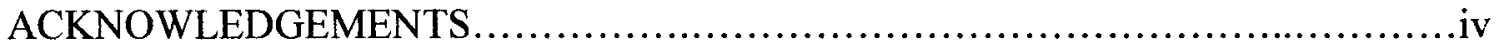

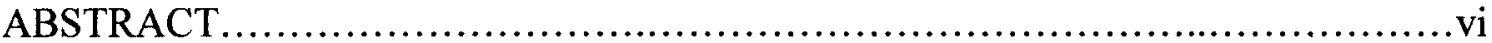

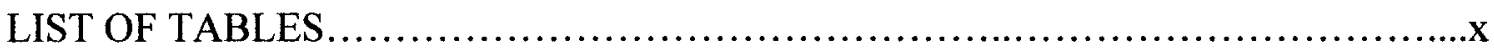

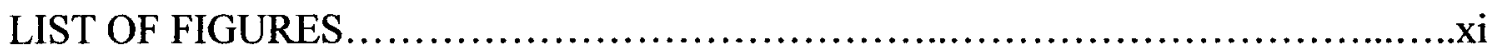

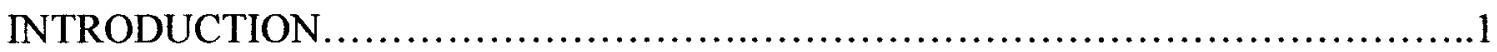

Background and Significance of the Problem...............................

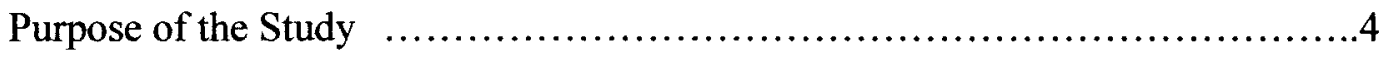

Definition of Terms...............................................................

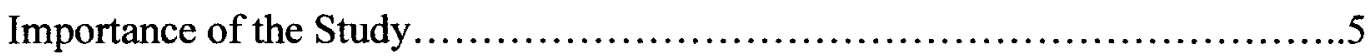

\section{REVIEW OF THE LITERATURE 8}

Incarceration Period.................................................................

Reasons women commit crimes......................................

Characteristics of incarcerated women................................11

Substance abuse ...............................................11

Education.....................................................

Socioeconomic status..........................................13

Consequences for the children.......................................

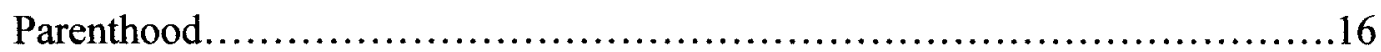

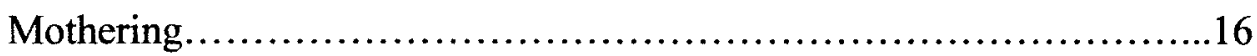

Preparing to Go Home............................................................ 
Reintegration and Reestablishing Relationships.......................19

Characteristics of the formerly incarcerated mother.......................19

Reintegration of the formerly incarcerated woman......................20

Reestablishing relationships....................................21

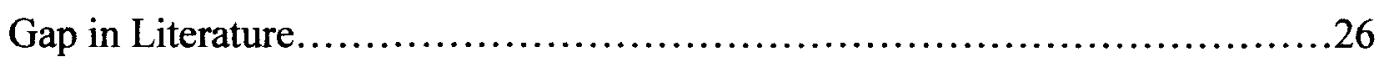

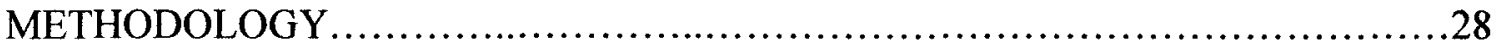

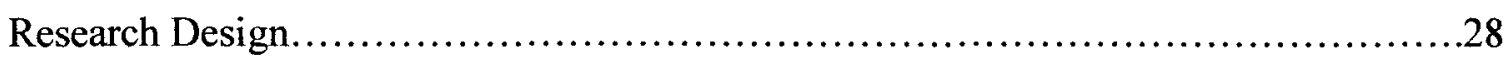

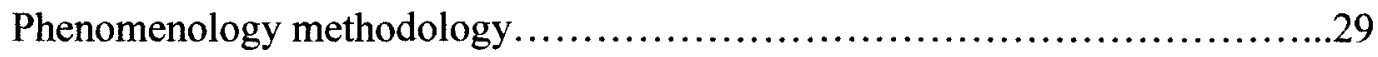

van Manen's phenomenological method......................................

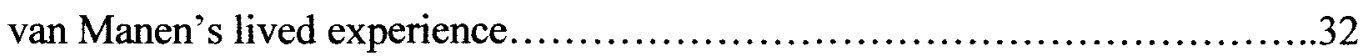

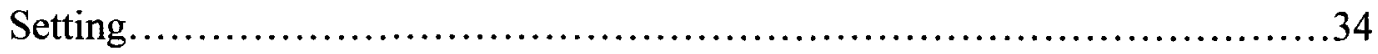

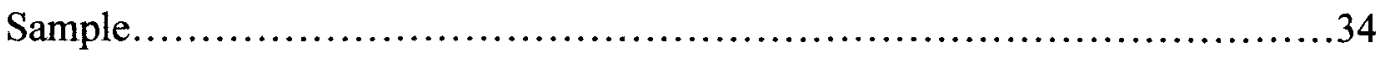

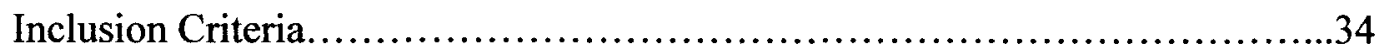

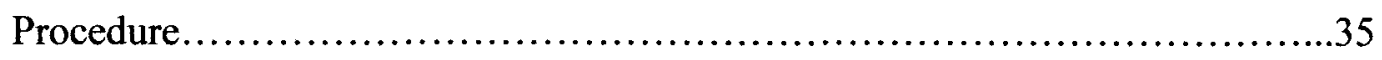

Recruitment........................................................

Data Collection.............................................................

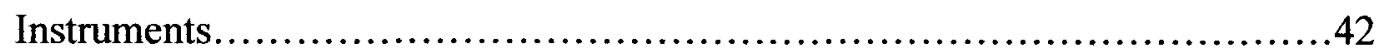

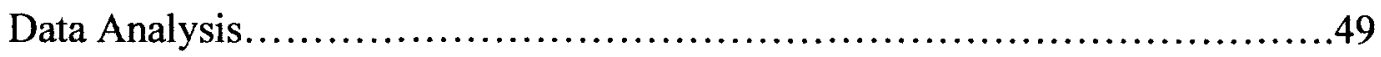

Trustworthiness in phenomenological research.....................49

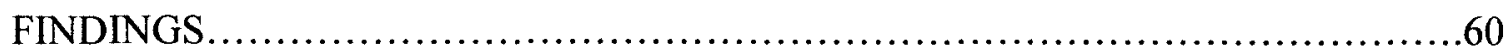

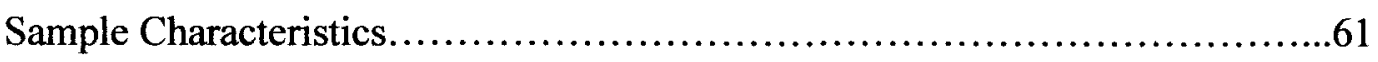

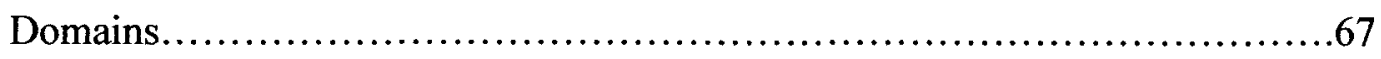

Use of metaphors in research............................................68 
The Phoenix Rising from the Ashes......................................68

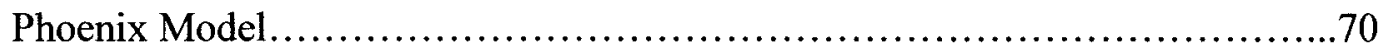

The Lived Experience of Mothering ........................................

Theme \#1: Living in the Fire: The Lived Experience of Incarcerated Mothers...72

Theme \#2: Emerging from the Fire: Dreams for the Future as Mothers...........75

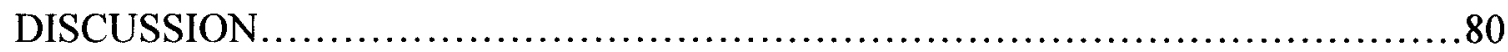

Nursing Literature: Importance of this Research.............................80

Nursing Practice: Importance of this Research.............................83

Nursing Research: Importance of this Research..............................85

Public Policy: Importance of this Research...................................86

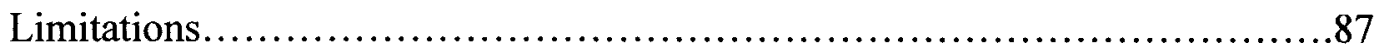

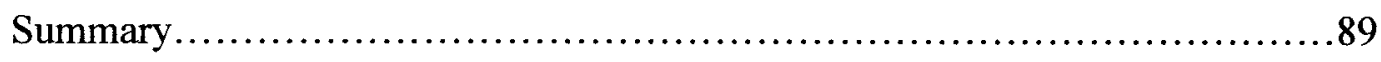

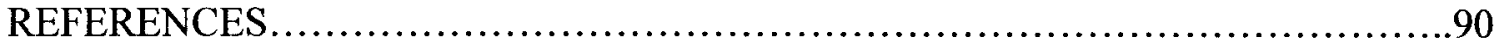

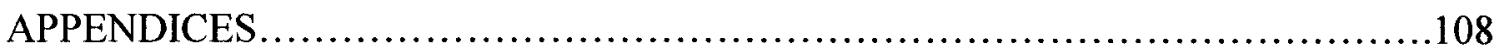

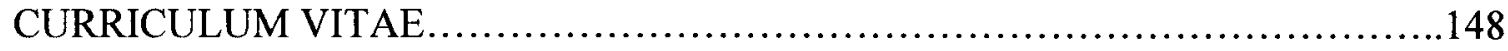




\section{LIST OF TABLES}

$\begin{array}{ll}\text { TABLE } & \text { PAGE }\end{array}$

1. Mothering Domains and Corresponding Interview Questions.....................45

2. Characteristics of Rigor and Approaches Used in this Research....................52

3. Primary Questions and Identified Codes/Responses.............................57

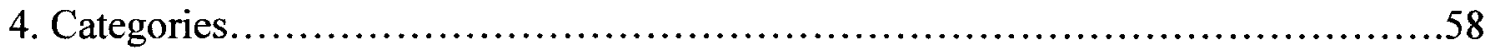

5. Philip Burnard's Stages of Interview Analysis...................................59

6. Age, Time Served, and Number of Children of the Participants................62

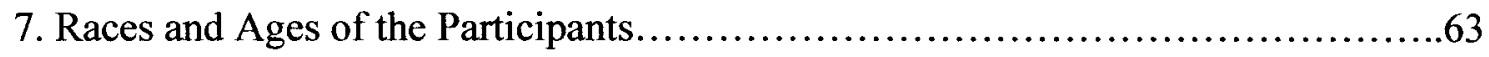

8. Number of Children per Mother and Ages of Children........................64

9. Contact with Children per Month..........................................65

10. Length of Sentence and Type of Offense.................................66 


\section{LIST OF FIGURES}

1. Relationship between Research Questions, Domains, and Interview Questions........46

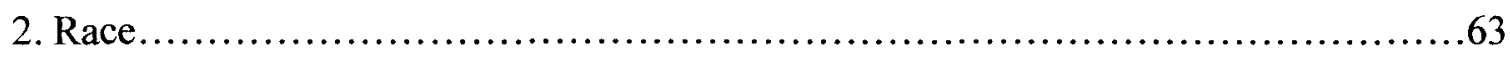

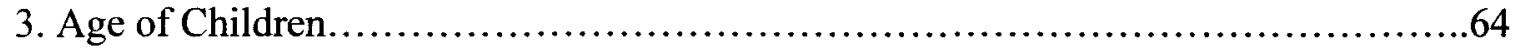

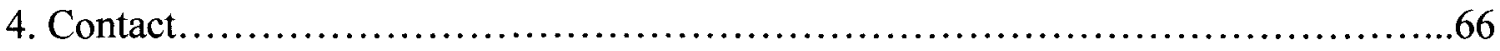

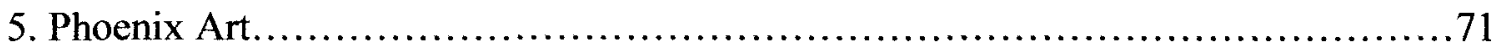




\section{CHAPTER 1}

\section{INTRODUCTION}

\section{Background and Significance of the Problem}

Mothering evokes different ideas among different people. To some, it is the memory of the warmth of loving arms soothing a hurt. To others, it is a more barren memory. We like to think that everyone has experienced positive mothering. When a woman becomes a mother, she draws on the memories of her own experiences with her mother to define her own maternal identity. Maternal identity evolves as a woman moves toward assuming the role of mother through her connection to her new identity. While many influences encourage the growth of a mother's identity, others threaten to disrupt the evolution of maternal identity and the development of mothering skill. These facilitators and barriers to the development of mothering identity include maternal age, socioeconomic status, culture, support systems and maternal-infant separation (Flagler, 1990; Mercer, 1986; Rubin, 1984).

Maternal-infant separation due to incarceration is an increasingly common threat to the development of maternal identity and mothering skill. There has been a dramatic increase in the number of women incarcerated in federal and state prisons in the United States over the past four decades jumping from 5,635 in 1970 to 115,779 by mid 2008 (Ruiz, 2002; West \& Sabol, 2009). When compared to the number of incarcerated men (growing $416 \%$ from 1977 to 2007), the number of incarcerated women jumped $832 \%$ over those same years (West \& Sabol, 2008). 
Nationally it is estimated that $51 \%$ of incarcerated women are between the ages of $30-44$ and $80 \%$ of incarcerated women are mothers. Approximately $60 \%$ of the women who are mothers have minor children (Mumola, 2000; West \& Sabol, 2009). Kentucky has also experienced a dramatic increase in incarcerated women, increasing by $20.1 \%$ between 1999 and 2003 (Kentucky Corrections, 2005). Kentucky Correctional Institution for Women, (KCIW), the only state prison for women until the year 2010, had an average daily population of 675 women, or $5 \%$ of the total prison population in the state in 2008 (Kentucky Corrections, 2008). KCIW is one of only two women's state prisons in the state with the other prison having opened in the year 2010.

There are no published data on the number of incarcerated women in Kentucky who have minor children. The author's personal experience teaching prenatal classes at KCIW in 2004 clearly illustrated the need for attention to the issue of mothering during incarceration. Attendees of the prenatal classes were first-time and experienced mothers. During prenatal classes, the women who were separated from their children spoke of how they missed their children and how their children were negatively affected by their incarceration. Many of these mothers expressed a belief in the importance of the mother and child bond which sparked the author's interest in the development of prison parenting programs. However, before a parenting program can be developed it is critical to understand the importance incarceration has on the process of mothering from the perspective of incarcerated women themselves. In addition to the author's firsthand experience, review of the literature indicates there has been limited research related to the experience of mothering in prison. In light of the growing numbers of women of childbearing age who are incarcerated, it is essential to increase understanding of the 
experience of mothering while incarcerated. An understanding of this phenomenon can serve as a foundation for the development and evaluation of programs for these underserved women and their children. Literature regarding the experience of mothering by incarcerated women is lacking. An absence of pertinent research can not only have an effect of those women who are mothers but also has broad implications for society. A mother's incarceration affects the family structure, her children and how those children function within their communities over the course of their lives.

The U.S. Census Bureau (2010) reported that 9,924,000 households were headed solely by women. Houck and Loper (2002), in their study of 362 incarcerated mothers, reported that $76.5 \%$ had day-to-day responsibility for their children, and $23.7 \%$ had sole responsibility for their child prior to incarceration. In addition to the basic needs, children are dependent on their mothers for security, and often maintain a close distance to her when they are anxious, hurt, tired or scared. As children age into adolescence and adulthood they continue to seek their mother's reassurance when they experience periods of anxiety and uncertainty. Children, regardless of their age, benefit from a positive mother-child relationship. The quality of the relationship between mother and child translates into the quality of other relationships for the child as s/he ages (Bowlby, 1982). This cycle of mother-child interaction can continue when that child becomes a parent and can either be a positive relationship or can have issues that cause it to be a negative relationship. External stressors such as unemployment and socioeconomic status, and interpersonal stressors such as domestic violence and divorce can challenge parental coping and trigger parents to be more critical and corrective (Webster-Stratton, 1990). In turn, these behaviors can heighten the possibility of a negative mother-child relationship 
and the chances of the children developing conduct problems, further increasing the stress on the relationship (Poehlmann, 2005b). There is a strong relationship between parenting stress and child emotional and behavioral maladjustment. The presence of legal stressors for the parent is clearly a source for negative parent-child interaction.

Statistics from the year 1997 showed that there were 1.3 million children with parents who were incarcerated and most of those were under age 10, which was an increase of $131 \%$ from 1991 (Johnson \& Waldfogel, 2002). Of the 65,600 incarcerated mothers in state and federal prisoners, estimates of the number of children under the age of 18 with an incarcerated mother ranged from 147,000 to 200,000 (Glaze \& Maruschak, 2008; Gaudin \& Sutphen, 1993; Houck \& Loper, 2002; Myers, Smarsh, Amlund-Hagen, \& Kennon, 1999). Most incarcerated mothers experience intense distress when initially separated from their children (Poehlmann, 2005b). Likewise, many children with an incarcerated mother describe themselves as having poor relationships with their mothers and they responded to the separation from their mothers with anger and sadness (Poehlmann, 2005a). Once the bond between mother and child is broken, then both the mother and child can experience depression and grief (Bowlby, 1990). Understanding the consequences of incarceration on the mother is important to further safeguard the motherchild relationship.

\section{Purpose of the Study}

The purpose of the study was to explore and describe the experience of mothering among incarcerated women to address the gap within this body of literature. This study probed the meaning and experience of being a mother in this sample. Data obtained from this study offers many insights regarding the experience of mothering during 
incarceration. The focus is to gain an understanding of the way incarcerated mothers experience their world and its influence on mothering. The research targets exploration of the mothers' evaluation of the mothering role, what hopes they have in relation to that role, what they see as barriers, their perceived needs and what values they hold related to mothering.

\section{Definition of Terms}

The following definitions applied to the terms mother and mothering throughout this study. The term Mother is defined as a woman who has lived with her dependent child/children, and for whom she has self-identified parental responsibility. Mothering is defined as a multifaceted process of caring for one's child/children that continues through the course of the lifespan. Inherently, mothering is influenced by many variables such as maternal age, maternal or infant illness, perception of the birth experience, maternalinfant separation, support system, self-concept, infant temperament, culture, and socioeconomic status (Francis-Connolly, 1998, 2000, \& 2004; Mercer, 1986; Rubin, $1967 \& 1984)$. The fundamental nature of mothering is influenced by these factors and is subjectively defined and valued. Although separation due to incarceration interrupts the process of mothering, this research intends to explore how mothering is viewed by these women and how the mothering role continues during this period of separation.

\section{Importance of the Study}

Very little research focused exclusively on women in prison has been found, particularly in nursing literature. The current body of literature reveals that research related to incarcerated mothers has centered primarily on four main categories; (1) pregnancy in prison, (2) how maternal incarceration affects the children, (3) evaluation of 
existing prison parenting programs and (4) the factors that support or hinder a woman's transition from prison into the community (Golden, 2005; Hagen \& Myers, 2003;

Johnson \& Waldfogel, 2003; Liptak, 2006; Nesmith \& Ruhland, 2008; Palm, 2003; Pollack, 2002a; Williams \& Schulte-Day, 2006). No studies were identified that focused on the mothering "role" experience of women who are incarcerated. A literature search in CSA Illumina of Criminal Justice abstracts, using the key words "prisoners" and "mothers", resulted in 58 publications. Many of these publications focused on the effect on the children, the need for program development and assessment of policy. Conducting the same literature search using the Cumulative Index to Nursing and Allied Health Literature (CINAHL) database resulted in 38 articles. Most of the resulting articles focused on the children of incarcerated mothers, the health of incarcerated mothers, and mothers' reentry into their communities upon release. The focus of this study was to explore and describe the experience of mothering among incarcerated women. Only three identified studies have been completed that are closely related to this study. The first was a qualitative study focusing on mothering behind bars (Berry \& Smith-Mahdi, 2006), the second focused on mothering subsequent to release from incarceration (Hayes, 2007) and the third study was a qualitative dissertation that focused on the experience of mothering behind bars (Weiss, 2010). All relevant studies are discussed in the review of literature.

Maternal-child separation is known to have serious effects on family structure and function, and on normal growth and development of children (Kuhn \& Schanberg, 1998). Maternal incarceration interrupts the lives of the mother and her children. More than $60 \%$ of incarcerated mothers in state prisons reported living with their minor children prior to arrest and $77 \%$ of those had the primary caregiving responsibility of their children and 
most will resume the mothering role after release (Glazen \& Maruschak, 2008). There has been a demonstrated increase in incarcerated women nationally, as a whole and specifically, in Kentucky. A clearer understanding of mothering among incarcerated women adds to the knowledge on which appropriate interventions can be based.

Research is needed to understand the subjective views and perceived needs of mothers that may be foundational in successful treatment and rehabilitation of incarcerated women. This study seeks to expand that knowledge regarding the experience of mothering while incarcerated. 


\section{CHAPTER 2}

\section{REVIEW OF LITERATURE}

This chapter reviews the literature as it relates to incarcerated mothers and includes descriptions and characteristics of the population, the implications of incarceration on their children and the process of reintegration of formerly incarcerated women into the community. Extant literature on mothering and influences on mothering ability, including maternal self-efficacy will also be presented.

\section{Incarceration Period}

\section{Reasons women commit crimes.}

It has been widely documented that men commit more crime than women (Steffensmeier \& Allan, 1996; Blitz, Wolff, Pan, \& Pogorzelski, 2005; Simpson, 1989) and crime committed by males has been an ongoing focus in the literature (Freeman, 1996; Jiang \& Winfree, 2006). Much less has been written about incarcerated women. However, within this literature, theories have evolved over time that attempt to explain why women commit crimes.

The literature regarding incarcerated women has identified that motivators which draw women into criminal activities are different from the motivations that draw men in to the same activities. Criminologists in the late 1800's forecasted an increase in female criminality as social norm changes occurred between men and women, and as women continued their pursuit of economic equality (Pollak, 1950). As women entered the 
workforce and began to enjoy more independence such as driving, shopping, and banking, these changes in social activity were proposed as explanations for some of the increases in female criminality. Other theories focused on excessive masculine traits in some women or female specific motives in other women as a cause for criminal behavior. A study ( $\mathrm{n}=87$ ) exploring the link between age, testosterone levels and incarcerated women's behaviors found that there are higher levels of aggressive behaviors in younger inmates than those of their older counterparts in part as a result of decreasing testosterone levels as they age (Dabbs Jr. \& Hargrove, 1997). Although crimes are committed by women of all ages, $77 \%$ of women in state prisons are between the ages of 25 and 44 (Greenfeld \& Snell, 1999). Glueck and Glueck (1950), in their study of juveniles and crime perpetrated by women, identified that some women from disadvantaged neighborhoods and negative family contexts use sex as a source of income and therefore were incarcerated for prostitution at significantly higher rates than men. Likewise, Pollak (1950) described the biological, psychological, and sociological factors that contribute to female crime. Regardless of being male or female, being from lower socioeconomic conditions, having low education levels, having poor employment opportunities, and being from a minority group result in more serious criminal offenders. One key distinction is that there are a high number of dependent children among women who commit crimes (Steffensmeier \& Allen, 1996).

One researcher that sought to explore the differences in male and female characteristics as they pertain to criminal activity was Denno in Gender, crime, and the criminal law defenses (1994). Denno reported that women who commit crimes have a larger number of diagnosed psychological or biological and neurological disorders. Her 
findings were based on analysis of a longitudinal study conducted in Philadelphia with 1000 participants. The participants whom she followed from birth through early adulthood were African American youth whose mothers were part of a much larger study looking at biological and environmental influences on pregnancy. Along with the internal factors that can lead a woman to commit a crime, there are external factors that play a role in female criminality.

Steffensmeier and Allan (1996) and others have focused on the economic motivations for women to commit crime (Sommers \& Baskin, 1993; Sampson \& Wilson, 2005). Since women have higher rates of arrest for shoplifting, check and welfare fraud, a downward turn in the economy can lead to an increase in these economic crimes among women (Zaplin, 2008). Economic crimes do not demand specific talents, are more amenable to a woman's lifestyle as the primary household shopper, and easier to carry out with increases in available credit (Steffensmeier \& Allan, 1996). Bloom, Owen and Covington (2003), in a three-year national study, conducted 40 group and individual interviews with women offenders, the developers of public policy and those who work with women in the criminal justice arena. These investigators described effective gender specific interventions through their identification that "Women's most common pathways to crime are based on survival of abuse, poverty, and substance abuse" (Bloom, Owen \& Covington, 2004, p. 34). The resulting report identified significant gender disparities, implications for improving services for incarcerated women, and identification of incarcerated women's needs from the women's perspectives (Bloom, Owen \& Covington, 2003). 
Having an understanding of the motivators for female perpetrated crimes provides insight into the lives of this population and is important for treatment, punishment and rehabilitation. Factors such as financial burden, drug addiction, and domestic violence may result in economic or drug crimes for survival (Ferraro \& Moe, 2003). Paradoxically, the period of incarceration may function as a time in which women improve their personal health status related to communicable diseases, substance abuse, and mental health problems (Baldwin, 2000).

\section{Characteristics of incarcerated women.}

Johnston and Gabel (1995) reported that the incarcerated female offender typically comes from a single-parent home and/or has grown up in a dysfunctional household where other members of her family have also been incarcerated. Female offenders come primarily from lower socioeconomic groups, exhibit economic dependency on other people or the welfare system, experience low self-esteem, and perceive a lack of possibilities and a lack of choices in their future; hence, the prison experience only serves to add to these disadvantages (Morash \& Schram, 2002; Morton, 2004). Throughout the literature several factors were consistently linked to the incarcerated woman's criminal behaviors. These factors were substance abuse, low educational achievement, and low socioeconomic status. These factors are briefly described below.

Substance abuse. The Bureau of Justice Statistics (1999) reports that drug related incarcerations of women in 1979 accounted for $15 \%$ of incarcerations and by 1999 accounted for roughly $45 \%$. Experts propose that the increase in incarcerated women can be traced to national and state drug policies that commanded prison terms for drug offenses. Approximately $30 \%$ of women in prison report that they committed crimes to 
get money for drugs and the number of women who reported that they used drugs prior to incarceration was greater than the number of men who reported drug use (Morton, 2004). Sixty-five percent of incarcerated mothers reported drug use in the month prior to the arrest while $43 \%$ reported that they committed their offense because of drugs (Mumola, 2000). Theall, Elifson, Sterk, and Stewart (2007) report shoplifting, drug sales, prostitution, credit card fraud, and check fraud as crimes that can be associated with the female criminal's drug use. Women who are addicted to drugs have low self-esteem and as many as $75 \%$ have been a victim of sexual abuse (Henderson, 1998). McClellan, Farabee and Crouch (1997) found that early childhood mistreatment that continues into adulthood leads to a lower self-esteem and higher rate of drug abuse. Consequently they report that higher rates of drug abuse leads to higher rates of female criminality.

Theall et al. (2007) also report that violent female criminality is closely related to depression, lack of self-control, the riskiness of the setting in which the drug use took place, the frequency of drug use and the route by which the drugs were taken.

Education. An understanding of the role of education as it relates to criminality in women has evolved over time. The first comprehensive discussion of education and incarcerated women was in The Criminality of Women (Pollak, 1950). Pollak (1950) concluded that as a result of a low intelligence quotient (IQ), girls were apt to be truant from school and turn to the street, ultimately leading them to a life of professional crime. This view has changed to the recognition that a lack of education results in limited economic options for women. Pimlott and Sarri (2002) concluded that most female offenders have not reached sufficient academic achievement for the current job market. Of the total prison population, roughly one in six prisoners quit school because of their 
illegal actions, either from committing crime or being convicted of committing a crime (Harlow, 2003). Most women in prison have limited education with less than 50\% completing a high school education. The United States Department of Justice reports that $42 \%$ of female inmates had not graduated from high school or obtained their diploma through general education development (Harlow, 2003). Golden (2005) stated that most women enter prison without a high school diploma and the lack of academic qualifications makes career placement difficult upon release. This lack of education further places women who are mothers at greater risk for incarceration, maternal-child separation, and difficulty in the mothering role.

Socioeconomic status. The literature consistently identifies that women earn less on average than men. Ninety-two percent of incarcerated women report annual incomes of less than $\$ 10,000$ prior to their incarceration (Child Welfare League, 2004). According to the United States Department of Health and Human Services (2008), this number falls below the 2008 poverty threshold for a single person in the United States. There is a common myth that the proverbial glass ceiling is broken and that women can compete in the workforce by being given equal opportunities for promotion and equal salaries. However, as seen in the research, that myth is shattered when it is shown that economic stability is unattainable for many women (Morash \& Schram, 2002). This instability is further increased when women have children and have not obtained adequate education (Schein, 1995, p. 153). Women in lower socioeconomic groups generally have less control over their lives and are stuck in the cycle of going between welfare and low paying jobs and back again (Zaitzow, 2006). For many women the cycle also includes a prison sentence if they commit crimes associated with welfare fraud, check fraud, or 
other economic crimes. For these women, there is a growing reliance on the welfare system after incarceration due to an inability to make a living wage, especially if they have children (Pearce, 2002). In spite of the increasing numbers of incarcerated women, little is known about their needs in general, and not much is documented about the care and welfare of their young children (Ruiz, 2002).

\section{Consequences for the Children.}

The incarceration of a mother has ramifications for the children she leaves behind, especially if she was the primary caregiver of those children prior to her imprisonment. Children of incarcerated mothers face unique challenges. Because of the mother's arrest, the child may have experienced distress from the unexpected separation from their mother and most children are at risk for feelings of fear, worry, resentment, sadness, depression and blame (Poehlmann, Shlafer, Maes, \& Hanneman, 2008; Simmons, 2000). Depending on their ages, children are at risk for behavioral issues, delinquency, cognitive delays, and attachment anxiety (Hagen, Myers, \& Mackintosh, 2005; Murray \& Farrington, 2007; Poehlmann, 2005a).

The literature shows some consistent findings in relation to the effect of a mother's incarceration on her children. Travis and Waul (2003), in their report of the consequences of a parent's incarceration on children, have detailed five common negative effects a parent's incarceration has on the children: (1) trauma related to the event; (2) impaired developmental tasks as the child's energy is diverted due to the trauma; (3) uncertainty making it more difficult for children to cope; (4) reactions that vary over time, i.e. initial reaction to the crisis versus the longstanding response, or whether they learn to adapt or experience anxiety or depression; and (5) experiencing stigma related to 
having a parent in prison. Young children with an incarcerated mother experience problems that differ depending on each family's situation. In some cases, the disruption of having to move into a new home situation will cause suffering (Myers, Smarsh, Amlund-Hagen, \& Kennon, 1999). Hagen and Myers (2003) suggest that children are at risk for inadequate or inappropriate relationships with peers and adults, and may isolate themselves because of embarrassment or may experience an inability to form close relationships. The child may experience the shame and stigma of having a mother in prison. An adolescent with an incarcerated mother is at higher risk for association with a deviant peer group such as a gang, and less involvement with conventional social situations, such as school. These children drop out of high school at a rate three times higher than other adolescents, and they take part in more deviant behaviors, including lying, cheating, and stealing (Johnston \& Gabel, 1995; Myers, Smarsh, Amlund-Hagen \& Kennon, 1999). There is a strong relationship between parental criminal activities and criminal behavior of their children especially if the parent and child are the same sex and a first degree relative. That relationship is only half as strong if the parent and child are the opposite sex (Rowe \& Farrington, 1997).

Children of incarcerated mothers have described a number of concerns including worrying about caregivers and social isolation; however, they also show resilience in establishing places of support and self-reliance (Nesmith \& Ruhland, 2008). In children who had not lived with their mothers prior to incarceration, there were no identified signs of distress due to the separation as the separation had occurred at an earlier time, often due to their mother's substance abuse behaviors (Kampfner, 1995). The incarceration of a mother may in fact result in a more stable situation if a child has been living in a home where substance abuse is common (Myers, Smarsh, Amlund-Hagen \& Kennon, 1999). This 
stability only occurs if a dependable family member is able to be the child's caregiver (Mumola, 2000).

There is a growing understanding that the consequences of incarceration are not endured by mothers alone; the children of incarcerated mothers are also adversely affected. They have been found to experience difficulties in adjustment, emotional growth and development and educational attainment. They are more likely to drop out of school, take part in delinquent activities, and/or be incarcerated themselves.

Phillips, Dettlaff, and Baldwin (2010) explored the overlap of the repercussions of a parent's involvement in the criminal justice system and existing child welfare cases. Child welfare agencies are significantly impacted by parental criminal activity when there had been corresponding child abuse committed by the parent. The child welfare system was involved when a decision was made to remove the children from the home as a result of the criminal activity, and the lack of relatives free of criminal histories meant the children were placed in the foster care system (Phillips \& Dettlaff, 2009; Phillips, Dettlaff, \& Baldwin, 2010).

\section{Parenthood}

\section{Mothering.}

Many internal and external factors affect a person's ability to mother effectively. The intrapersonal factors that influence how effectively a woman parents are: routine methods of coping and means of adaptation, level of self esteem and self confidence, perceived self efficacy and competence, feelings of isolation, sense of empowerment or lack thereof, perceptions of support, and perceptions of themselves in the maternal role (Coleman \& Karraker, 2000; Flagler, 1990; Friedman, Bowden \& Jones, 2003; Leerkes \& Crockenberg, 2002; Orthner, Jones-Sanpei \& Williamson, 2004; Teti \& Gelfand, 1991). 
The health and well being of a mother and her child frequently relies on the mother's parenting skills and her confidence in her ability to parent. A mother can experience improved self-confidence and maternal contentment if she feels fully prepared with the necessary knowledge and understanding to rear her child and care for her child's well being.

Morawska and Sanders (2007), in their study of child behaviors, parenting styles, parenting confidence and family adjustment, concluded that parental self-efficacy was a key determinant in child and family outcomes and that higher maternal confidence decreases the level of stress and dysfunctional parenting. This quantitative study utilized six instruments with 126 participants and sought to examine the connection between parenting skills and self-confidence. The aims were to distinguish parental low selfefficacy from high self-efficacy and its influence on the behavior of the child. The study reports that a mother's self-confidence and parenting functionality were interconnected. Since they can be modified, parenting skills and parenting self-confidence are significant factors. Obstacles exist that can hamper a mother's ability to parent successfully. Obstacles such as negative socioeconomic conditions, unplanned stressful situations, the lack of familial or social support, or geographical distances from support systems, similar to those that are experienced when a parent is incarcerated, can lead to a mother's lower self-esteem and decreased parental self-efficacy (Pollock, 2002).

A woman's self-efficacy in her work role and her parental role was identified as a key predictor of the strain experienced by women as they balance career and family (Erdwins, Buffardi, Casper, \& O'Brien, 2001). A woman who is reliant on her employment to maintain her family is further strained when she suffers an injury 
(Scherzer, Rugulies, \& Krause 2005). Higher levels of social support have been established as a source of strength in low income families; however few low-income families report that they have friends or family on which they can rely (Orthner, JonesSanpei \& Williamson, 2004). A mother who does not experience positive interactions with others in her family can be left struggling and feeling isolated (O'Brien \& Harm, 2002). Furthermore, it is important to note that the difficulties a mother experiences can potentially lead to child neglect, which is the most frequent type of reported child abuse (DePanfilis \& Dubowitz, 2005). Mothers with poor parenting skills lack self-confidence in their ability to parent, experience depression, low self esteem, and feelings of the failure to cope.

The mothering role is further complicated by a woman's incarceration. It is important to examine modifiable factors so that they can be adequately addressed prior to being encountered upon the mother's release from prison and reunification with her children. While a separation due to incarceration complicates the role of the mother, subsequent incarcerations may lead to added problems in an already complex relationship. The most recent United States Department of Justice data showed that the national average for length of time to prison recidivism for all offenders is three years from release. The rate of recidivism was $67.5 \%$ in 1997 which was an increase of $5 \%$ from the previous measurement in 1983 (Langan \& Levin, 2002).

Kreager, Matsueda \& Erosheva (2010) using data from a longitudinal study of 500 women explored the influence that motherhood had on women's criminal activity, drug use or alcohol use among a sample of women living in disadvantaged neighborhoods in Denver. The investigators found that transitioning to motherhood is 
significantly associated with decreases in criminal behavior and drug use, in teenage mothers $(\mathrm{p}<.001)$ and decreases in drug and alcohol use in young adult mothers $(\mathrm{p}<.05)$. Furthermore, motherhood appears to be a more significant event than marriage on whether a woman commits criminal acts. The transition to motherhood is a key turning point for disadvantaged women to stop drug and criminal behaviors (Kreager, Matsueda \& Erosheva, 2010). Also, the quality of the relationship between a mother and her children may influence whether or not a mother will recidivate (Slocum, Simpson, \& Smith, 2005). A poor relationship, along with the other post-release stressors, can increase the likelihood of recidivism (Huebner, DeJohg \& Cobbina, 2010). As described by Harm and Phillips (2000), the variables that most influence whether or not a woman recidivates are a setback in substance abuse, lack of employment, and the presence or absence of relationships with children and families. Because these relationships are so influential, the issues influencing the reintegration and reestablishment of relationships of the formerly incarcerated woman are explored further.

\section{Preparing to Go Home}

\section{Reintegration and reestablishing relationships.}

The process of reintegrating a formerly incarcerated mother into her community following release and supporting the process of reestablishing relationships with her children takes collaboration (Lipman \& Boyle, 2005; Minkler \& Wallerstein, 2005). Several important factors have been identified for consideration when an incarcerated mother is preparing to reintegrate into the community.

Characteristics of the formerly incarcerated mother. Numerous studies have been done that focus on the reintegration of men after incarceration but few studies have 
been completed that focus exclusively on women. Low self-esteem, depression, powerlessness, the inability to see solutions to their problems and resistance to help and change are characteristics identified in the literature about reintegration of women into the community (Johnston \& Gabel, 1995; O'Brien \& Harm, 2002; Parsons \& WarnerRobbins, 2002). Women who are released to a family member's home after prison have identified it as a difficult situation and there is often conflict related to the care of the woman's children, especially if those children had been cared for by this family member during her incarceration (Harm \& Phillips, 2000). These women focus on repairing the relationship with their children and improving their own personal situation (Baumann, 2000).

Reintegration of the formerly incarcerated woman. Of the studies that focus on women's reintegration, most of those involve women who are recovering from substance abuse or who are living with mental illness (Banonis, 1989; Belle \& Doucet, 2003; Henderson, 1998; Mumola, 2000; Sayil, Gure, \& Ucanok 2006). Successful reintegration relies on the woman's avoidance of an addiction relapse. With approximately half of the incarcerated women having substance abuse related convictions, it is important that substance abuse treatment programs be included in the reintegration plan for these women (Mumola, 2000). It is also critical that these treatment programs provide followup treatment post-release for greater success (Henderson, 1998).

Difficulty in attaining sufficient employment is also closely related to the history of drug use. Women are less apt to find employment or receive help from family members after they are released if they had a drug history or mental health issues prior to being incarcerated (Blitz, 2006; Mallik-Kane \& Visher, 2008). Women living in poverty 
are at a higher risk for depression and because of their usually low paying jobs they cannot pay for mental health care and the lack of health care benefits means these women cannot seek treatment (Belle \& Doucet, 2003).

Theall, Elifson, Sterk, and Stewart (2007) reported that violent female criminality is closely related to depression, lack of self-control, the frequency of drug use, the route by which the drugs were taken, and the riskiness of the setting in which the drug use took place. Programs targeting women in recovery from substance abuse are important since recidivism has been found to be closely associated with drug use (Dowden \& Brown, 2002; Harm \& Phillips, 2001; Mallik-Kane \& Visher, 2008; Uggen \& Kruttschnitt, 1998). Women shifting from incarceration back into their communities have identified their needs for successful reentry into the community which include refraining from illegal activities, remaining drug-free, stable housing, support of family and friends, and gaining employment (O'Brien, 2001; Parsons \& Warner-Robbins, 2002). It has been found that unemployment has a direct effect on depressive symptoms of mothers $(n=241)$ of $7^{\text {th }}$ and $8^{\text {th }}$ grade children. Those mothers experiencing depression disciplined their teenage children more regularly and had a negative perception of their mothering role which can lead to difficulty in reestablishing a relationship with her children (McLoyd, Jayaratne, Ceballo, \& Borquez, 1994).

Reestablishing relationships. Arditti and Few (2006) in a study of twenty eight mothers who had been incarcerated for a minimum of two months reported that incarcerated women experienced a close relationship with their children whether or not they saw their children while incarcerated. This study sought to examine how a mother's incarceration and consequent release impacted family relationships. Results indicated that 
successful reentry was influenced by family support and availability of resources and that the risks included mental health issues and parental stress. The participants also believed that they were good parents and were anxious to be reunited with their children (Arditti \& Few, 2006).

Positive family relationships can be supported if the women increase their use of the existing community resources that most closely fit with the goals of reintegration and reestablishment of relationships. Considering that formerly incarcerated women suffer from discrimination, societal obstacles, and a need to readjust psychologically (Evans, 2007), support in those areas is imperative for them to successfully reintegrate (Hayes, 2007) and have the opportunity to focus on reestablishing a positive relationship with their children. Hence, the formerly incarcerated woman should be encouraged to build alliances with the members of her community that would be able to provide support and assistance.

Jones and Unger (2000) found that low-income single mothers experienced considerable stress due to the lack of money, which severely limited their ability to obtain housing, meet needs of daily living, and purchase school items for their children. These circumstances occur in conjunction with the stress of trying to reestablish the relationships with their children, family and friends, resulting in the formerly incarcerated woman's need for additional support. While the focus of community-based interventions is on parole, drug treatment, and employment, these programs are usually inadequate to aid the women in successfully meeting those needs (O'Brien \& Young, 2005; Parsons \& Warner-Robbins, 2002; Zaitzow, 2006). Once the released women get their immediate needs met and are able to add stability to their daily lives, they are better able to focus 
their attention on long-term goals for themselves and their families. Improving outcomes for formerly incarcerated mothers and their families requires examination of the factors that influence women's admission to prison, their treatment while in prison, and the availability of supports after their release (O'Brien \& Young, 2005). Rebuilding those core relationships can be the foundation for healing, connection, and support that formerly incarcerated women need upon release (Minkler, 2005). Because the soon-to-be released incarcerated mother is the focus of the current research, it is important to identify how they perceive their mothering role in the past, present and future. Through this exploration there is a unique opportunity to identify the potential barriers she may anticipate as she reintegrates into her community and begins to reestablish the relationship with her children, family and friends.

As previously identified, a search of the nursing literature using CINAHL database produced thirty eight $(\mathrm{N}=38)$ articles related to incarcerated mothers. Nine of the resulting articles focused on the children of incarcerated mothers. Seventeen of the articles focused on the mothers' reentry into their communities upon release, issues with the caregivers of the children, prison nursing and policy reform. Six of the remaining studies focused on the health of incarcerated mothers, primarily on disease processes such as mental health issues or substance abuse.

Finally, there were seven $(n=7)$ articles that focused on being a mother during and after incarceration. Shamai and Kochal's (2008) qualitative study focused on the experience of motherhood within a population of Israeli prisoners. Through their interviews with nine mothers, they identified themes related to motherhood in prison as: a) motive for survival; (b) sense of failure; (c) coping vs. avoidance in mother-child 
relationship; (d) motive for change; and (e) the transition from questioning the right to be a mother to redeeming motherhood, A study conducted by Moe and Ferraro (2006) focused on women $(n=30)$ in a southwestern detention facility. They described the mothers' self-perception of what spurred their criminal activity, and sought to discover the ways in which gender-specific programming could be focused for incarcerated women. Specific issues facing these women, such as physical, emotional and sexual abuse, meant they faced high poverty rates, high rates of substance abuse and consequently, the need to find a life with a criminal record. A third study by Arditti and Few (2006) explored the distress experienced by criminal offenders who were mothers with mental health issues, lack of resources, and the stress of parenting after incarceration. Through interviews with these twenty-eight women who had experienced depression, domestic violence and substance abuse, investigators identified the importance of family support on successful reintegration (Arditti \& Few, 2006). The fourth study by Pulido-Criollo, Rodríguez-Landa, and Colorado-Martínez (2009) examined depression in 51 women housed in two Mexican prisons using quantitative methods. They found that symptoms of depression were most strongly associated with the women having children and the frequency or infrequency of the visits from their children (Pulido-Criollo, Rodríguez-Landa, \& Colorado-Martínez, 2009). These studies investigated the difficulties facing incarcerated mothers after their imprisonment, and how those factors can influence their decision toward continued criminal activity, and how they approach motherhood after their release.

The final three studies were the most closely related to this author's research. Qualitative research conducted by Hayes (2007) explored the experience of mothering 
$(n=6)$ after the release from prison. Mothers who were included in the sample had been previously incarcerated in one of two prisons in New Hampshire and one in Massachusetts. Study participants identified that mothering after their release was more complicated than they expected and that their social support system, including family and friends, was helpful. Unresolved family issues hampered the ability of the women to successfully mother their children and sometimes resulted in custody battles and further complicated the family relationships. Some women returned to their previous drug using activities and irresponsibility. What is not addressed in this study is the way in which the women view their role as mothers and what the consequences were of their incarcerations on the relationship with their children. A qualitative study (Berry \& Smith-Mahdi, 2006) was conducted which explored, through written questionnaire, what the word "mother" meant to 109 incarcerated mothers in a minimum-security prison in the southwest United States (Berry \& Smith-Mahdi, 2006). The Berry and Smith-Mahdi (2006) study used handwritten questionnaires and administered them in a group format. Investigators identified that the majority of respondents $(74 \%)$ stated that a mother is someone who loves their children and that few (3\%) defined a mother as someone who gives birth. When asked how they fulfilled their mothering role during incarceration, the majority of the participants said that they called, wrote or visited with their children. Asked what they missed most about being without their children, many women said that they missed everything while others said they missed teaching them God's word, loving them and watching them grow.

The seventh and final study which is closely related to the current research was a qualitative study conducted at a Pennsylvania prison with 10 mothers (Weiss, 2010). The 
investigator sought to explore the lived experience of mothering behind bars and discovered that mothers in this study felt hurt being separated from their children but continued to care for them through their relationship with God. Study participants also revealed that they had previously suffered from addictions and thusly experienced hurtful pasts. The investigator also reported conflicting focus on their addiction and care of their children.

More studies focused on the children of incarcerated mothers rather than the mothers themselves (Gaudin \& Sutphen, 1993; Johnson \& Waldfogel, 2003; Kampfner, 1995; Murray \& Farrington, 2007). Others focused on the evaluation of existing prison parenting programs or the factors that support or hinder a woman's transition from prison into the community (DePanfilis, \& Dubowitz, 2005; Evans, 2007; O'Brien \& Harm, 2002; Parsons \& Warner-Robbins, 2002). Only one study focused on mothering during incarceration (Weiss, 2010). The currently reported research differs in its method, the increased number of participants and what it seeks to identify as it relates to mothering.

\section{Gap in Literature}

There is a gap in the literature as it pertains to the target population of incarcerated mothers. Very little research focuses exclusively on women in prison, particularly in nursing literature. Research of gender-based needs or programs that influence treatment of incarcerated mothers is limited. Incarcerated mothers exhibit unique stressors related to the separation from their children and the ongoing role they must maintain even through that separation. There is limited understanding of what factors function as barriers or facilitators to mothering during incarceration. Little is known about how the incarcerated mother views her past and whether or not she gives 
her past much thought while she is incarcerated. While some research is beginning to surface that explores how the mother feels about being incarcerated, there is a lack of understanding about how her role as a mother of her children is influenced by her current incarceration. Considering that it is known that socioeconomic status of the family, presence of substance abuse and level of education shape the role of mothering, further exploration into the incarcerated mother's experience of being a mother in prison, her view of the role of mothering, the quality of her relationship with her children, including the challenges they face, and how her incarceration transforms her relationship with her children is greatly needed. 


\section{CHAPTER 3}

\section{METHODOLOGY}

A Hermeneutic phenomenological approach was used to explore and describe the experience of mothering with a select group of incarcerated women at the Kentucky Correctional Institution for Women. Data were collected using individual interviews. This research was completed to also address the gap within this body of literature. The methods section presents the following components of the study: phenomenological methodology, setting, sample, inclusion criteria, study procedures, and data analysis.

\section{Research Design}

In phenomenological research, meaning does not occur randomly, but is arranged according to specific essential situations, and these situations reveal themselves in language, religious practices, and behaviors (Pilotta, 1982). Interpretive or Hermeneutic phenomenology is a qualitative research approach in which participants define and describe their experiences and the investigator interprets the meaning of the narrative texts (Cohen, Kahn, \& Steeves, 2000). In addition, Max van Manen (1990) posits that a Hermeneutic phenomenological approach is expressed as the study of lived experience. Lived experience is defined as an approach to research with reflection on the phenomena

of the lifeworld of the research participants and it is an understanding and appreciation of the lived meaning of their lifeworld (van Manen, 1990, 2006). Inquiry into the lived experience aims to gain a deeper understanding of the experiences of others. 
Phenomenology asks, "What is this or that kind of experience like?" (van Manen, 1990, p.9).

The lived experience reflects on experiences retrospectively or during the event, situation or encounter. The purpose of this phenomenological study is to examine the lived experience of mothers during incarceration and the focus is to gain an understanding of the way that incarcerated mothers experience their world and its impact on mothering.

\section{Phenomenological Methodology}

Phenomenology is the study of phenomena and how it appears to the individual through their experience and human consciousness. Phenomenology makes a distinction between appearance and essence. Phenomenology seeks to give the phenomenon under study a universal meaning, make it explicit and present the internal significance, or essence, of the lived experience. The phenomenological approach includes skills of reflection, clarification, examples and expanded description. Immanuel Kant, a well known philosopher, first used the term phenomenology to differentiate between the study of the phenomena of events as they are experienced and as the events are perceived. Husserl, Heidegger, Satre and Merleau-Ponty were the most famous of the traditional phenomenologists and their individual interpretations of the craft use different methods with varied results.

Husserl developed phenomenology as a descriptive method of studying human science based on method of reflection which is at the core of philosophic thought (Munhall, 1986; 2007). Ontology, Heidegger's method of phenomenology, is the philosophical study of the nature of being and the nature of existence. Martin Heidegger 
proposed that truth was a choice and he focused on the matter of being and on language as a method of interpretation (Munhall, 2007). Jean-Paul Sartre believed that the essence of being follows the experience of being. He believed that human beings had the power to do what they wished with elements of their being such as those over which they had no control such as their "gender, class or country" (Munhall, 2007, p.116) Maurice Merleau-Ponty, one of the classical phenomenologists, defined phenomenology as "the study of essences." He believed that being and the essence of being were intertwined.

Hermeneutic phenomenology espouses the idea of allowing things to speak for themselves while understanding that the phenomena are interpreted. The interpretative process captures the details of the lived experience and, through the use of written language, captures the essence. Heidegger contends that giving a description is always the interpretation of the person giving the description. He maintains that all manner of human consciousness are interpretive and in his later works he used poetry and art as expressions of the interpretations of the essence of being and the language used in the descriptions (Wilson \& Hutchinson, 1991).

Hermeneutic phenomenological reflection is the method of trying to seize the fundamental meaning of the phenomenon through the essences of the experience and developing multi-dimensional themes that compose the experience (van Manen, 1990). Hermeneutic phenomenology uses observations and in-depth interviews to gain a greater understanding and the investigator then validates the findings with the participant. There are numerous ways an investigator can explore the lived experience. This can be done through art, life histories, and interviews. Interviewing is a process that centers on the fundamental research question. It is a method through which the investigator takes part in 
the participant's lifeworld. Consequently, the investigator participates and observes in the phenomenological discussion. The result is a lived experience depiction.

Lived experience is our reflective understanding of life. Phenomenology attempts to explore the lived experience and establish the meaning in a written description. Exploring the experience as it is lived necessitates that the investigator examine the experience in all aspects and communicate that experience (van Manen, 1990). The Hermeneutic process involves giving names and labels to experiences that are described while not interjecting the investigator's preconceived meaning (van Manen, 1999). It is a practice of reflective writing. Through writing, the author attempts to bring a new dimension to the words used by a person describing their lifeworld and provide a meaning to their experience (van Manen, 1997a). The words that are used in the interpretation invoke a mental picture to the reader and if done effectively, allows the reader to better understand the lived experience of the participant (van Manen, 1997b).

\section{van Manen's Phenomenological Method}

van Manen describes his phenomenological approach as a "dynamic interplay among six research activities" (1990, p.30). These activities are as follows: 1) aspire to reach the nature of the lived experience by trying to make sense of a small bit of the human experience; 2) explore the experience as it is lived; 3) reflect on the fundamental themes by questioning what embraces the lived experience; 4) communicate through writing the lived experience as precisely as it is presented; 5) avoid any presumptions or theories; 6) reflect on the separate elements and the text as a whole. Translating the lived experience into writing required following these activities so as to reach the essence of the experience. 
In van Manen's phenomenological method, themes are defined as the focal points of the lived experience. The themes simplify the phenomenon and attempt to capture the experience using thematic phrases to describe segments of the phenomenon. Isolating thematic assertions entails reading the transcript numerous times and asking, "What statement(s) or phrase(s) seem particularly essential or revealing about the phenomenon or experience being described?" (van Manen, 1990, p. 93). Themes become the point of reflection during the interview process.

An important phase of Hermeneutic phenomenological reflection is to determine whether the themes are incidental or fundamental. Imaginative variation is used to establish whether or not a theme is essential, which involves imagining that the theme is deleted from the phenomenon and then consider if the phenomenon loses its fundamental meaning. As the writing of the findings commence, it is important that the investigator be sensitive to the connotations of language, such as the tone of the speech and periods of silence (van Manen, 1990). Stories are used in phenomenological writing to clarify the essence of the phenomenon and offer an in-depth, rich description of the experience.

\section{van Manen's Lived Experience}

Phenomenology searches for the essence of phenomena and seeks to express the lived experience. Max van Manen (1990, p.10) stated, "The essence of phenomenon is universal which can be described through a study of the structure that governs the instances or particular manifestations of the essence of that phenomenon." Research studies using phenomenology pursue the meanings in our everyday existence. Ultimately, the aim of researching the lived experience is the "fulfillment of our human nature: to become more fully who we are" (van Manen, 1991, p.12) 
Phenomenology is both the meaning of the expressions and the description of the lived experience as told by the researcher. The description of meaning is an interpretation by the researcher and the expression of that understanding. Text and symbolic expression are used to articulate the interpretation of the life experience. Max van Manen (1990, p.30) recognized hermeneutic phenomenological research in the human sciences as the relationship of six explorative activities although it is widely understood that there is not a set of fixed procedures. van Manen proposed three methods for setting aside thematic statements: the "wholistic" or sententious approach; the selective or highlighting approach; and the detailed or line-by line approach (1990, p. 93). Depending on how explicit the examination of the narrations, each of the three methods offers a different view. The holistic method seeks the general meaning of the text, and is more global in nature. Focusing on the stand out sentences or phrases in the text is the selective method and close examination of each sentence independently in the text is the line-by-line method. To systematically inform the themes and to connect the themes and interview text together, Burnard's (1991) method of interview analysis was used.

van Manen (1990, p. 153-162) deems necessary that the researcher, ethically, be aware of the following:

(1) There may be definite consequences on the participants who take part in the research.

(2) There may be consequences of the research methods on where the research is conducted.

(3) There may be lasting effects on the participants of the research.

(4) There may be a transformation of the researcher after conducting a phenomenological study. 


\section{Setting}

The setting for the study was the Kentucky Correctional Institution for Women (KCIW), the only state-run correctional institution exclusively for women in the state. The facility which opened in 1938 is a multi-custody level prison with minimum, medium, and maximum security inmates. On average there are 682 women housed in single or double occupancy rooms in campus or dorm style housing. There are many programs offered to the women including Paws with Purpose which has inmates training service dogs for placement with individuals with disabilities. The inmates can also participate in programs such as Life without a Crutch, with a focus on substance abuse, Prison to the Streets, with a focus on reintegrating into the community, and the Parenting Program, which gives inmates the skills to better care for their children when they are released, to name a few.

\section{Sample}

A purposive sample of incarcerated women, who are mothers that were primary caregivers prior to incarceration, was used in this study. Final determination of the sample size occurred during the process of the interview sessions. Benner (1994) describes the final sample size being determined by the richness of the resulting data and saturation of the collected narrative data. Sample size was 24 incarcerated women which was determined as sufficient to provide a vivid appreciation of the experience (Creswell, 1998; Sandelowski, 1995).

\section{Inclusion Criteria}

Incarcerated mothers for this study were selected using the following inclusion criteria: 1) those who have at least one living child, which is defined in this study as any 
dependent biological or adopted individual who is legally or physically considered to be a child of the mother in prison ranging in age from 1-12 years, 2) were the primary caretaker of and lived with their children prior to incarceration, 3) are to be released from prison within 12 months, 4) will be the primary caretaker of their children upon release, 5) understand and speak English and 6) agree to participate in the study. Mothers not meeting all six inclusion criteria were excluded from the study.

Including mothers who were the primary caretakers of their children prior to incarceration and planned to be primary caretakers after release from prison provided some consistency of their mothering experiences and future plans. Including mothers with a potential prison release date assured greater consistency in the preparation time for parenting during incarceration. Since it was unknown how these mothers perceived their role, the goal was to attempt to eliminate wide variations in experiences that may arise in those mothers who have many years until release and those who are to be released within 12 months. Including only English speaking mothers reduced misunderstanding and misinterpretation due to language incongruence.

\section{Procedure}

The Institutional Review Board at University of Louisville has information essential for an investigator to work with the incarcerated population. The 45 CFR 46 Subpart $\mathrm{C}$ was reviewed for the protections afforded the prison population (Appendix 4) prior to acquiring the appropriate research approvals. After careful review and submission of the research requests, University of Louisville Institutional Review Board and Commonwealth of Kentucky Office of Research and Grants approvals were obtained. Once approvals were granted, the investigator contacted the warden at the facility to work 
out the research plan. She provided the investigator with the name of the person who would be the direct contact for the duration of the study. During the meeting with the warden, the flyer was reviewed, the recruitment plan was discussed, and the interview location was decided. Because of the protected status of the population the warden and investigator discussed what strategies would be utilized to safeguard the prisoners' rights to voluntarily participate in the study. The participant sign-up sheet was approved by the warden and the date for the first information session was scheduled.

As a condition to conduct research in the Kentucky Department of Corrections, a copy of the completed research project was given to the Office of Research and Grants. All participants had full access to a summary of the results of the study upon conclusion.

\section{Recruitment.}

Recruitment took place over a two week period through the following mechanisms. Contact was made with prison administration to identify approved locations for flyer placement and schedule of consent and interview sessions. Flyers were placed in locations approved by the correctional facility staff for the purpose of informing incarcerated mothers of the impending study (Appendix 5). Incarcerated mothers selfidentified their interest, signed the sign-up sheet with their dormitory case worker to attend an information session, and subsequently attended a study information session. Thirty-nine women signed up to attend the first, and ultimately the only, information session. During that one hour session, the study was described, and the inclusion criteria and enrollment process were explained, and all questions were answered by the investigator. Participants had the opportunity to withdraw from the study at any time during the process if they chose. The potential risks for participating in the research were 
explained to each mother including: possible emotional distress, thoughts about not being with the children causing sadness and possible discomfort in answering personal questions. The participants were informed that there were questions during the interview phase which could make them feel uncomfortable and they were reminded that they were free to refuse to answer any specific question or questions that they did not wish to complete.

The potential benefits of the study were identified for the mother prior to beginning data collection. These benefits included but were not limited to: self-awareness of current parenting skill set, identification of potential areas for improvement in the relationship between mother and child, identification of communication techniques for use between mother and child and mother and child's caregiver. Mothers were told an indirect benefit would be an increase in knowledge regarding incarcerated mothers' experiences which could lead to improved services. Informed consent and permission to record data were obtained at the time of the initial interview with each woman (Appendix $6 / 7)$

The mothers reviewed the consent form for as long as they wished. At the conclusion of the information session, the researcher informed the attendees that consent forms were available for signatures of those interested in participating. Mothers who selfreported that they met the criteria and agreed to participate signed a written informed consent. Of the 34 information session attendees, 29 women signed consent forms. The signed consent forms are being stored in a locked cabinet in the locked office of the investigator. Copies of the signed consent forms were given to the participants at the time of their interview. Those names were then given to the Procedures Officer for interview 
scheduling. Once scheduled, the women were given the opportunity to attend the interview on the correct date and time.

When the participants arrived at the assigned location for the interview the previously signed consent form was made available to the participant, in the event she wanted to review it or ask additional questions. Furthermore, the Kentucky Department of Corrections required an additional consent form to be signed at the time of the interview. The Kentucky Department of Corrections consent form was explained to each participant, opportunity for questions was offered, and signatures were obtained. Once a signature was obtained, each consent form was assigned a number and a pseudonym, which was then used as the alternative identification of the participant. Once the interview was complete, the alternative identifier was separated from the participant's name to assure confidentiality.

Of the 29 mothers who signed consents, 28 mothers were scheduled to participate in the interviews. One enrolled participant had been granted parole and was lost to the study. One enrolled participant withdrew from the study when her interview time arrived. Three additional enrollees were eliminated as not meeting all criteria after the demographic survey and interview had been completed. Those data were not included in the data analysis process. The total number of participants was 24 and their demographic and interview data are included in the data analysis.

\section{Data Collection}

Data collection included an 18 item demographic questionnaire (Appendix 1), which was developed by evaluating similar research conducted with this population; a 19 item semi-structured interview guide (Appendix 2), which was developed as a result of 
the literature review, and a focus group discussion as a member check related to study findings (Appendix 3). Participant interviews were conducted individually with women in the prison family visiting room to ensure as much privacy as was allowed by prison administration and it provided a relaxed atmosphere. Since the participants had previously met the investigator during the information session, there was a familiarity when they entered the family visiting room. After a brief greeting and the participant being seated at the table, the researcher reminded the participant of the need to use a tape recorder and obtained permission from the participant to begin taping the interview session

Time was incorporated into the session to establish rapport which included general conversation about the weather, how the women were feeling, the approaching weekend and holidays. To establish rapport with a prisoner, it was essential to be positive and respectful towards the prisoner and genuinely attempt to get to know them (NZ DOC, 2010). The mothers were then asked to complete the demographic questionnaire.

Sensitivity was used when determining each mother's ability to complete the form and the investigator determined whether or not it was necessary to ask the questions verbally and note the responses. The investigator first gained an awareness of each of the participants' reading abilities when they were signing the Department of Correction consent form, either by them asking where to sign the form or by the quality of their signature. Eight participants hesitated when they began to complete the demographic questionnaire which led the investigator to ask if they needed clarification on the questions. Those eight participants needed assistance on approximately $50 \%$ of their respective questionnaires. All of the participants were able to complete the demographic 
questionnaire independently although 21 participants asked for clarification of at least one of the demographic questions. Once the demographic questionnaire was complete the tape recorder was started and the interview began using a guide developed for the study.

The initial interview guide questions included: What was it like being a mother before you came to prison? What is it like being a mother in prison? What kinds of things do you do that identify you as a mother? How is your relationship with your child? What kinds of things worry you the most about your child at this time?

Secondary questions or probes were used when needed and they included: What would you like others to know about being a mother in prison? How does it feel to be a mother and be incarcerated? Who do you turn to when you need to talk to someone about your child? What is your experience of how your mother took care of you? What is your experience of caring for your child/children? How is that experience the same or different? What kinds of things give you joy or good feelings with your child? When you are worried or stressed, how does that impact the way you react to your children?

Women were asked to talk about their experiences of being a mother while incarcerated. The interview was a dialogue, allowing the women's experiences to be revealed. The mothers were allowed to tell their stories, and if any of the interview questions had not been answered during their dialogue, they were prompted by any or all of the semi-structured interview prompt questions. The final request asked of all participants was: "Tell me again what it is like to be a mother and to be incarcerated." Once the participant was finished answering that question the participant was thanked for talking to the investigator and she was reminded that she would be invited to a focus group after analysis was completed to discuss the general findings. 
Interviews were audio-taped and field notes were taken. The field notes included such things as participant posture, intensity of language, participant emotion, and eye contact or lack thereof. Care was taken in the field notes to write verbatim statements rather than rephrase statements, thus preserving the local language. Field notes were transcribed, compiled with the interview transcription, and used as supplementary data. Audiotapes were labeled with the interview number to ensure anonymity and sent to a professional transcriptionist. Verbatim transcriptions were made of the audio-taped data and entered into a computer within two weeks of the interview. This allowed for prompt review of the transcript and alleviated any delay in analysis of the individual transcripts as they were completed. Once returned, the audiotapes were kept in a locked cabinet for further review as necessary. The de-identified data will be kept indefinitely. The crossreferenced list with identifiers will be kept for three years beyond the closure of the study.

Participants were contacted approximately two months following the completion of data analysis and were asked to participate in a group discussion about the interpretation of the findings. In this session, which was held in the family visiting room, participants were asked to review the findings from the study. Although van Manen describes a process in which transcripts are reviewed by participants, this investigator had to consider the literacy level of many of the participants in this study. To address any possibilities of illiteracy among the participants, it was decided to use a focus group discussion as the member checking method. 


\section{Instruments}

Three instruments were administered to the participants of the study. The instruments allowed for collection of demographic data, provided participants with a guide of the questions that were to be asked during the interview, and validated findings.

\section{Demographics questionnaire (Appendix 1).}

Demographic data were gathered at the beginning of each participant interview, using an instrument that included items regarding socioeconomic and demographic characteristics, e.g., age, race and ethnic background, education level, support system, number of children, etc.

\section{Interview guide (Appendix 2).}

The interview guide questions focused on being a mother while incarcerated. The questions centered around four domains of mothering including: the meaning of mother, the roles of mothering, the mother's relationship with her children, and how the mother views the impact of the separation on her children. These domains were determined by performing a literature search, evaluating research that had been previously done with incarcerated women and research that had been done related to being a mother and parenting and then grouping that information (Polit \& Beck, 2004). This process led to the establishment of the four domains. These domains guided the investigator into the area of question development. These questions were reviewed by three experts in the field of nursing.

To explore the meaning of mother, the participant had the opportunity to describe what it was like for her to be a mother before she came to prison. She was then asked what it is like for her to be a mother during her time in prison. If the dialogue ceased, a 
secondary question was used that asked the mother to describe what she would like other people to know about what it like to be a mother in prison. To talk about the roles of mothering, the participant was asked what things she does that identify her as a mother and who she turns to when she needs someone to talk to about her child. She was also asked to share her childhood experiences of being mothered. Based on these descriptions, it was hoped that the participants' ideas of the roles of mothering would be revealed. To establish the participant's perception of her connection with her children, she was asked to describe their relationship. If she had difficulty answering that question, she was asked to describe what things give her joy or good feelings with her children and how she reacts to her children during stressful times and when she is worried. To understand how she views the situation and the consequences of the separation on her children she was asked to talk about what worries her about her children and to talk about what it is like having children in her situation. The guide was piloted with two mothers unfamiliar with the proposed study. To address the fact that these mothers were not incarcerated, the words were changed to being a mother who is employed. This was done to eliminate any preconceived idea the women had about what it would be like to be incarcerated but to allow for a concern that many women have with being employed outside the home and raising children.

The interview guide included a general question for each of the domains. The interview guide ensured that all participants responded to specific content areas. To be effective, the interview process had to be warm but also contain clarity and be purposefully directed to the scientific needs of the research. Again, the research questions target exploration of the mothers' evaluation of the mothering role, what hopes they have 
in relation to that role, what they see as barriers, their perceived needs and what values they hold related to mothering. These questions are directly related to interview questions in that the mothers were asked to describe what they did that identified them as a mother, what their experience was in caring for their children, how they were cared for by their mother, how that experience resembled or differed from how they cared for their children, what things gave them good feelings about their children and what things worried them about their children and how the experience of being incarcerated will impact their role as a mother. Other questions were included to enhance the conversation in times that the participant was at a loss for words or was unclear about the question that was being asked. The domains of mothering and the interview questions are related to the research questions and their relation to each other can be found in Table 1. Figure 1 shows the relationship between the research question, the domains, the primary interview questions and the secondary interview questions. The domains are shown in purple, the primary questions are shown in blue and the secondary questions are shown in orange. 
Table 1 Mothering Domains and Corresponding Interview Questions

\begin{tabular}{|c|c|c|c|c|c|}
\hline $\begin{array}{l}\text { Domains of } \\
\text { Mothering }\end{array}$ & $\begin{array}{l}\text { Primary } \\
\text { Questions } \\
\end{array}$ & $\begin{array}{l}\text { Secondary } \\
\text { Questions }\end{array}$ & $\begin{array}{l}\text { Secondary } \\
\text { Questions }\end{array}$ & $\begin{array}{l}\text { Secondary } \\
\text { Questions }\end{array}$ & $\begin{array}{l}\text { Secondary } \\
\text { Questions }\end{array}$ \\
\hline $\begin{array}{l}\text { The meaning of } \\
\text { mother }\end{array}$ & $\begin{array}{l}\text { What was it like } \\
\text { being a mother } \\
\text { before you came to } \\
\text { prison? What is it } \\
\text { like being a mother } \\
\text { in prison? }\end{array}$ & $\begin{array}{l}\text { What would you } \\
\text { like others to know } \\
\text { about being a } \\
\text { mother in prison? }\end{array}$ & $\begin{array}{l}\text { How does it feel to } \\
\text { be a mother and be } \\
\text { incarcerated? }\end{array}$ & & \\
\hline $\begin{array}{l}\text { The roles of } \\
\text { mothering }\end{array}$ & $\begin{array}{l}\text { What kinds of } \\
\text { things do you do } \\
\text { that identify you } \\
\text { as a mother? }\end{array}$ & $\begin{array}{l}\text { Who do you turn to } \\
\text { when you need to } \\
\text { talk to someone } \\
\text { about your child? }\end{array}$ & $\begin{array}{l}\text { What is your } \\
\text { experience of how } \\
\text { your mother took } \\
\text { care of you? }\end{array}$ & $\begin{array}{l}\text { What is your } \\
\text { experience of caring } \\
\text { for your } \\
\text { child/children? }\end{array}$ & $\begin{array}{c}\text { How is that } \\
\text { experience the } \\
\text { same or different? }\end{array}$ \\
\hline $\begin{array}{l}\text { The mother's } \\
\text { relationship } \\
\text { with her } \\
\text { children }\end{array}$ & $\begin{array}{l}\text { How is your } \\
\text { relationship with } \\
\text { your child? }\end{array}$ & $\begin{array}{l}\text { What kinds of things } \\
\text { give you joy or good } \\
\text { feelings with your } \\
\text { child? }\end{array}$ & $\begin{array}{l}\text { When you are } \\
\text { worried or stressed, } \\
\text { how does that } \\
\text { impact the way you } \\
\text { react to your } \\
\text { children? }\end{array}$ & & \\
\hline $\begin{array}{l}\text { How the mother } \\
\text { views the } \\
\text { impact of the } \\
\text { separation on } \\
\text { her children }\end{array}$ & $\begin{array}{l}\text { What kinds of } \\
\text { things worry you } \\
\text { the most about your } \\
\text { child at this time? }\end{array}$ & $\begin{array}{l}\text { How does being in } \\
\text { prison change your } \\
\text { experience/role of } \\
\text { caring for your } \\
\text { child? }\end{array}$ & $\begin{array}{l}\text { How has the } \\
\text { experience of being } \\
\text { incarcerated affected } \\
\text { your ability to care } \\
\text { for your child? }\end{array}$ & $\begin{array}{l}\text { How does your } \\
\text { child/do your } \\
\text { children feel about } \\
\text { you being } \\
\text { incarcerated? }\end{array}$ & $\begin{array}{l}\text { How does that } \\
\text { make you feel? }\end{array}$ \\
\hline
\end{tabular}


Figure 1 Relationship between Research Questions, Domains and Interview Questions

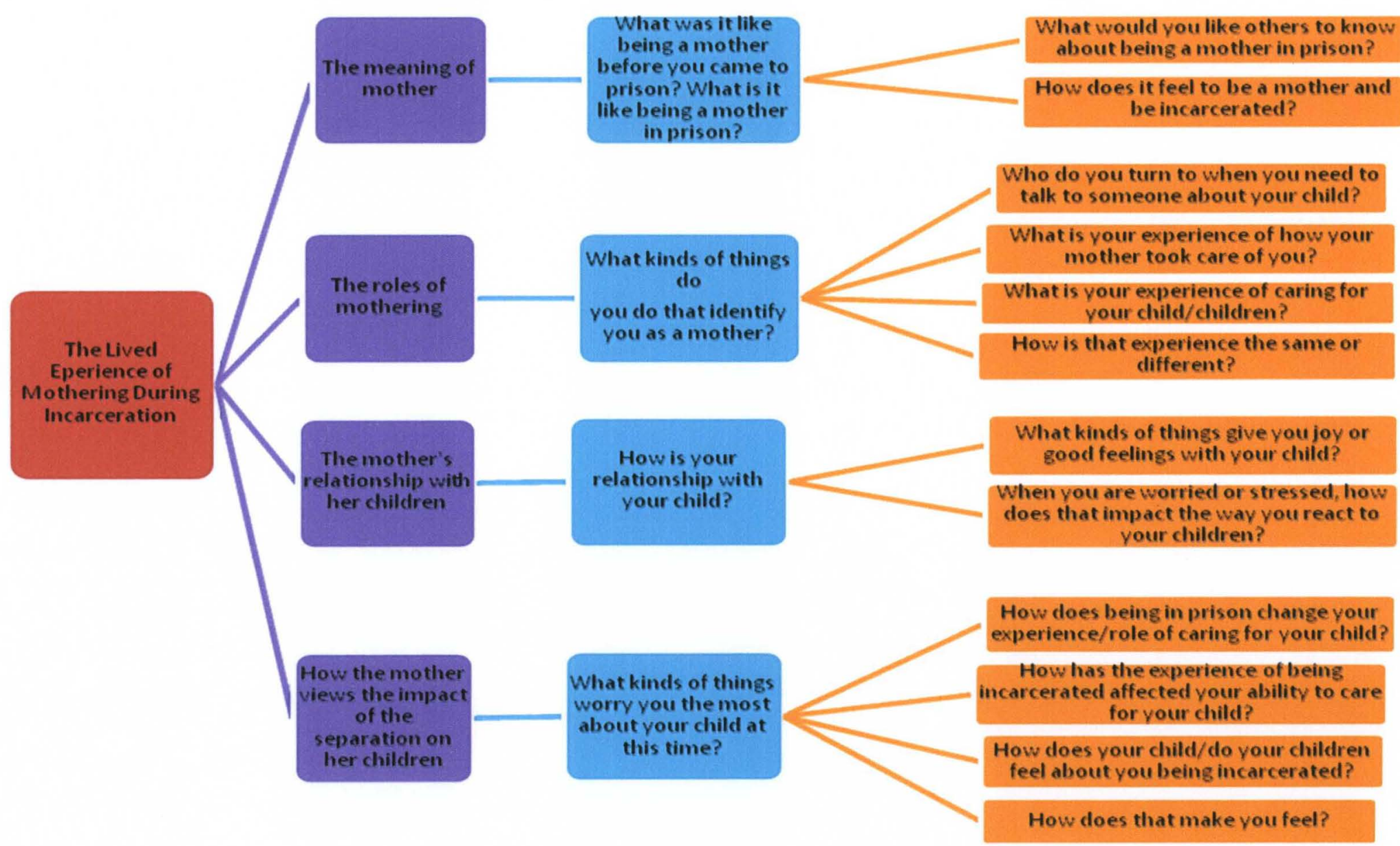


The interview guide is a valuable tool that aids in consistency of the interviews since the investigator may stray during the dialogue. In the course of progressing through the participants it is necessary for the investigator to reflect on the interviews as they related to the interview guide. In qualitative research, reflection by the investigator is a major component in data collection and during the analysis of the interviews. The process of reflection demonstrated in qualitative research, necessitated revision of the interview guide as the process of interviewing continues (Creswell, 2007).

After three interviews it became apparent that the participants were talking about topics that were not specifically included on the interview guide. Participants were talking about their fathers and their brothers and sisters in their childhood experiences. The participants also talked about the quality of their relationships with these family members while they were incarcerated. All three participants also discussed the programs they had taken part in and the impact that these programs have had. Also, these mothers talked about their future with their children but were having a difficult time verbalizing what that future held. Because these topics were important enough to be included in the participant responses the following secondary questions were added to the interview guide: What was your relationship with your father? What was your relationship with your siblings? Describe what an ideal day will be like for you and your children. And finally, in what programs have you participated?

Two additional secondary questions were added for interview five and those thereafter because the participants were also describing what part their children played in their decision making related to their crimes and if they had an addiction, in their substance abuse issues. It also became important to ask them what measures they are 
using to endure their incarceration. The added questions included: How do you cope? And did children have any impact on you committing your crime?

Starting with interview six, the question about how their experience of caring for their children was the same or different than that of their experience of how their mother took care of them was separated into two separate questions. This was to aid the participants in differentiating their experiences. Also added with this interview was the prompt question about what their typical day with their child was like. This secondary question was added for those mothers who had a difficult time answering the questions about what things they did that identified them as a mother. Asking about their typical day allowed them to articulate an aspect of their life that had a more concrete meaning.

The final secondary question that was added started with interview number seven. As the women were talking about how they coped with their incarceration, some women were discussing the friendships they had formed or avoided with other inmates and other supports. Because of the interconnection with other mothers in prison, it was decided that the remaining participants would be asked about that and how they received support from other incarcerated mothers.

\section{Focus group guide (Appendix 3).}

The focus group guide included questions that sought to validate interpretation of the findings. The focus group participants were asked to verify or clarify the interpretation of the results. To ensure comprehensive results, supplementary data that was revealed during the focus group session was not excluded from the study. 


\section{Data Analysis}

The meaning of the experience of being an incarcerated mother was examined and the researcher had to keep the aim of the research in mind. Mothers were encouraged to consider their experiences to reveal the deeper meanings and themes of their experiences. Once the transcripts were generated from the conversations, the mothers and the researchers reflected on the conversations for meaning in a focus group.

The Demographic Questionnaire was used to describe the participant characteristics. Descriptive statistics related to the mothers was obtained including age, race, education level, and occupation prior to incarceration and crime and sentencing information. Information was also obtained related to the number of children involved, age and gender or the children, and who had custody of the children while the mother was incarcerated. Data related to the fathers' of the children and the mothers' support systems were also obtained. This data were compiled and is used to give a description of the population of participants of this study.

\section{Trustworthiness in phenomenological research.}

Regardless of the qualitative approach used for research, qualitative research is often criticized for not clearly addressing issues of scientific adequacy or rigor in the conduct of the study. For research conducted with human beings to be ethical and useful as a basis for knowledge development, it must be scientifically adequate or rigorous. In qualitative research, trustworthiness is proposed as the term for the collective components of scientific adequacy or rigor (Sandelowski, 1993; Krefting, 1991).

The seminal model used in support of scientific adequacy in qualitative research is Lincoln and Guba (1985). Trustworthiness in qualitative research is the mechanism by 
which investigators demonstrate the rigor in which the chosen method was applied in the conduct of the study. Trustworthiness or scientific rigor in qualitative research includes components such as credibility, transferability, dependability and confirmability. Credibility is the confidence in the accuracy of the findings that someone can have, transferability is the notion that other researchers can apply the findings to their own research in another setting, dependability is the stability of the findings, and confirmability, are the results in an objective manner that interprets them from the perceptions of the participants rather than the partiality of the investigator (Polit \& Beck, 2004).

Credibility necessitates the investigator spend a prolonged period of time in the environment of the research. Since approximately three months was spent in the field, the investigator gained an in-depth understanding of the culture of the population. Persistent observation allowed the investigator to become immersed in the language and the characteristics of the situation. This was accomplished by the investigator spending up to six hours per day in the prison environment. Method triangulation was accomplished through the investigator making observations and keeping field notes, audiotapes of the interviews, and transcripts.

An option for establishing concordance is to return to three of the participants and allow them to review their own transcripts at which time they validate what they see as the main points of the interview (member checking). The participants make notes on their transcript which will also be compared to the researcher's categories to examine for similarities (Burnard, 1991). Meeting the criteria set in Burnard's Stage 11, respondents are revisited to have them verify that the identified themes and categories are correctly interpreted. However, contrary to the option of having respondents review their 
transcripts, a focus group discussion was held with those participants who chose to attend the session.

Dependability involves the appropriateness of interpretation or assuring accuracy between experience being investigated and the language being used by the investigator. One element that is necessary to accurately represent the participants' experience is the use of bracketing on the part of the investigator. It is vital that the investigator acknowledge their preconceived ideas, but set them aside and present a true representation of the participant's lifeworld. Using a field journal allows the investigator to self critique the process of inquiry (Tobin \& Begley, 2004). Creating the audit trail establishes that a systematic approach was used in the collection of the data, which is then verified by the inquiry auditor. In this case the inquiry auditor was the doctoral committee chairperson.

Confirmability is the establishment that the interpretations arise from the data and not from the researcher's beliefs and thoughts. A method of ensuring confirmability is through the use of the audit trail. Interviews, field notes, a researcher's journal, and analysis documentation are all means of creating the audit trail.

Transferability is accomplished by providing a comprehensive description of the research setting. Thorough explanation of the research process was also provided to allow for reader judgment. The researcher must provide a thorough account of the research process to allow for the appropriate links between the data and the results. Transferability can be facilitated by the researcher by giving a clear description of the background, sample selection, participants' characteristics, data collection and analysis process. 
Polit and Beck's (2004) criteria for rigor in qualitative data were used for the trustworthiness of this study and is represented in Table 2 .

Table 2 Characteristics of Rigor and Approach Used in this Research

\begin{tabular}{|c|c|}
\hline Characteristic of Rigor & Approach \\
\hline Credibility & $\begin{array}{l}\text { - Sufficient field time of } 3 \text { months } \\
\text { - Member Check } \\
\quad \text { o focus group with participants } \\
\text { - Persistent observation } \\
\text { - Method triangulation } \\
\quad \text { o Interviews, observations, documents }\end{array}$ \\
\hline Dependability & $\begin{array}{l}\text { - Inquiry Auditor } \\
\text { ○ External reviewer - committee chairperson } \\
\text { - Reflexivity } \\
\circ \text { field journal } \\
\circ \text { bracketing }\end{array}$ \\
\hline Confirmability & $\begin{array}{l}\text { Auditing - trail of documents } \\
\circ \text { transcripts, field notes, analysis }\end{array}$ \\
\hline Transferability & $\begin{array}{l}\text { Sufficient data - applicability to other contexts } \\
\circ \text { Rich description of research setting } \\
\circ \quad \text { Thorough description of observed processes }\end{array}$ \\
\hline
\end{tabular}

Although there are multiple ways to address trustworthiness, there is not a single existing method of analysis that can be used for all types of interview text. One similarity among data analysis methods in phenomenology is that there is always interpretation of the text and interview text can potentially have multiple meanings. A review of methods focused on data analysis and trustworthiness, including Lincoln and Guba (1985), Colaizzi (1978) and Burnard (1991) was undertaken. Lincoln and Guba (1985) were the pioneers in the development of naturalistic inquiry. Naturalistic inquiry authorizes that methods develop during the course of research and must meet the standards of trustworthiness, characterized as credibility, transferability, dependability, and confirmability (Lincoln \& Guba 1985, Guba \& Lincoln, 1981, 1989). They state that 
regardless of the method of data analysis that is chosen, if trustworthiness is questionable, the study is meaningless. There is a heavy focus on being able to impart the audit trail that can be called on once the study is complete.

Colazzi's (1978) method of data analysis utilizes seven strategies. These include becoming familiar with the data, pulling significant statements, assigning meaning to the statements, organizing the meanings into groups of commonalities or themes, providing a detailed and logical description of the themes, identifying the basic structure of the descriptions of the themes, and returning to the participants to verify the findings. While these are the essential elements to data analysis in phenomenology, this investigator sees the seven strategies allowing for greater possibility of researcher bias.

Burnard's (1991) method involves clearly defined steps and a methodical approach for analysis of interview data. Burnard's method (1991) is used when interview questions are semi-structured and open-ended and the interviews are recorded and transcribed in full. It unites features of content analysis employed in phenomenology with characteristics of grounded theory approach proposed by Glaser and Strauss (1967) which involves identifying the key elements of a phenomenon and developing a substantive theory related to that phenomenon. Similar to using a grounded theory approach, Burnard (1991) explains that an investigator should be able to critically analyze a situation while being aware of personal biases, be sensitive to the words and actions of the interview participants, and be absorbed in the analysis process. It is this systematic approach and work ethic that is necessary to preserve the integrity of the interview data using a more structured style. Short of allowing the public to have full access to the interview transcripts, a complication for the investigator is that she must 
find a method of analysis that allows the interview data to be represented and the findings to be presented both truthfully and consistently.

Table 2 described criteria (Polit \& Beck, 2004) for establishing trustworthiness in qualitative research which is also seen in Burnard's methods for establishing scientific rigor. Although Burnard (1991) uses different terminology and is most established for use with phenomenology, the processes are related and will be explained. Burnard explains that the investigator should enlist a reviewer to read three of the transcripts and make a list of categories. These categories are compared to the investigator's categories to review for similarities (inter-rater concordance), indicating internal validity, or credibility.

According to Burnard (1991), this will provide ease in understanding how the analysis was done for the future readers of the study regardless of their academic discipline or area of expertise.

Burnard (1991) identifies fourteen stages for analysis of interviews in qualitative research and his steps address trustworthiness. The investigator should be aware of the complexities of qualitative study and avoid oversimplifying the process. The prescribed stages were followed for analyzing data in the proposed research.

Stage 1: Note-making. Preliminary thoughts and comments are made during the interview.

Stage 2: Immersion in the data. A systematic read-through of the transcribed interview, as well as, participant comparison, to ensure the researcher becomes intimately familiar with each participant. At this point, categories begin to surface.

Stage 3: $\quad$ Open coding. Categories are generated and coded. 
Stage 4: $\quad$ Refining categories. Collapse the number of categories into broad inclusive categories. Broadening the categories allowed for more data to fit.

Stage 5: Developing broader categories. Once again the categories were refined to eliminate like categories.

Stage 6: Guarding against bias. Without knowledge of the researcher's categories or themes, a colleague should read the transcripts and generate categories of their own. The lists should be compared and modified to identify the complete and final list of categories. Burnard suggests that the final list should be reviewed by peers to further guard against bias.

Stage 7: $\quad$ Establishing categories that cover all aspects of the interviews. Interviews should be systematically reread with the list of categories to guarantee complete inclusion in the categories.

Stage 8: Coding of interview data into the identified categories. Alongside the list of categories, each transcript is coded to identify which data fits into each category.

Stage 9: Ensuring context. The identified interview data is protected to ensure that its context does not get lost. Enough sentences are identified to maintain the context.

Stage 10: Individual analysis. The identified comments are attached to the document which contains the headings and subheadings. 
Stage 11: Checking validity. Validity is addressed in this stage by revisiting selected respondents to have them verify that the identified themes and categories are correctly interpreted.

Stages 12-14: Organizing and writing up. Interpretations are rechecked in the interviews. Since the full interviews are kept, they can be revisited if clarifications are needed. A written report of the findings is completed.

Analysis of the qualitative data followed a step-by-step procedure developed by Philip Burnard (1991). Data analysis began with a verbatim transcription of each of the audio taped interviews. The data were entered into the computer software package, QSR NVivo 9.0, for coding and analysis. NVivo allows for efficient coding of themes and categories of the transcripts and uncomplicated retrieval of the analyzed material. Although the transcripts were entered into NVivo 9.0, hand coding was completed for a more in-depth and complete analysis of the interview transcripts and field notes. Using Burnard's (1991) method of analyzing the interviews, the first stage was to keep field notes during the interviews. The next stage was to read and re-read each interview in its entirety which allowed the researcher to become immersed in the participant's "life world" (Burnard, 1991). The investigator reflected on each interview in order to capture the distinctiveness of each woman's depiction of the experience of being incarcerated and being a mother. Stage three of Burnard's method had the investigator examine the verbatim transcriptions and develop a list of headings which is recognized as open coding (Berg, 1989). These headings included a list of the range of answers to each interview question. Based on the fourth stage, these headings were then grouped together based on 
similarities and a category was named. Once the list was generated, "like" responses were collapsed together to get a list of the range of answers (Table 3).

Table 3 Primary Questions and Identified Codes/Responses

\begin{tabular}{|c|c|c|}
\hline Primary Question & \multicolumn{2}{|c|}{ List of Codes/Responses (Most Common responses in Bold) } \\
\hline $\begin{array}{l}\text { What was it like being a } \\
\text { mother before you came to } \\
\text { prison? What is it like being } \\
\text { a mother in prison? }\end{array}$ & $\begin{array}{l}\text { Best thing } \\
\text { Bom to be a mom } \\
\text { Kids are my life } \\
\text { Great } \\
\text { Hard/Difficult } \\
\text { Awesome } \\
\text { Love it } \\
\text { Missing Out } \\
\text { Milestones } \\
\text { No Contact }\end{array}$ & $\begin{array}{l}\text { Guilt/Shame } \\
\text { Stressful } \\
\text { Horrible } \\
\text { Not worth it/ Think Twice } \\
\text { Don't make mistakes } \\
\text { Not a place to be a mom } \\
\text { Still their mom } \\
\text { Keep in touch } \\
\text { Not a bad person } \\
\text { Not a bad mom }\end{array}$ \\
\hline $\begin{array}{l}\text { What kinds of things (did) } \\
\text { do you do that identify you } \\
\text { as a mother? }\end{array}$ & $\begin{array}{l}\text { Took places } \\
\text { Active in school/homework } \\
\text { Holidays/events } \\
\text { Play with the kids } \\
\text { Always with me/Be a } \\
\text { mom/Love them } \\
\text { Should have been there more } \\
\text { Taking every class I can }\end{array}$ & $\begin{array}{l}\text { Followed same path as my mom } \\
\text { They're taken care of } \\
\text { Child happy to see her/wants } \\
\text { her/loves her } \\
\text { Seeing them } \\
\text { I was there/involved } \\
\text { Not as involved } \\
\text { Getting Better } \\
\text { My responsibility to teach them }\end{array}$ \\
\hline $\begin{array}{l}\text { How is your relationship with } \\
\text { your child? }\end{array}$ & $\begin{array}{l}\text { Great } \\
\text { Good } \\
\text { They support me/Love me } \\
\text { Tell them/Show them love } \\
\text { Strained } \\
\text { Kids mad }\end{array}$ & $\begin{array}{l}\text { Walked away/Hid Stress } \\
\text { Got aggravated } \\
\text { Snapped/Yelled } \\
\text { Would get high } \\
\text { Drugs } \\
\text { Will be more grateful }\end{array}$ \\
\hline $\begin{array}{l}\text { What kinds of things worry } \\
\text { you the most about your } \\
\text { child at this time? }\end{array}$ & $\begin{array}{l}\text { Grow up like me } \\
\text { Thinking I forgot them } \\
\text { Do drugs } \\
\text { Health/emotions } \\
\text { Worry about something } \\
\text { happening to child } \\
\text { Go to prison }\end{array}$ & $\begin{array}{l}\text { Sex } \\
\text { Growing up } \\
\text { Forgetting mom } \\
\text { Long term effects } \\
\text { How they're taken care of } \\
\text { What people think/say to child } \\
\text { Should be there }\end{array}$ \\
\hline
\end{tabular}

The numbers of responses by all of the participants to each of those list items was recorded and counted. Stage five of Burnard's method involved eliminating like categories to ultimately create the list of categories. The list of categories is listed in Table 4 with an expanded explanation in Appendix 9. Headings, categories, sub-themes, and Themes are tabled in Appendix 10. 


\section{Table 4 Categories}

Should have done a better job
Adthe children down
Not worth it
Gratitude
Still wanted, still loved
Missing out
Impetus for change
Teaching them the right way
Self improvement
Vision of being the ideal mother
Being a mom the kids need

To address Stage six, the dissertation chair read interview transcripts to identify whether any more or different categories should be identified. This stage validates the categories identified by and protects against bias by the researcher. Again, for Stage seven, the transcripts were read with the list of categories to ensure the completeness of the list. Stage eight was used to code the data. This stage was completed by identifying the data in the transcripts which fit into each category. Pertinent participant responses were identified that adequately reflected the categories in Stage nine. The identified comments were then grouped together under each identified subtheme in Stage ten. Stage eleven was developed to test the validity of the categories and subthemes by holding a 
focus group of the participants. Stages twelve, thirteen and fourteen involved the organization and writing up of the research. To achieve trustworthiness (credibility, dependability and transferability) throughout this study, Burnard's (1991) stages were applied (Table 5).

Table 5 Philip Burnard's Stages of Interview Analysis

\begin{tabular}{|l|l|}
\hline Burnard's Stages & Application in this study \\
\hline Stage 1: note-making & Field Notes \\
\hline Stage 2: immersion in the data & Read through \\
\hline Stage 3: open coding & Coding \\
\hline Stage 4: refining categories & Collapsing into broader categories \\
\hline Stage 5: developing broader categories & Eliminating like categories \\
\hline Stage 6: guarding against bias & $\begin{array}{l}\text { Having list of categories peer reviewed to } \\
\text { guard against bias }\end{array}$ \\
\hline $\begin{array}{l}\text { Stage 7: establishing categories cover all } \\
\text { aspects of the diaries }\end{array}$ & $\begin{array}{l}\text { Interview reread with the list of categories } \\
\text { to guarantee complete inclusion }\end{array}$ \\
\hline $\begin{array}{l}\text { Stage 8: coding of interview data into the } \\
\text { identified categories }\end{array}$ & $\begin{array}{l}\text { Using list of categories, each transcript is } \\
\text { coded to identify which data fits into each } \\
\text { category }\end{array}$ \\
\hline Stage 9: ensuring context & $\begin{array}{l}\text { Enough sentences are identified and used } \\
\text { to maintain the context of the comment. }\end{array}$ \\
\hline Stage 10: individual analysis & $\begin{array}{l}\text { Identified comments are attached to the } \\
\text { document which contains the headings and } \\
\text { subheadings. }\end{array}$ \\
\hline Stage 11: checking validity & $\begin{array}{l}\text { A focus group was conducted to verify that } \\
\text { the themes and categories are appropriate. }\end{array}$ \\
\hline Stages 12-14: organizing and writing up & $\begin{array}{l}\text { Interpretations are rechecked in the } \\
\text { interviews. A written report of the findings } \\
\text { is completed. }\end{array}$ \\
\hline
\end{tabular}




\section{CHAPTER 4}

\section{FINDINGS}

The research was focused on gaining an understanding of the lived experience of mothers who are incarcerated. Although mothers in prison described vastly different experiences, one concept prevails and that is hope for the future. Humbled by what they experienced in the past and fearful for their children's welfare in the present, the mothers are hopeful for the future armed with new perspectives about how their mothering experience can be. They revealed insights about their lives and spoke of the need to dispel the myths about themselves. The lived experience of these mothers reflects a painful yet hopeful transformation.

\section{The Phoenix Rising above the Ashes}

So often, we believe that we have come to a place that is void of hope and void of possibilities, only to find that it is the very hopelessness that allows us to hit bottom, give up our illusion of control, turn it over, and ask for help.

Out of the ashes of our hopelessness comes the fire of our hope -By Anne Wilson Schaef (2004)

Participants described their experiences in prison with a focus on the future. Although they expressed the anguish of being incarcerated and separated from their children, the participants described their hope for the future. The notion of hoping for the 
future can be related to the story of the rise of the Phoenix. This story from Greek Mythology and its relationship to the findings of this study are further described beginning on page 72 . Like the phoenix rising from the ashes, the participants believed that they would emerge from their prison experience as better mothers to their children. Sample Characteristics

\section{The participants.}

Twenty-four incarcerated mothers participated in this study. Each woman was interviewed one time in the family visiting room at the prison where they were housed and on average the interviews lasted 45 to 60 minutes. They were asked to describe their experiences of being incarcerated mothers. The data from 24 participants were analyzed as the mothers' experiences were analogous and each interview provided the researcher with rich data. Detailed descriptions about each participant and her experience of mothering while incarcerated is represented in Appendix 8. Organization of findings will include background and demographics related to the participants, detailed information about each mother and her story, and relevant statistics related to the whole of the participants. Also included in this section are the domains relevant to the study, mothers' descriptions of their lived experience while incarcerated and their dreams for their future as non-incarcerated mothers. Table 6 displays each of the participants including, their pseudonyms, their ages, length of incarceration, and the number of children. 
Table 6 Age, Time Served, and Number of Children of the Participants

\begin{tabular}{|c|c|c|c|}
\hline $\begin{array}{l}\text { Assigned } \\
\text { Pseudonym }\end{array}$ & $\begin{array}{l}\text { Age of } \\
\text { participant }\end{array}$ & $\begin{array}{l}\text { Length of time } \\
\text { served at interview } \\
\text { (months) }\end{array}$ & $\begin{array}{l}\text { Number of } \\
\text { children }\end{array}$ \\
\hline Janet & 20 & 7 & 1 \\
\hline Farrah & 24 & 12 & 1 \\
\hline Wendy & 22 & 5 & 1 \\
\hline Regina & 22 & 3 & 1 \\
\hline Jordan & 38 & 12 & 2 \\
\hline Lydia & 28 & 33 & 4 \\
\hline Susan & 25 & 13 & 2 \\
\hline Renee & 36 & 20 & 4 \\
\hline Khloe & 35 & 24 & 2 \\
\hline Francis & 38 & 48 & 5 \\
\hline Chelsea & 31 & 31 & 3 \\
\hline Madeline & 35 & 4 & 10 \\
\hline Leslie & 40 & 27 & 3 \\
\hline Melinda & 42 & 96 & 6 \\
\hline Randi & 30 & 24 & 3 \\
\hline Tammy & 32 & 14 & 2 \\
\hline Jackie & 34 & 26 & 2 \\
\hline Betty & 31 & 12 & 3 \\
\hline Kara & 29 & 4 & 1 \\
\hline Kaitlyn & 39 & 27 & 1 \\
\hline Abby & 34 & 36 & 3 \\
\hline Marcie & 28 & 12 & 1 \\
\hline Cathy & 31 & 42 & 2 \\
\hline Kristin & 22 & 28 & 3 \\
\hline
\end{tabular}




\section{Characteristics of the sample.}

The sample of participants included 24 mothers. One participant that was included in the final sample was actually the grandmother to the children but was the primary caretaker and had full custody of the children prior to being incarcerated. She referred to those children as "her babies" and considered them her children. For this reason, her interview and demographics were left in as part of the sample. The participants ranged in age from 20 to 42 years with the majority of the participants being in their 30 s (Table 4). The sample included 20 Caucasian mothers, two African American mothers, one Hawaiian mother and one mixed-race mother (Table 7; Figure 2).

Table 7 Races and Ages of Participants

\begin{tabular}{lll|lll}
\hline $\begin{array}{l}\text { Age of } \\
\text { Mother }\end{array}$ & $\mathrm{n}$ & $\%$ & Race & $\mathrm{n}$ & $\%$ \\
\hline $20-29$ & 9 & 37.5 & Caucasian & 20 & 83 \\
$30-39$ & 13 & 54.2 & African American & 2 & 8.3 \\
$40+$ & 2 & 8.3 & Other & 2 & 8.3 \\
\hline
\end{tabular}

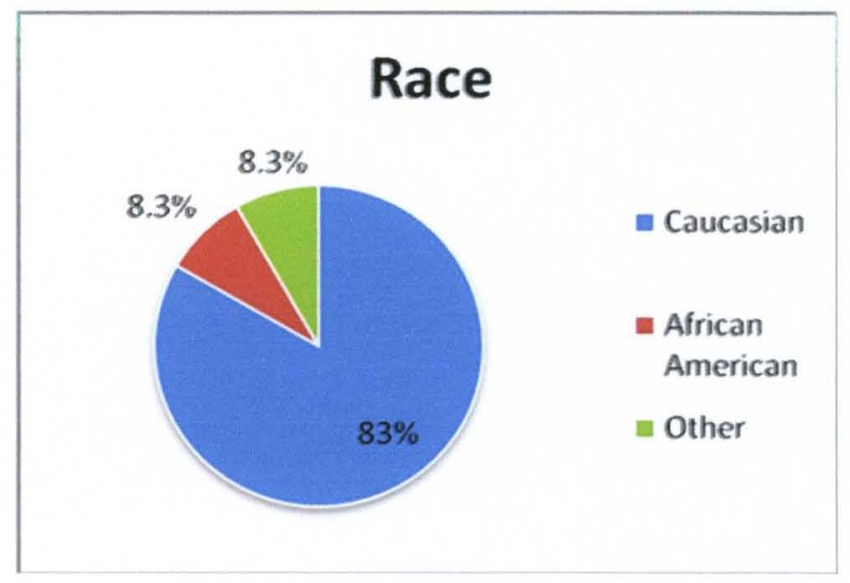

Figure 2 Race

A total of 66 children were bearing the burden of their mothers' incarcerations with a mean of 2.75 children per mother. Of all of the children involved, there was an 
average age of eight years old with the youngest child being seven months old. Of the 66 children of these incarcerated mothers, 30 were being cared for by their fathers and 13 being cared for by the mother of the participant. The remaining children were cared for by various family members except for one child who was in state custody and another who was being cared for by a non-family member. The children had a total of 40 fathers of which 18 lived with their children. Table 8 and Figure 3 provide the details related the numbers of children per mother and the ages of those children.

Table 8 Number of Children per mother and Ages of Children

\begin{tabular}{lll|lll}
\hline $\begin{array}{l}\text { \# Children } \\
\text { Per Mother }\end{array}$ & $\mathrm{n}$ & $\%$ & $\begin{array}{l}\text { Age of } \\
\text { Children }\end{array}$ & $\mathrm{n}=66$ & $\%$ \\
\hline 1 & 7 & 29.2 & $<1$ & 3 & 4.5 \\
2 & 6 & 25 & $1 \mathrm{y}-2 \mathrm{y}$ & 10 & 15.2 \\
3 or more & 11 & 45.8 & $3 \mathrm{y}-5 \mathrm{y}$ & 14 & 21.2 \\
& & & $6 \mathrm{y}-8 \mathrm{y}$ & 10 & 15.2 \\
& & $9 \mathrm{y}-11 \mathrm{y}$ & 10 & 15.2 \\
& & $12 \mathrm{y}+$ & 19 & 28.8 \\
\hline
\end{tabular}

\section{Age of Children}

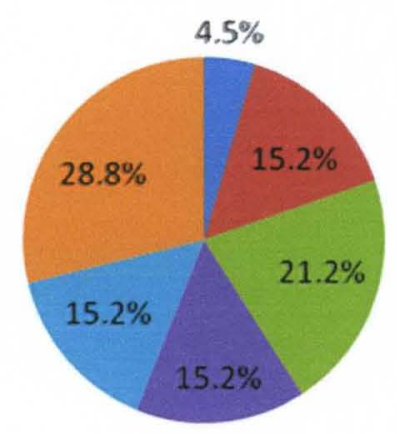

$E<1$

- $1 \mathrm{y}-2 \mathrm{y}$

- $3 \mathrm{y}-5 \mathrm{y}$

- $6 y-8 y$

nay-11y

$12 \mathrm{y}+$

Figure 3 Age of Children 
As it was described by the participants, four of them were not eligible to take part in any programs in the prison because one was a Class D Felon and three of them were county inmates. Some women described taking part in "anything and everything" that was offered by the prison. Other women reported having taken part in a variety of programs including the Prison to the Streets, Life without a crutch, college courses or a general equivalency diploma program. The two most attended programs were the substance abuse program (SAP) in which 11 participants had attended or were attending and the parenting class which 12 mothers had taken.

Contact and communication were documented as visits, call and letters. Participants recorded whether they had any contact with their children and what types of contact (Table 9; Figure 4). Four participants had no contact of any kind with their children. Of the 24 participants, 16 had at least one visit during their current incarceration. Twelve mothers reported that they were able to talk to their children by phone at least one time each month. Sixteen mothers reported that they sent or received at least one letter per month.

Table 9 Contact with children per month

\begin{tabular}{ll}
\hline Contact & $\%$ \\
\hline Visits & 66.6 \\
Calls & 50 \\
Letters & 66.6 \\
No Contact & 16.6 \\
\hline
\end{tabular}




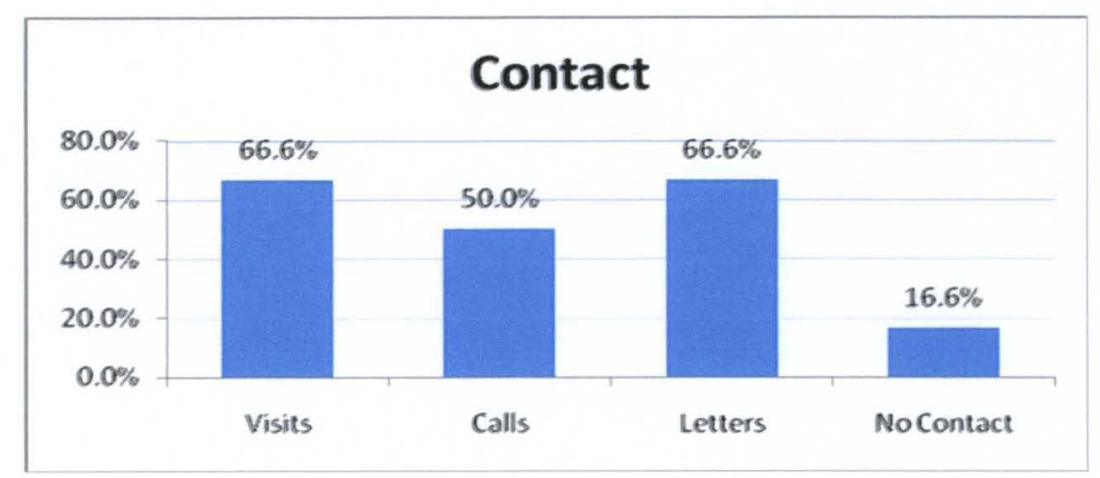

Figure 4 Contact

The participants' had been sentenced from one year to 28 years for their crimes and the amount of time they had served at the time of the interviews ranged from three months to seven years. The amount of time remaining for the women to serve ranged from two weeks to four years although of the four mothers who reported their remaining time left to serve as over one year, they all reported approaching parole hearings or the intention of requesting shock probation. Two women had not been sentenced for their crimes at the time of the interviews but were anticipating court hearings. Table 10 presents the information related to the lengths of sentences for the participants and they types of offenses of which they were convicted.

Table 10 Length of Sentence and Type of Offense

\begin{tabular}{|c|c|c|c|c|c|}
\hline \multicolumn{4}{|c|}{ Sentence Length ( in Months) } & \multirow{2}{*}{$\begin{array}{l}\text { Offense } \\
\text { Drug Related* }\end{array}$} & \multirow{2}{*}{$\frac{\%^{* * *}}{70.8}$} \\
\hline Min. & Max & Total & Mean & & \\
\hline \multirow[t]{4}{*}{12} & 342 & 2964 & 123.5 & Burglary/Robbery & 12.5 \\
\hline & & & & Financial Crimes** & 33.3 \\
\hline & & & & Identity Theft/Forgery & 16.6 \\
\hline & & & & Escape & 8.3 \\
\hline
\end{tabular}

* Includes sales, trafficking, manufacturing, possession, etc.

** Includes tax fraud, credit card fraud, bad check

$* * *$ Greater than $100 \%$ because some participants with multiple charges 
Eight women reported no prior incarcerations, four had one prior incarceration, five had two prior incarcerations, and seven reported more than three prior incarcerations. The most incarcerations reported by any of the participants were the two women who had over 20 incarcerations each; one woman was currently in prison for possession of a controlled substance and one who was currently in prison for credit card fraud.

\section{Domains}

The literature review guided the investigator to explore four domains of mothering including: the meaning of mother, the roles of mothering, the mother's relationship with her children, and how the mother views the impact of the separation on her children. Each of these domains had primary corresponding questions. To explore what the meaning of mother was to the participants, they were asked, "What was it like being a mother before you came to prison?" and "What is it like being a mother in prison?" Secondary questions included "What would you like others to know about being a mother in prison?" and "How does it feel to be a mother and be incarcerated." Next, to understand their view on the roles of mothering, they were asked, "What kinds of things do you do that identify you as a mother? and "What kinds of things did you do before coming to prison that identified you as a mother?

The corresponding secondary questions included 1) "Who do you turn to when you need to talk to someone about your child?" 2) "What is your experience of how your mother took care of you?" 3) What is your experience of caring for your child/children?" 4) How is that experience the same or different?" To answer the third domain, the mother's relationship with her children, the participants were asked, "How is your relationship with your child?" The corresponding secondary questions for this domain 
include, "What kinds of things give you joy or good feelings with your child?" and "When you are worried or stressed, how does that impact the way you react to your children?" Finally, how the mother views the impact of the separation on her children, the fourth domain, they were asked about the things that worry them the most for their children. The corresponding secondary questions associated with the mother views on the impact of the separation include, 1) "Tell me about having children in your situation." 2) How does being in prison change your experience/role of caring for your child?" 3) How has the experience of being incarcerated affected your ability to care for your child?" 4) How does your child/do your children feel about you being incarcerated?" and

5) How does that make you feel?"

\section{Use of Metaphors in Qualitative Research}

Metaphors are used to illustrate the meaning of a concept that is being explained. Metaphors can be used in writing up research findings to frame a situation or explanation that offers the reader a clear picture and can aid in understanding and can create knowledge through storytelling (Morgan \& Smircich, 1980). They are a creative way to convey the findings of a study (Patton, 1990). The Phoenix Rising from the Ashes is used in this writing to illustrate the experience of mothering during incarceration. The relationship between the Phoenix metaphor and my findings will be discussed on page 76.

\section{The Phoenix Rising from the Ashes}

The story of the Phoenix originated in Egyptian and Greek Mythology. Many cultures have adopted this mythical creature and have altered the legend to fit their cultural beliefs. The Chinese culture has adopted the Phoenix and has called it 
Fenghaung. It is the second most respected creature in Chinese culture, second only to the dragon, and it is said to represent empresses and females. The Persian version of the Phoenix is called Simurgh and has appeared in many classic novels in Iran. The Egyptian Phoenix was adopted by the early Catholic Church as a symbol of the death and resurrection of Christ.

The Greek version of this story is that of a mythical bird in Arabia that lives for 500 years. As it nears death, the Phoenix gathers aromatic wood and spices into its nest and sets the nest and itself ablaze. It resurrects and the Phoenix is reborn to live again. A common theme in all of the versions of this famous story is the resurrection and rebirth of the creature.

After exploring the meaning of the interviews and the emerging categories and subthemes of this research, it was determined that the story of the Phoenix is very similar to the lived experience of the incarcerated mothers. When exploring the meaning of the subthemes it became increasingly clear that the phases of the mythological bird's life corresponded to the phases of the new beginning that the incarcerated mothers were experiencing. The Phoenix itself can be equated to that of the incarcerated mother. As she moves along her path of self discovery and begins to make changes and self improvements, her old ways of thinking and prior behaviors are seen as obstacles to her renewal. These obstacles to her mothering and to her renewal can be equated to the aromatic wood and spices that the Phoenix gathers into its nest.

As the bird sets its nest and self on fire, it is ridding the world of those things that were old and no longer necessary. When looking at the role that the incarceration plays in the women making changes in themselves and making the preparations to be reunited 
with their children, they often made statements related to what their mothering focus would be when they are released. These changes and ridding themselves of the obstacles can be likened to the fire of the Phoenix and the nest. The nest is filled with their preincarceration experiences, behaviors, and familial patters that let the incarcerated women to the place of death and the fuel that must be burned. The phoenix must transform herself through the burning of all of the ties with her former life and her life begins anew. Finally, it is clear that the resurrection of the Phoenix can be compared to the rebirth of the mother and in her new, improved role in her children's lives.

The phoenix model. As Max van Manen (1990) described, art enhances the appreciation of a lived experience and can bolster the understanding of the phenomenon by offering visualization. The artist's rendering in Figure 5 is of the Phoenix Rising from the Ashes. This picture represents the mothers rising out of their current circumstances to mother again. The deep reddish-orange color of the body of the bird represents the fire within each woman to return home and mother their children. The smooth edges around the head and upper wings of the birds represent the soft nature that is still deep within each woman. The defined, structured design of the upper part of the wings represents the definite plans and distinct ideas of what the mothers' lives will be when they are released. The unstructured formation of the lower wings represent the parts of their lives that continue to be fluid, such as their living arrangements, job prospects, their relationship with their children. The pile of ashes at the bottom of the painting represents the obstacles to mothering that the women are trying to leave behind. 


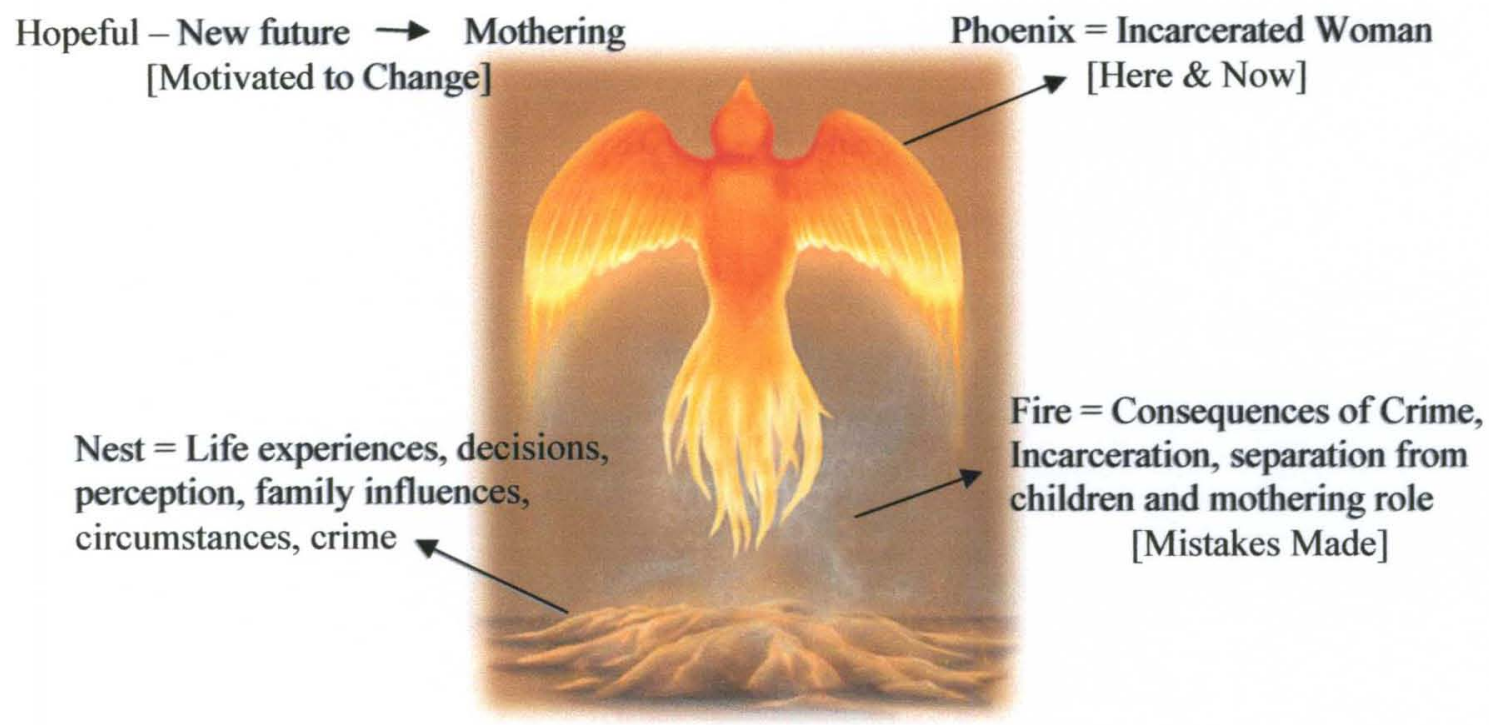

(C)By Katrina Birch

Figure 5 Phoenix Art

\section{The lived experience of mothering.}

Although the stories of the participants were varied and regardless of their childhood experiences, their past mistakes or their imprisonment experience, participants planned for future reunification with their children. They had hopes and dreams about what their futures held once their family unit was reunited. Two themes, Living in the Fire: The Lived Experience of Incarcerated Mothers and Emerging from the Fire:

Dreams for the Future as Mothers, emerged during the analysis of the data. In addition, four subthemes that were ascertained were: Mistakes were Made, The 'Here and Now' of it, Motivated to Change, and Redefining Themselves. Categories that emerged from the subtheme Mistakes were Made were associated with issues regarding the mothers' beliefs that they should have done a better job with their children and that they let the children down. Categories related to The 'Here and Now' of it included addressing the stigma attached to being in prison, doing the crime was not worth it, learning gratitude, and still being loved and wanted by their children. Mothers experienced different motivators and 
this subtheme was comprised of Categories such as missing out, having an impetus for change and teaching them the right way to behave in the world. In the subtheme Redefining Themselves, the categories related to their desire to improve themselves and make themselves better, their vision of being an ideal mother, and focusing on being the mother that their children needed. Appendix 1 explains how the Categories were exposed and themes and subthemes were developed, along with significant statements made by the mothers that were relevant to each theme.

When analyzing the transcripts it became clear that the participants separated their lives into two distinct times. The division occurred between their life prior to their anticipated release from prison and their after-prison future with their children. Of the aforementioned subthemes, Mistakes were Made and The 'Here and Now' of it were clearly related to their lives prior to and while incarcerated. These subthemes came from the responses where mother's reflected on their past mistakes, what their lives were like with their children and what their incarceration means to their role as a mother and how they are preparing to leave the prison a better person. The other two subthemes, Motivated to Change and Redefining Themselves were related to the participants' views on the future. They describe what they want for their lives after they leave prison and what things motivate them to make the changes necessary to be successful when they go home.

\section{Theme \#1}

\section{Living in the Fire: The Lived Experience of Incarcerated Mothers}

The mothers who participated in the research were reflective about their lives prior to being incarcerated and were coming to terms with their past. Many of the 
participants recognized that their behaviors and choices damaged the emotional bond between them and their children. For those mothers who experienced drug addiction, the choice to take drugs rather than focus on their attention on the children imparted a great amount of distress. Cathy, a 31 year old mother of two children described her experience of taking and selling drugs.

.... Only thing they was missin was me because I was like always dropping em off to my mom's to go sell drugs or do drugs, you know. I think more or less, the quality time was missing, but I always tried to make it up, I always, you know, would take em out and stuff, give em money or do stuff with em.

\section{Mistakes Were Made}

All men make mistakes, but only wise men learn from their mistakes. --Winston Churchill (1874-1965)

The first essential subtheme discovered in this research was mistakes were made. All of the participants described a sense of the mistakes they made before coming to prison. Because they were the primary caretakers of their children, they describe the experience of being incarcerated as a result of their mistakes and that their children were paying the price. They reveal that they should have done a better job of focusing their attention on their children and in providing the parenting that their children needed. These mothers also described how they let their children down by choosing to take part in their crimes and ultimately be incarcerated. For the 21 mothers who had been suffering from drug or alcohol addiction, their feelings of letting their children down involved choosing their addictive substance over taking care of their children.

\section{The 'Here and Now' of it}

A man's memory is bound to be a distortion of his past in accordance with his present interests, and the most faithful autobiography is likely to mirror less what a man was than what he has become. --Fawn M. Brodie (1915-1981) 
This subtheme began to emerge as the women described their lives while incarcerated. Although they had been reflective about their pasts, they were focusing on the life they were currently leading and the opportunity to refocus their attentions away from the criminal past. A major concern of the participants was the stigma they felt of being an incarcerated mother. They were concerned that people on the outside of prison understand that they, as incarcerated mothers, weren't bad people and bad mothers and that they simply had made bad decisions and life choices. They also revealed a common notion that their addiction if they had one and their crimes weren't worth them being incarcerated and separated from their children. Many of the participants talked about the prison experience making them grateful for the life they had or could have. They revealed that even with all of the faults that they experienced and created in their lives, they would be more grateful for their children and for the lives they had with their children once they were reunited with them. One thing that brought the participants joy was them knowing that their children still wanted to be with them and still loved them. This idea emerged from all of the mothers even those who had no contact with their children. When asked how their children felt about their incarceration, the mothers who had no contact with their children spoke as if their children's feelings were a reality instead of something they were imagining. Although all of the mothers had a fear of their children forgetting them or of being angry with them, they all spoke of their children knowing their children wouldn't forget them and knowing that their children loved them. 


\section{Theme \#2}

\section{Emerging from the Fire: Dreams for the Future as Mothers}

As mothers dreamed of and planned for the future, they discussed their motivations to change and how they were redefining themselves as a mother. Their motivations included their understanding of how much of their children's lives they were missing and included descriptions of milestones and holidays. For many of these mothers there was an impetus to make the changes in their lives and these impetuses included childhood accomplishments or family tragedies. The participants were also clear on their responsibility to teach their children the right way to grow up and live responsible lives.

The mothers spoke of not allowing the children to follow in their footsteps and how they needed to fix their issues and make improvements in themselves so that they could go home and be a positive influence on their children. There was also discussion about what an ideal mother should do for her children and how they were taking steps to be the ideal mother they aspired to be. They wanted to take the necessary steps to be the mother that their children needed not just what they believed met those needs. They were concerned with their children's well-being and were easy to point out that they would take things slow once they were released for the sake of their children.

\section{Motivated to Change}

When we are motivated by goals that have deep meaning, by dreams that need completion, by pure love that needs expressing, then we truly live life.

--Greg Anderson (American Author)

Many things motivated these incarcerated mothers to make changes in their lives.

One thing that was extremely evident was that they knew they were missing out on the lives of their children. If they had very young children, the mothers spoke of missing milestones including first steps, first words, and such. Because the interviews were done 
in the autumn, many mothers talked about the upcoming Halloween holiday and if they had contact with their children, they described what their children would be dressed up as. If they didn't have contact, a number of the participants imagined how the holiday would be for their children and they guessed how their children would be dressed. There was much conversation about simply missing that event. Many also talked about the upcoming Christmas holiday and that seemed to be distressing to those who talked about it. Leslie, a 40 year old mother of three described the holidays,

"Just like joy at Halloween I knew what they were doing... The only holiday that really bothers me is Christmas, being locked up. But uh, I know they're having a good time, I know they're being taken care of, and they're bein raised, the way I would be raisin em. You know, maybe even better in some aspects with my mother..."

\section{Redefining Themselves}

Man cannot remake himself without suffering, for he is both the marble and the sculptor. -- Dr. Alexis Carrel

As these incarcerated mothers were reflecting on their lives before their incarceration and were talking about changing their lives, they were focusing on getting themselves better and improving themselves as mothers. Many of the participants voiced their understanding that if they didn't improve themselves then they wouldn't be able to be an effective mother when they are released. Also focusing on their future meant that they had a vision of what the ideal mother was and how they could be an ideal mother. Their vision of the ideal mother was not an unrealistic image but in fact it was a sensible, practical visualization of the type of mother they sought to be. Finally, their vision of their future with their children and their vision about being an ideal mother included their idea of being the mother that their children needed. There were comments about making sure they took things slow and made the children feel comfortable after they are released. 
They didn't want to force the children into accepting them back into their lives and didn't want to make the transition for the children any more difficult. Kaitlyn, a 39 year old mother of 1 explained,

"I can't just jump back into his life and make him come back and live with me. It's going to take time for him to be comfortable."

Kristin, a 22 year old mother of three, describes her view of how this incarceration had changed her ability to care for her children as:

"I think it's bettered myself, it really has. I want to go out there and be the best mom that I can to them. I'm gonna do what I can to not leave them, yet again. It's changed me, my whole outcome of everything, the way I think, the way I react to things. The way I look at what I want to do in my life, because before I didn't really have no ambitions."

The abovementioned descriptions illustrate how the mothers view their experiences of being incarcerated mothers. These representations underscore the overall impression that this experience has left on each of the participants and their children and families. One thread that was consistently heard in the participant's interviews was the idea that they had an opportunity to repair their relationship with their children and they had bright hopes for the future.

\section{The Member Check Discussion}

A focus group discussion was scheduled and held with the participants who chose to attend or did not have previous obligations. Of the 24 participants from the study, 16 mothers were still incarcerated at the time of the focus group session. Of those 16, eight participants chose to or were available to attend the discussion session. This session was held to verify the findings of this research. The session was held in the same visiting room where the individual interviews were held. The session lasted one hour and twenty minutes and generated a considerable amount of discussion amongst the participants. All 
but one of the attendees was serving their first incarceration and the range of their release dates was one week to 8 months. All attendees were Caucasian and were between the ages of 22 and 35 years. The discussion session followed the focus group guide (Appendix 3).

As this investigator went through each of the original interview questions and their related findings, the participants signaled their agreement through nodding their heads, answering affirmatively, and smiling. There were no negative responses in conjunction to the study findings. When the question arose asking if there was anything that they had wanted to share related to the research, a lively discussion began. The participants talked about the program offerings at the prison and what they felt was missing as a part of the related content. There was considerable discussion about the parenting program and they conveyed the content that they supported about the program and listed the content that was not included. They described that they felt that the parenting program taught focused too heavily on infant care and lack in teaching about various age groups. They stated that the majority of the content centered on caring for and raising an infant and that there was no coverage related to adolescents. They clearly explained that there needed to be content related to what behaviors they as mothers could expect from their children once they were reunited as a family.

Another discussion that took place during the focus group session was related to the timing of the information that was provided to them about reintegrating once they are released. They voiced their frustration over the fact that information related to support services available to them wasn't given to them until after they were granted parole and all participants agreed that they had no way to prepare for their release until that time. 
Related to that topic they also discussed the need for a way to help prepare their kids for their homecoming. One of the topics that they voiced strong feelings about was related to the lack of programs focusing on reentry into their communities without reoffending if they were convicted of crimes other than those related to sexual predators or substance abusers. They shared that there was a lot of information and tools available for "drug addicts" but nothing for the "drug traffickers" and one of the issues related to that was the lack of tools related to making a viable living without returning to the drug trade.

Through all of the discussion about what was missing in the programs, side conversations were taking place between the mothers related to their experiences with their children while they were incarcerated. They began to share with each other strategies that they used to better communicate and emotionally connect with their children. They also talked about their concerns about returning home and the seven participants who were serving their first incarceration began to rely on the one participant who was serving her second incarceration. She was able to share her experiences of returning home and described the challenges she faced. The seven participants appeared to take seriously the advice from someone who was in their same situation.

There was open communication and periods of laughter as the focus group participants talked about their children and their similar mothering experiences. When a focus group participant said to the investigator, "It's nice to have someone to talk to that isn't focused on the prison but is focused on us as moms and our kids" and as this investigator listened to the discussion that was freely being had by the participants in the focus group, I once again understood the importance of the current study and the need for further research. 


\section{CHAPTER 5}

\section{DISCUSSION}

The purpose of the study was to explore and describe the experience of mothering among incarcerated women to address the gap within this body of literature and to contribute to the understanding of the phenomenon of mothering during incarceration. Twenty-four participants described their experience of being incarcerated mothers. The data provided a clearer understanding of the mother who is incarcerated and affords insight into how she views her past, how her current incarceration alters her role as the mother to her children, and how she envisions her future once she is released. Various factors such as the socioeconomic status of the family, presence of substance abuse and level of education all have a bearing on the role of the mother and the research findings support the literature that mothering is complex. Burnard's (1991) stages for data analysis were used to analyze the data garnered from these interviews. The discussion chapter examines how the data from this study are important to the field of nursing. Discussion of the findings, study limitations, recommendations and the contributions of the study are reported.

\section{Nursing Literature: Importance of this Research}

Female offenders exhibit economic dependency on other people or the welfare system, experience low self-esteem, perceive a lack of possibilities for their future, and a lack of choices (Morash \& Schram, 2002). Similar to what was found in the literature, the 
majority of participants in this study committed economic crimes, such as credit card fraud. Add on top of that the many internal and external factors that influence a person's ability to mother effectively and it makes clear the complexity of the experience of mothering during incarceration. Generally, mothers have to contend with issues such as self-esteem, level of support, confidence in themselves as mothers, and coping abilities, just to name a few. It became clear that the experience of mothering was similar among the participants in spite of their diverse backgrounds and personal characteristics. The mothers came from varied circumstances and had experienced things like substance abuse, domestic violence, mental illness and poverty, yet their mothering experiences during their incarcerations were similar in nature. Also similar was the fact that most of the participants had experienced something in their lives prior to their incarceration that influenced and interfered with their mothering ability. Like those characteristics typically seen in incarcerated women, the participants in this study shared the same traits. In addition, most of the participants spoke of childhood and early adulthood experiences that fundamentally predisposed their mothering ability.

Kates, Mignon, and Ransford (2008), employed by the Center for Women in Politics and Public Policy at the University of Massachusetts Boston, conducted a study in three Massachusetts prisons and focused on the family relationships and the concerns for the children by incarcerated mothers in that state. Findings from their study were very similar to the findings related to the family issues and concerns in my study. In Kates, Mignon, and Ransford's study the mothers had experienced little or minimal communication with their children and their children's caregivers, difficulty in 
maintaining a relationship with their children, and distress over their child's overall wellbeing.

Appleyard and Osofsky (2003) studied the repercussions of trauma on parenting abilities and the outcomes for the children. This study produced similar results related to depression, anxiety and post traumatic stress disorder. They reported that the children of parents who live with fear and feelings of helplessness often lack in trust and security. Mothers in my study who had young children expressed their concern about their children's lack of trust and anxiety. They also spoke about the need to assure their children that they wouldn't leave them again in the future. According to one mother, her children are indifferent to her incarceration and she expressed anguish that they don't seem to need their mother. While some of the children's caregivers, especially grandparents, offered support and encouragement to the incarcerated mother, many others lacked trust in the ability of the mother to be responsible and voiced those concerns to the incarcerated mother if they allowed contact.

Ruiz (2002) identified that grandmothers who were care giving their incarcerated daughter's children became increasingly attached to the children and became fearful of the mother's ability to care for her children. Similar concerns arose in the incarcerated mothers' responses when they talked about going home and expressed their fear of not being able to regain custody. Different from the literature was the fact that the majority of the children were living with their respective fathers as opposed to their grandmothers. Although Arditti and Few (2006) reported that the women in their study who voiced their biggest challenge was staying away from the alcohol and drugs, the mothers in my study didn't voice those concerns themselves and because they were still incarcerated they did 
not have to face those challenges. They were unwavering in their belief that they would be able to avoid the substance they had previously been addicted to.

The highlighted studies are diverse and few in the large number of studies that exist related to various topics in incarceration. Many studies exist that focus on pregnancy in prison, the children of incarcerated parents, incarcerated fathers, parenting programs in prison and women's transition from prison to the community. It is necessary to examine how this research study contributes to the current body of literature, specifically nursing literature. The purpose of this study was to examine and explore the meaning of mothering during incarceration. This research was to aid in gaining insight into the experience of being a mother in prison. Because of the lack of knowledge regarding the experience of mothering in incarcerated women, this study is focused on one specific perspective. The implications of this are that the findings of this research have significance in nursing literature.

\section{Nursing Practice: Importance of this Research}

This research was conducted with the intention of exploring the lived experience of incarcerated mothers. Although those people who work within the criminal justice arena have a special interest in how these mothers conduct themselves within the prison walls, they also have a concern about how these women prepare to return to their families. Past experience has shown that there is a high recidivism rate amongst those who were formerly incarcerated. While the focus continues to be on aiding the inmates to rehabilitate, much research has been conducted about how to provide assistance to this population once they return to their communities. It begs the question then 'What does this have to do with nursing?' 
Nursing has been charged with the work of educating our society to better health. Nurses have also been involved with educating mothers when they leave the hospital to take their newborns home. If these two notions are combined, it is nursing's responsibility to educate mothers and in turn improve the health of our society. Once a mother is released from prison she may be in need of mental health care, substance abuse counseling in addition to primary health care. Nursing can provide the services that are necessary to potentially decrease the rate of recidivism of formerly incarcerated mothers. Looking at the effect of maternal incarceration, it is seen that this event not only transforms the woman involved in the incarceration but many, many children. Considering that $80 \%$ of women in prison have children, the significance of the incarceration is great to an abundance of children. Nurses who work with the pediatric population may very well come in contact and have the opportunity to provide health care and support to children of incarcerated mothers. Pediatric nurses are in a position to not only provide the necessary health care but they can provide these children and their caregivers with necessary education and referrals to mental health providers if needed by the children. What we have to consider is that these children are living with someone else while their mother is away so there is a burden on the caregivers. Nurses who work with the adult population may be providing services to the caregivers of children of incarcerated mothers. These nurses may be able to provide the caregivers with the needed encouragement, support and necessary referrals to mental health providers and information about community resources available to them. The family unit is disrupted and whether that includes a spouse, a significant other, or simply the mother and her children, it has to be considered when looking at the health of the community. We then 
also have to look at the consequences in the schools and neighborhoods. A mother's incarceration involves many more people than just the woman and as nursing has the responsibility to promote the health of our communities; the health and wellbeing of an incarcerated mother should be a starting point. So I beg to question 'Why not nursing?'

\section{Nursing Research: Importance of this Research}

The rich data acquired from this study offered many insights about mothering during incarceration. The new information shared by these mothers gave me new insights about their journey to bettering themselves while incarcerated as well as their hopes and concerns for the future with their children. Using phenomenology gave new insight that was not previously seen in the literature. Conducting the one on one interviews allowed for a rapport to be built between the researcher and participants.

Considering the small number of nursing studies focused on this population, there are many research prospects on this topic. This research and future research can serve to build the knowledge base for working with incarcerated mothers, formerly incarcerated mothers, children of incarcerated mothers, and all of those parties that are impacted by the incarceration of a mother. Another consideration is the lack of qualitative studies that have been conducted with this population. Previous research is limited both in the context of the population and in the context of the research method. This descriptive study demonstrated that mothers have essential experiences during incarceration. Implications for future research suggested by these research results include the need for education regarding specific strategies to maintain involvement with the children during incarceration and how to support these women in their journey home. Although the study lends itself to the body of nursing knowledge, further studies must be done to gain a 
thorough understanding of the experiences of incarcerated mothers. Gaining a better understanding about the phenomenon of mothering during incarceration was realized with this study. This research study can be used a starting point to increase nursing involvement with this population.

In light of the larger sample size in this study, and the varied experiences of the participants, topics related to future research arose and that research can be focused in many areas. Studies can be conducted to test the significance of the various programs offered in prison for substance abuse issues and for life skills. Short term and long term effects of these programs on the effect of recidivism could offer insight into the importance of the information offered and could evaluate the effectiveness on the women. A number of women described their experiences of being abandoned by their mothers either through choice, drugs, or death and expressed the repercussions that had on their ability to parent. This revelation could lead to research involving the importance of the mother-daughter dyad on a woman's mothering abilities. Another topic that surfaced frequently was the burden of low paying jobs and how it constrained the single mothered family. More research needs to be conducted to evaluate the hardship of the low paying job on the commitment of crimes and the impact of having children on the decision making process. Studies to investigate the self perception of herself as a mother could be conducted to explore the association between how they were mothered and how they perceive their mothering.

\section{Public Policy: Importance of this Research}

The influence of this and future research in this population could be far reaching. Considering the lack of specific policies related to the incarcerated mother and their 
needs, this and other research can contribute to the evidence that policies should be developed to protect and aid these women. Current policies surrounding the use of parenting programs should be updated to better meet the needs of the incarcerated mother. While there are policies to address the reentry needs of incarcerated persons, this research can better inform the policy makers about those needs. This qualitative study explored what the population describes as their experience. They are the experts of their incarceration experience and should be seen as the informants in the development of beneficial policies. Considering the number of people that bear the consequences of the incarceration of a mother, public servants should consider using the expertise of this significant population.

Another consideration is the increasing costs of incarceration to society. Not only is there a financial burden placed on the state and federal governments but the financial burden to the families is great. The costs in our communities includes the cost of fostering children of incarcerated mothers, the cost of administering community programs over and over when there is recidivism, the cost of public assistance to those who were formerly incarcerated, and the emotional cost to the children and families. All of these costs should be deliberated as policies are being developed and improved.

\section{Limitations}

Although research studies are planned and systematically developed to maintain integrity in the study, limitations are unavoidable in most instances. This study has a few limitations that will be discussed.

A limitation in this study was the fact that it was conducted in one facility. At the time that the study was developed, the Kentucky Correctional Institution for Women was 
the only state prison in the Commonwealth of Kentucky. During the course of the study another facility opened to meet the needs of this growing population. However, this study was conducted at only one facility. Another limitation is that the interviews were conducted in a single opportunity. This limited the response to a single place in time. Additional interviews with these participants could provide a deeper understanding of the phenomenon because it would allow for reflection time on the part of the mothers prior to subsequent interviews.

A third limitation is that the study included those mothers who had children of a certain age. Gaining the perspective of mothers with older children, with specific gendered children, or with infants or with special needs children could lend itself to a greater understanding about the experience of mothering faced in these specific groups. Research with the mothers based on the length of their incarceration or the length of their sentence could also provide specific rich data about the experiences of these mothers based on the length of time they are separated from their children. This sample consisted of individuals with specific characteristic which was gender. The other characteristics such as age and ethnicity were not specific to the inclusion criteria. However, since the majority of the inmates in this prison were of Caucasian race, the sample is heavily weighted with Caucasian mothers.

Finally there is a limitation in the fact that the participants were nearing the end of their sentences or were soon to be paroled. Their view related to mothering may have been different if they had a considerable amount of time still to serve. The possibility exists that their focus may have been less in the future and more on the here and now. 


\section{Summary}

Findings from this study have contributed to a better understanding of the experience of mothering during incarceration. While research has been conducted with pregnant inmates, with the children of incarcerated mothers and with those who were formerly incarcerated, little research specific to this population has been conducted. As the mothers reported, most of them faced challenges to being effective parents prior to their incarceration and had difficult life events that interfered with their mothering experience. The findings are consistent with other research in the area of parental involvement during incarceration, concerns for their children's wellbeing, and apprehensions about returning home to care for their children. This research gives the incarcerated mothers a chance to tell their story and gives them a voice. These findings give researchers, nurses, and policy makers the insights to further the research, improve the practice, and develop the policies. The results of this research can lend itself to the improvement of current programs and the development of relevant programs based on the needs voiced by the study population. The importance of this study, in addition to adding to the body of literature, is that it can be the starting point for improving the lives of the mothers, their children, and the health of their communities. 


\section{REFERENCES}

Appleyard, K. \& Osofsky, J. D. (2003). Parenting after trauma: Supporting parents and caregivers in the treatment of children impacted by violence. Infant Mental Health Journal, 24(2), 111-125. doi: 10.1002/imhj.10050

Arditti, J., \& Few, A. (2006). Mothers' reentry into family life following incarceration. Criminal Justice Policy Review, 17(1), 103-123.

Banonis, B.C. (1989). The lived experience of recovering from addiction: a phenomenological study. Nursing Science Quarterly, 2(1), 37-42. Retrieved March 25, 2008 from CINAHL database.

Baldwin, K.M., \& Jones, J. (2000). Health Issues Specific to Incarcerated Women: Information for State Maternal and Child Health Care Programs. John Hopkins University, Women and Children's Health Policy Center. Baltimore: Johns Hopkins University Press.

Baumann, S. (2000). The lived experience of feeling loved: A study of mothers in a parolee program. Nursing Science Quarterly, 13(4), 332-338.

Belle, D., \& Doucet, J. (2003). Poverty, inequity, and discrimination as sources of depression among U.S. women. Psychology of Women Quarterly, 27(2), 101-113.

Benner, P. (1994). Interpretive phenomenology: Embodiment, caring, and ethics in health and illness. Thousand Oaks, CA: Sage Publications, Inc. 
Berry, P. \& Smith-Mahdi, J. (2006). Doing mothering behind bars: A qualitative study of incarcerated mothers. Journal of Crime and Justice, 29(1), 101-120.

Blitz, C.L., Wolff, N., Pan, K., \& Pogorzelski, W. (2005). Gender-specific behavioral health and community release patterns among New Jersey prison inmates: Implications for treatment and community reentry. American Journal of Public Health, 95(10), 1741-1746.

Blitz, C. (2006). Predictors of stable employment among female inmates in New Jersey: Implications for successful reintegration. Journal of Offender Rehabilitation, 43(1), 1-22. Retrieved March 25, 2008 from PsycINFO database.

Bloom, B.E., Owen, B., \& Covington, S. (2003). Gender-responsive strategies: research, practice, and guiding principles for women offenders. Washington, DC: U.S. Department of Justice, National Institute of Corrections.

Bloom, B., Owen, B., \& Covington, S. (2004). Women offenders and the gender effects of public policy. Review of Policy Research, 21(1), 31-48.

Bowlby, J. (1982). Attachment and loss: Vol. 1. Attachment (2nd ed.). New York: Basic Books.

Bowlby, J. (1990). A secure base: Parent-child attachment and healthy human development. New York: Basic Books.

Bryman, A. (2001). Social Research Methods. New York, Oxford University Press.

Bureau of Justice Statistics. (1999). Women offenders. Washington, DC: U.S.

Department of Justice. Retrieved January 18, 2007 from http://www.ojp.usdoj.gov/bjs/pub/press 
Burnard, P. (1991). A method of analysing interview transcripts in qualitative research. Nurse Education Today, 11(6), 461-466.

Child Welfare League of America. Child, Youth, \& Family Development. (n.d.). An Overview of Statistics. Retrieved August 1, 2008 from http://www.cwla.org/programs/incarcerated

Cohen, M.Z., Kahn, D.L., \& Steeves, R.H. (2000). Hermeneutic phenomenological research: A guide for nurse researchers. Thousand Oaks, CA: Sage Publishing.

Coleman, P.K., \& Karraker, K. (2000). Parenting self-efficacy among mothers of schoolage children: Conceptualization, measurement, and correlates. Family Relations, $49(1), 13-24$.

Creswell, J.W. (1998). Qualitative inquiry and research design: Choosing among five traditions. Thousand Oaks, CA: Sage.

Creswell, J.W. (2007). Qualitative inquiry and research design ( $2^{\text {nd }}$ ed.). Thousand Oaks, CA: Sage.

Dabbs Jr., J.M. \& Hargrove, M.F. (1997). Age, testosterone, and behavior among female prison inmates. Psychosomatic Medicine, 59(5), 477-480.

Denno, D. (1994). Gender, crime, and the criminal law defenses. Journal of Criminal Law and Criminology, 85(1), 80-180.

Denzin, N. K., \& Lincoln, Y. S. (Eds.). (2000). Handbook of qualitative research (2nd ed.). Thousand Oaks, CA: Sage Publications, Inc.

DePanfilis, D., \& Dubowitz, H. (2005). Family Connections: A program for preventing child neglect. Child Maltreatment, 10(2), 108-123. 
DeSantis L. \& Uganiza D.N. (2000). The concept of theme as used in qualitative nursing research. Western Journal of Nursing Research, 22(3), 351-372.

Dowden, C., \& Brown, S. L. (2002). The role of substance abuse factors in predicting recidivism: A meta-analysis. Psychology, Crime and Law, 8, 243-264.

Erdwins, C.J., Buffardi, L.C., Casper, W.J., \& O'Brien, A.S. (2001). The relationship of women's role strain to social support, role satisfaction, and self-efficacy. Family Relations, 50(3), 230-238.

Evans, L. (2007). Locked up, then locked out: Women coming out of prison. Women \& Therapy: A Feminist Quarterly, 29(3/4), 285-308.

Ferraro, K. J. \& Moe, A.M. (2003). Mothering, crime and incarceration. Journal of Contemporary Ethnography, 32(1), 9-40.

Flagler, S. (1990). Relationships between stated feelings and measures of maternal adjustment. Journal of Obstetric, Gynecologic, and Neonatal Nursing, 19(5), 411416.

Francis-Connolly, E. (1998). It never ends: Mothering as a lifetime occupation. Scandinavian Journal of Occupational Therapy, 5, 149 -155.

Francis-Connolly, E. (2000). Toward an understanding of mothering: A comparison of two motherhood stages. American Journal of Occupational Therapy, 54(3), 281289.

Francis-Connolly, E. (2004). Mothering across the lifecourse. In Esdaile, S.A. \& Olson, J.A. (Eds.). Mothering Occupations: Challenge, Agency, and Participation. Philadelphia: FA Davis Co. 
Freeman, R.B. (1996). Why do so many young American men commit crimes and what might we do about it? Journal of Economic Perspectives, 10(1), 25-42.

Friedman, M., Bowden, V., \& Jones, E. (2003). Family stress, coping, and adaptation, In Family Nursing: Research, Theory, and Practice. (pp. 463-505). Upper Saddle River, New Jersey: Prentice Hall.

Gaudin, J., \& Sutphen, R. (1993). Foster care vs. extended family care for children of incarcerated mothers. Journal of Offender Rehabilitation, 19(3/4), 129-147.

Glaser, B.G. \& Strauss, A.L. (1967). The discovery of grounded theory. New York: Aldine de Gruyter

Glaze, L. \& Maruschak, L. (2008). Parents in prison and their minor children. Bureau of justice statistics special report NCJ 222984. Washington, DC: US Department of Justice, Office of Justice Programs. Retrieved May 6, 2009 from http://www.ojp.usdoj.gov/bjs/pub/pdf/pptmc.pdf

Glueck, S., \& Glueck, E. (1950). Unraveling Juvenile Delinquency. New York, NY: The Commonwealth Fund.

Golden, R. (2005). What is to be done in the meantime? In War on the Family: Mothers in Prison and the Families They Leave Behind. New York, NY: Routledge.

Greenfeld, L.A. \& Snell, T.L. (1999). Women offenders. Bureau of justice statistics special report NCJ 175688. Washington, DC: US Department of Justice, Office of Justice Programs. Retrieved February 2, 2011 from http://bjs.ojp.usdoj.gov/content/pub/pdf/wo.pdf 
Guba, E. G., \& Lincoln, Y. S. (1981). Effective evaluation: Improving the usefulness of evaluation results through responsive and naturalistic approaches. San Francisco, CA: Jossey-Bass.

Guba E.G. \& Lincoln Y.S. (1989) Fourth Generation Evaluation. Newbury Park, CA: Sage.

Hagen, K.A., \& Myers, B.J. (2003). The effect of secrecy and social support on behavioral problems in children of incarcerated women. Journal of Child and Family Studies 12(2), 229-242.

Hagen, K.A., Myers, B.J., \& Mackintosh, V.H. (2005). Hope, Social Support, and Behavioral Problems in At-Risk Children. American Journal of Orthopsychiatry75(2), 211-219.

Halpern, E.S. (1983). Auditing Naturalistic Inquiries: The Development and Application of a Model. Unpublished Doctoral Dissertation, Indiana University, Indiana.

Harlow, G. (2003). Education and Correctional Populations. Bureau of Justice Statistics: Special Report, NCJ 195670. Retrieved July 15, 2007 from http:/www.ojp.usdoj.gov/bjs/pub/pdf/ecp.pdf

Harm, N. \& Phillips, S. (2000). You can't go home again: Women and criminal recidivism. Journal of Offender Rehabilitation, 32(3), 3-21.

Hayes, M. (2007). The lived experience of mothering after prison. (Doctoral Dissertation). Retrieved from CINAHL with Full Text database. UMI Order AAI3301792

Henderson, D. (1998). Drug abuse and incarcerated women: A research review. Journal of Substance Abuse Treatment, 15(6), 579 - 587. 
Houck, K., \& Loper, A.B. (2002). The relationship of parenting stress to adjustment among mothers in prison. American Journal of Orthopsychiatry, 72(4), 548-558.

Huebner, B. M., DeJong, C. \& Cobbina, J. (2010). Women Coming Home: Long-Term Patterns of Recidivism, Justice Quarterly, 27(2), 225-254.

Jasper, M.A. (1994). Issues in phenomenology for researchers of nursing. Journal of Advanced Nursing, 19(2), 309-314.

Jiang, S. \& Winfree Jr., L.T. (2006). Social Support, Gender, and Inmate Adjustment to Prison Life. The Prison Journal, 86(1), 32-55.

Johnson, E., \& Waldfogel, J. (2003). Where children live when parents are incarcerated. Joint Center for Poverty Research Policy Briefs, 5(4), 1-3.

Johnston, D., \& Gabel, K. (1995). Incarcerated parents. In Gabel K. \& Johnston, D. (Eds.). Children of Incarcerated Parents. (pp. 3-20). New York, NY: Lexington Books.

Jones, C.W., \& Unger, D.G. (2000). Diverse adaptations of single parent, low-income families with young children: Implications for community-based prevention and intervention. Journal of Prevention \& Intervention in the Community 20(1/2), 5 23.

Kampfner, C.J. (1995). Post-traumatic stress reactions in children of imprisoned mothers. In Gabel, K. and Johnston, D. (Eds.) Children of Incarcerated Parents. (pp. 89102). New York, NY: Lexington Books.

Kates, E., Mignon, S. \& Ransford, P. (2008). Parenting from Prison: Family Relationships of Incarcerated Women in Massachusetts. Center for Women in 
Politics and Public Policy Publications. Paper 3. Retrieved March 1, 2011 from http://scholarworks.umb.edu/cwppp_pubs/3

Kentucky Corrections (Kentucky Department of Corrections) (n.d.), 2005 Profile of inmate population. Kentucky Correctional Institution for Women. Retrieved July 15, 2008 from http://www.corrections.ky.gov/about/factsfigures.htm.

Kentucky Corrections (Kentucky Department of Corrections) (n.d.), 2008 Sourcebook of Criminal Justice Statistics in the Commonwealth. Kentucky Justice and Public Safety Cabinet. Retrieved March 1, 2011 from http://justice.ky.gov/NR/rdonlyres/15878C81-10EF-443A-B3C3FD386219B5A1/239379/KYSourcebook2008FINAL.pdf

Kreager, D. A., Matsueda, R. L., \& Erosheva, E.A. (2010). Motherhood and criminal desistance in disadvantaged neighborhoods. Criminology, 48(1), 221-258.

Krefting, L. (1991). Rigor in qualitative research: The assessment of trustworthiness. The American_Journal of Occupational Therapy, 45(3), 214-222.

Krueger, R.A. \& Casey, M.A.(2000). Focus Groups. A Practical Guide for Applied Research (3rd Ed). Thousand Oaks, CA: Sage Publications.

Kuhn, C.M. \& Schanberg, S.M. (1998). Responses to maternal separation: Mechanisms and mediators. International Journal of Developmental Neuroscience, 16(3/4), 261-270.

Langan, P. \& Levin, D. (2002). Recidivism of prisoners released in 1994. Bureau of justice statistics special report NCJ 193427. Washington, DC: US Department of Justice, Office of Justice Programs. Retrieved December 12, 2009 from http://bjs.ojp.usdoj.gov/content/pub/pdf/rpr94.pdf 
Leerkes, E.M., \& Crockenberg, S.C. (2002). The development of maternal self-efficacy and its impact on maternal behavior. Infancy, 3(2), 22-247.

Lincoln, Y. S. \& Guba, E. G. (1985). Naturalistic inquiry. Beverly Hills, CA: Sage.

Lipman, E.L., \& Boyle, M.H. (2005). Social support and education groups for single mothers: a randomized controlled trial of a community-based program. Canadian Medical Association Journal, 173(12), 1451-1456.

Liptak, A. (2006, March 2). Prisons often shackle pregnant inmates in labor. The New York Times. Retrieved November 18, 2008 from http://www.nytimes.com/2006/03/02/national/02shackles.html.

Mallik-Kane, K., \& Visher, C. A. (2008). Health and prisoner reentry: How physical, mental, and substance abuse conditions shape the process of reintegration. Washington, DC: The Urban Institute.

McClellan, D.S., Farabee, D. \& Crouch, B.M. (1997). Early victimization, drug use, and criminality: A comparison of male and female prisoners. Criminal Justice and Behavior, 24(4), 455-476

McLoyd, V.C., Jayaratne, T.E., Ceballo, R. \& Borquez, J. (1994). Unemployment and work interruption among African American single mothers: Effects on parenting and socioemotional functioning. Child Development, 65(2), 562-589.

Mercer, R.T. (1986). First-time motherhood: Experiences from teens to forties. New York, NY: Springer Publishing Company, Inc.

Minkler, M. (2005). Community Organizing and Community Building for Health. New Brunswick, NJ: Rutgers University Press. 
Minkler, M., \& Wallerstein, N. (2005). Improving health through community organization and community building. In Minkler, M. (Ed.) Community Organizing and Community Building for Health. New Brunswick, NJ: Rutgers University Press.

Moe, A., \& Ferraro, K. (2006). Criminalized mothers: the value and devaluation of parenthood from behind bars. Women \& Therapy, 29(3/4), 135-164. Retrieved from CINAHL with Full Text database.

Morash, M., \& Schram, P.J. (2002). The Prison Experience: Special Issues of Women in Prison. Long Grove, IL: Waveland Press.

Morawska, A., \& Sanders, M.R. (2007). Concurrent predictors of dysfunctional parenting and maternal confidence: implications for parenting interventions. Child: Care, Health, and Development, 33(6), 757-767.

Morgan, G. \& Smircich, L. (1980). The case for qualitative research. The Academy of Management Review, 5(4), 491-500.

Morton, J.B. (2004), Working with Women Offenders. Lanham, MD: American Correctional Association.

Mumola, C.J. (2000). Incarcerated parents and their children. Bureau of Justice Statistics Bulletin. August 2000, NCJ 182335. Office of Justice Programs, U.S. Department of Justice. Retrieved July 25, 2005 from http://www.ojp.usdoj.gov/bjs/.

Munhall, P.L., \& Oiler, C.J. (1986). Nursing Research: A Qualitative Perspective. Norwalk, CT: Appleton-Century-Crofts.

Munhall, P.L. (2007). Nursing Research: A qualitative perspective, Fourth Edition. Sudbury, MA: NLN Press. 
Murray, J., \& Farrington, D. P. (2007). Effects of parental imprisonment on children. Crime and Justice: A Review of Research, Vol.37, Chicago: University of Chicago Press

Myers, B.J., Smarsh, T.M., Amlund-Hagen, K., \& Kennon, S. (1999). Children of Incarcerated Mothers. Journal of Child and Family Studies, 8(1), 11-25.

Nesmith, A., \& Ruhland, E. (2008). Children of incarcerated parents: Challenges and resiliency, in their own words. Children and Youth Services Review, 30(10), 1119-1130.

NZ DOC, (2010). Principles of motivational enhancement. New Zealand Depart of Corrections. Retrieved on April 11, 2010 from http://www.corrections.govt.nz/policy-and-legislation/offender-managementmanual/part-1-general-information-index/chapter-1-4-motivational-enhancementme-index/principles-of-motivational-enhancement.html

O'Brien, P. (2001). Making it in the "free world": Women in transition from prison. New York: SUNY Press

O'Brien, P., \& Harm, N.J. (2002). Women's recidivism and reintegration: Two sides of the same coin. In Figueira-McDonough, J. \& Sarri, R.C. (Eds.) Women at the Margins: Neglect, Punishment, and Resistance. (pp. 295-318). Binghamton, NY: Hawthorn Press.

O'Brien, P., \& Young, D.S. (2005). Challenges for Formerly Incarcerated Women: A Holistic Approach to Assessment. The Journal of Contemporary Social Services, $87(3), 359-366$. 
Orthner, D.K., Jones-Sanpei, H., \& Williamson, S. (2004). The resilience and strengths of low-income families. Family Relations, 53(2), 159-167.

Palm, G.F. (2003). Parent education for incarcerated parents: Understanding what works. In Gadsden, V.L. (Ed.) Heading Home: Offender Reintegration into the Family. (pp. 89-121). Lanham, MD: American Correctional Association.

Parsons, M.L., \& Warner-Robbins, C. (2002). Factors that support women's successful transition to the community following jail/prison. Health Care for Women International, 23(1), 6-18.

Patton, M.Q. (1990). Qualitative evaluation and research methods (2nd ed.). Newbury Park, CA: Sage.

Pearce, D.M. (2002). Welfare reform now that we know it: Enforcing women's poverty and preventing self-sufficiency. In Figueira-McDonough, J., \& Sarri, R.C. (Eds.) Women at the Margins: Neglect, Punishment, and Resistance. (pp. 125-150). Binghamton, NY: Hawthorn Press

Phillips, S.D. \& Dettlaff, A.J. (2009). More than parents in prison: The broader overlap between the criminal justice and child welfare systems. Journal of Public Child Welfare, 3(1), pages $3-22$

Phillips, S.D., Dettlaff, A.J. \& Baldwin, M.J. (2010). An exploratory study of the range of implications of families' criminal justice system involvement in child welfare cases. Children and Youth Services Review, 32(4), 544-550

Pimlott, S., \& Sarri, R.C. (2002). The forgotten group: Women in prison and jails. In Figueira-McDonough, J., \& Sarri, R.C. (Eds.) Women at the Margins: Neglect, Punishment, and Resistance. (pp. 55-85). Binghamton, NY: Hawthorn Press 
Poehlmann, J. (2005a). Representations of attachment relationships in children of incarcerated mothers, Child Development, 76(3), 679-696.

Poehlmann, J. (2005b). Incarcerated mothers' contact with children, perceived family relationships, and depressive symptoms. Journal of Family Psychology. 19(3). 350-357.

Poehlmann, J., Shlafer, R.J., Maes, E., \& Hanneman, A. (2008). Factors associated with young children's opportunities for maintaining family relationships during maternal incarceration. Family Relations, 57(3), 267-280.

Polit D.F. \& Beck C.T. (2004) Nursing Research. Principles and Methods. Lippincott Williams \& Wilkins, Philadelphia, PA.

Pollak, O. (1950). The Criminality of Women. Philadelphia: PA. University of Pennsylvania Press.

Pollock, J.M. (2002). Women, Prison, and Crime. Belmont, CA: Wadsworth Thomson. Pulido-Criollo, F., Rodríguez-Landa, J., \& Colorado-Martínez, M. (2009). Sociodemographic factors associated with symptoms of depression in a sample of women held at two prisons in Mexico [Spanish]. Revista Panamericana de Salud Pública, 26(3), 209-215. Retrieved from CINAHL with Full Text database.

Robbins, C.A., Martin, S.S. \& Surratt, H.L. (2009) Substance abuse treatment, anticipated maternal roles, and reentry success of drug-involved women prisoners. Crime \& Delinquency, (55)3, 388-411

Rowe, D. C., \& Farrington, D. P. (1997). The familial transmission of criminal convictions. Criminology, 35(1), 177-202.

Rubin, R. (1967). Attainment of the maternal role. Nursing Research, 16(3), 237-245. 
Rubin, R. (1984). Maternal Identity and the Maternal Experience. New York: Springer Publishing Company.

Ruiz, D. (2002). The increase in incarcerations among women and its impact on the grandmother caregiver: some racial considerations. Journal of Sociology and Social Welfare, 29(3). Retrieved July 25, 2006 from http://www.umich.edu/hhs

Sampson, R.J. \& Wilson, W.J. (2005). Toward a theory of race, crime, and urban inequality. In Gabbidon, S.L. \& Greene, H.T. (Eds.) Race, Crime, and Justice (pp. 177-190). New York, NY: Routledge.

Sandelowski, M. (1993). Rigor or rigor mortis: The problem of rigor in qualitative research revisited. Advances in Nursing Science, 16 (2), 1-8.

Sandelowski, M. (1995). Sample size in qualitative research. Research in Nursing \& Health, 18(2), 179-183.

Sayil, M., Gure, A., \& Ucanok, Z. (2006). First time mothers' anxiety and depressive symptoms across the transition to motherhood: Associations with maternal and environmental characteristics. Women and Health, 44(3), 61-77.

Schein, V.E. (1995). Working from the Margins: Voices of Mothers in Poverty. Ithaca, NY: Cornell University Press.

Scherzer, T., Rugulies, R., \& Krause, N. (2005). Work-Related Pain and Injury and Barriers to Workers' Compensation Among Las Vegas Hotel Room Cleaners. American Journal of Public Health, 95(3), 483-488.

Shamai, M., \& Kochal, R. (2008). "Motherhood starts in prison": the experience of motherhood among women in prison. Family Process, 47(3), 323-340. 
Simmons, C.W. (2000). Children of incarcerated parents. California Research Bureau, $7(2), 1-13$.

Simpson, S. (1989). Feminist theory, crime, and justice. Criminology, 27(4), 605 - 632

Slocum, L. A., Simpson, S., \& Smith, D. A. (2005). Strained lives and crime: Examining intra-individual variation in strain and offending in a sample of incarcerated women. Criminology, 43(4), 1067-1110.

Sommers, I. \& Baskin, D.R. (1993). The Situational Context of Violent Female Offending. Journal of Research in Crime and Delinquency, 30(2), 136-162.

Steffensmeier, D., \& Allan, E. (1996). Gender and crime: Toward a gendered theory of female offending. Annual Review of Sociology, 22, 459-487.

Strauss, A. \& Corbin, J. (1998). Basics of Qualitative Research: Second Edition: Techniques and Procedures for Developing Grounded Theory. Thousand Oaks, CA: Sage Publications.

Teti, D.M., and Gelfand, D.M. (1991). Behavioral competence among mothers of infants in the first year: The mediational role of maternal self-efficacy. Child Development, 62(5), 918-929.

Theall, K., Elifson, K., Sterk, C., \& Stewart, E. (2007). Criminality among female drug users following an HIV risk-reduction intervention. Journal of Interpersonal Violence, 22(1), 85-107.

Tobin, G.A. \& Begley, C.M. (2004). Methodological rigour within a qualitative framework. Journal of Advanced Nursing 48(4), 388-396. 
Travis, J., \& Waul, M. (2003). Prisoners Once Removed: The Impact of Incarceration and Reentry on Children, Families, and Communities. Washington, DC. The Urban Institute Press.

Uggen, C., \& Kruttschnitt, C. (1998). Crime in the breaking: Gender differences in desistance. Law and Society Review, 32, 339-366.

U.S. Census Bureau (2010) America's Families and Living Arrangements, U.S. Census Bureau, Housing and Household Economic Statistics Division, Fertility \& Family Statistics Branch. Retrieved March 1, 2011 from www.census.gov/population/www/socdemo/hh-fam.html

U.S. Department of Justice; US DOJ. (1995). Parenting Program Standards: Program Statement, U.S. Department of Justice, Federal Bureau of Prisons, 5355.03. Retrieved on January 18, 2007 from http://www.bop.gov/progstat/53550003.html. van Manen, M. (1990). Researching Lived Experience. Albany, NY: State University of New York Press.

Van Manen, M. (1997a). Researching lived experience: Human science for an action sensitive pedagogy. Ontario, Canada: Althouse Press.

van Manen, M. (1997b). From meaning to method. Qualitative Health Research, 7(3), 345-369.

van Manen, M. (1999). The pathic nature of inquiry and nursing. In Madjar, I. \& Walton, J. (Eds.) Nursing and the experience of illness: Phenomenology in practice. (pp. 17-36). New York, NY: Routledge.

van Manen, M. (2006). Writing qualitatively or the demands of writing. Qualitative Health Research, 16(5), 713-722. 
Wallerstein, N. (1999). Power between evaluator and community: research relationships within New Mexico's healthier communities. Social Science \& Medicine, 49(1), $39-53$.

Webster-Stratton, C. (1990). Stress: A Potential Disruptor of Parent Perceptions and Family Interactions. Journal of Clinical Child and Adolescent Psychology, 19(4), $302-312$.

Weiss, A.M. (2010). Mothers behind bars: The lived experience. (Doctoral Dissertation). Retrieved from CINAHL with Full Text database. UMI Order 3432393

West, H.A. \& Sabol, W.J. (2008). Prisoners of 2007. Bureau of Justice Statistics Bulletin, December 2008, NCJ 224280. Retrieved March 5, 2011 from www.ojp.usdoj.gov/bjs/pub/pdf/p07.pdf

West, H.A. \& Sabol, W.J. (2009). Prison Inmates at Midyear 2008 -Statistical Tables. Bureau of Justice Statistics Bulletin, March 2009, NCJ 225619. Office of Justice Programs, U.S. Department of Justice. Retrieved May 6, 2009 from http://www.ojp.usdoj.gov/bjs/abstract/pim08st.htm

Williams, L., \& Schulte-Day, S. (2006). Pregnant in prison-The incarcerated woman's experience: A preliminary descriptive study. Journal of Correctional Health Care, 12(2), 78-88.

Wilson, H.S. \& Hutchinson, S.A. (1991). Triangulation of Qualitative Methods: Heideggerian Hermeneutics and Grounded Theory. Qualitative Health Research, $1(2), 263-276$. 
Zaitzow, B.H. (2006). Empowerment not entrapment: Providing opportunities for incarcerated women to move beyond "doing time" Justice Policy Journal, 3(1), 124.

Zaplin, R.T. (2008). Female offenders: Critical perspectives and effective interventions. Sadbury, MA: Jones and Bartlett Publishers. 


\section{APPENDIX 1}

Demographic Questionnaire

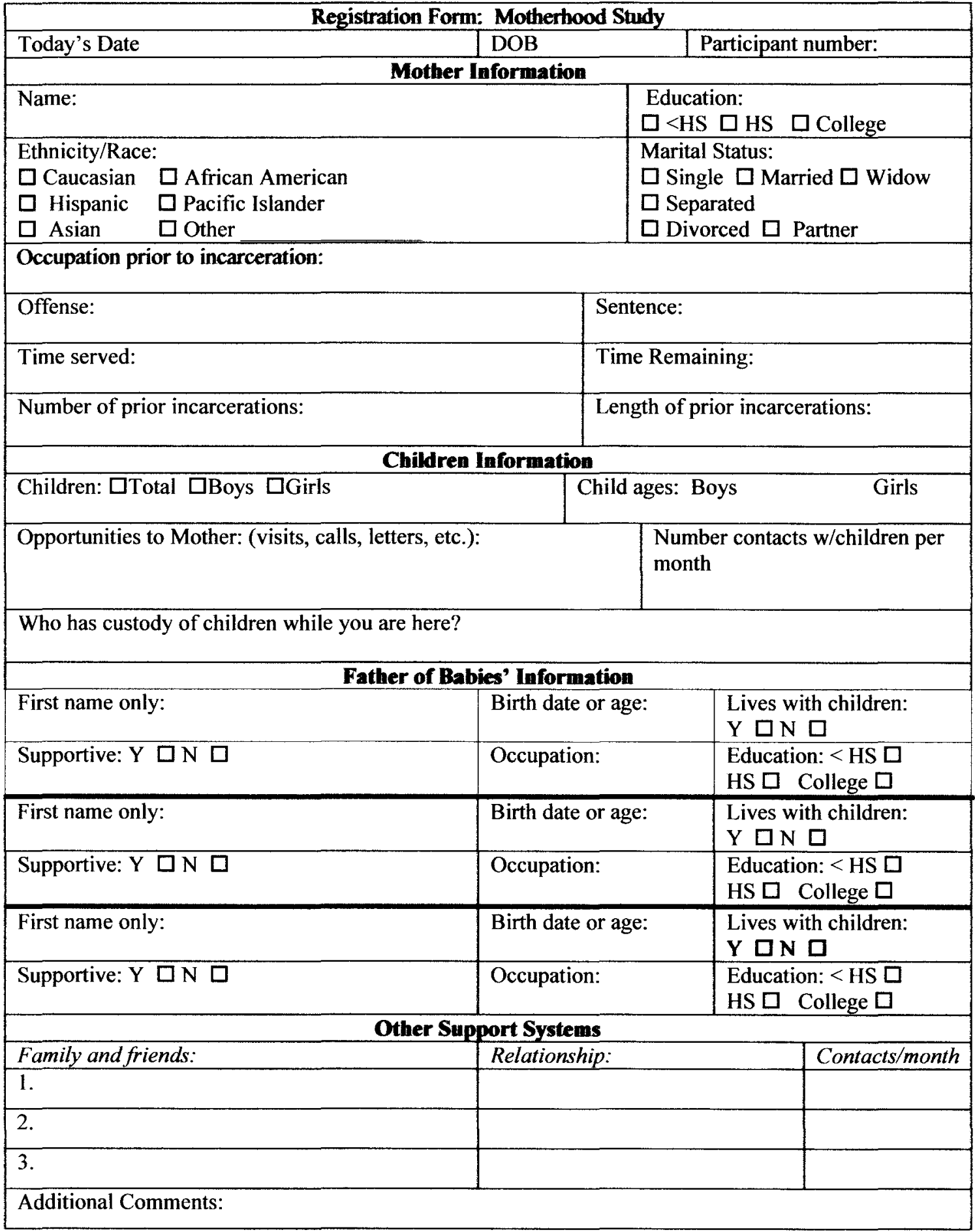




\section{APPENDIX 2}

Procedure \& Interview Guide

1. Supplies \& Equipment needed: consent form, audio recorder, demographic questions form, field note notebook, Interview Guide

2. Procedure:

a. Set up audio cassette player

b. Begin audio recorder

c. Establish rapport

d. Review informed consent form $\&$ answer any questions

e. Begin field notes

f. Complete demographic portion of the interview

g. Begin interview. Mothers will be asked to talk about their experiences of being a mother while incarcerated. When the mother has completed telling her story, she will be prompted by any of the semi-structured interview questions that have not been answered.

Motherhood Questions. The questions will center around four domains of mothering including: the meaning of mother, the roles of mothering, the mother's relationship with her children, and how the mother views the impact of the separation on her children. Each of the primary questions corresponds with the domains as they are listed respectively. The additional questions will be asked if the dialogue ceases or if the participant has difficulty answering the primary questions.

1. What was it like being a mother before you came to prison? What is it like being a mother in prison?

1a. What would you like others to know about being a mother in prison?

$1 \mathrm{~b}$. How does it feel to be a mother and be incarcerated?

2. What kinds of things do you do that identify you as a mother?

2a. Who do you turn to when you need to talk to someone about your child?

$2 \mathrm{~b}$. What is your experience of how your mother took care of you?

2c. What is your experience of caring for your child/children?

$2 \mathrm{~d}$. How is that experience the same or different?

3. How is your relationship with your child?

3a. What kinds of things give you joy or good feelings with your child?

$3 \mathrm{~b}$. When you are worried or stressed, how does that impact the way you react to your children?

4. What kinds of things worry you the most about your child at this time?

4a. Tell me about having children in your situation.

$4 \mathrm{~b}$. How does being in prison change your experience/role of caring for your child?

4c. How has the experience of being incarcerated affected your ability to care for your child?

$4 \mathrm{~d}$. How does your child/do your children feel about you being incarcerated?

$4 \mathrm{e}$. How does that make you feel? 
5. Tell me again what it is like for you to have children and to be incarcerated. What would you like it to be?

Thank each mother and tell them you will be back in 1-2 months to talk with them alongside other mothers to verify $\&$ clarify responses to the questions.

1. Audio-tapes will be labeled and sent to a transcriptionist. Upon being returned to the researcher, the tapes will be locked in a file cabinet drawer with access only by the investigator.

2. The consents, field notes and transcripts will be stored in a file cabinet under lock and key with access only by the investigator. Computerized records will be stored in a password protected computer. All individual records will be destroyed after 3 years. 


\section{APPENDIX 3}

Focus Group Guide

1. Reacquaint the participants to the purpose of the research.

2. Explain that the function of the focus group is to verify the investigator's interpretations of interview responses.

3. Each interview question will be restated to the group participants as a refresher.

4. The interview results will be communicated to the group participants.

5. The participants will be asked to verify, clarify, or add to the interpretation of the interview responses.

\section{Focus Group Questions}

a. What other information did you want to say during the interview that was not included in these results?

b. Think back to our last meeting, was there any additional information that you wanted to add to your responses to question 1 ? (Restate the question), Question 2? Etc.

c. When hearing about the results to question one, do the results sound right?

d. Do you think we've missed anything in our discussion?

(Krueger \& Casey, 2000) 


\section{APPENDIX 4}

\section{APPENDIX C}

Use of Prisoners as Subjects in Research

See 45 CFR 46 Subpart $C$ for more information about the use of prisoners as subjects.

The use of prisoners as subjects requires that the investigator comply with the additional protections provided in 45 CFR 46.306 , Subpart C. The proposed research must meet the criteria of one of the following categories:

The investigator should choose the category s/he believes the fits the proposal being submitted.

Study of the possible causes, effects, and processes of incarceration, and of criminal behavior, provided that the study presents no more than minimal risk and no more than inconvenience to the subjects. (45 CFR 46.306(a)(1)(A))

$\square$ Study of prisons as institutional structures or of prisoners as incarcerated persons, provided that the study presents no more than minimal risk and no more than inconvenience to the subjects. (45 CFR 46.306(a)(1)(B))

Research on conditions particularly affecting prisoners as a class (for example, vaccine trials and other research on hepatitis which is much more prevalent in prisons than elsewhere; and research on social and psychological problems such as alcoholism, drug addiction, and sexual assaults) provided that the study may proceed only after the Secretary has consulted with appropriate experts including experts in penology, medicine, and ethics, and published notice, in the Federal Register, of his intent to approve such research. (45 CFR 46.306(a)(1)(C))

$\square \quad$ Research on practices, both innovative and accepted, which have the intent and reasonable probability of improving the health or well-being of the subject. In cases in which those studies require the assignment of prisoners in a manner consistent with protocols approved by the IRB to control groups which may not benefit from the research, the study may proceed only after the Secretary has consulted with appropriate experts, including experts in penology, medicine, and ethics, and published notice, in the Federal Register, of the intent to approve such research. (45 CFR 46.306(a)(1)(D))

45 CFR 46.305(a) - Approval may be given only if the IRB finds that:

$\square$ (1) the research under review represents one of the categories of research permissible (above); 
$\square$ (2) any possible advantages accruing to the prisoner through his/her participation in the research, when compared to the general living conditions, medical care, quality of food, amenities and opportunity for earnings in the prison, are not of such a magnitude that his/her ability to weigh the risks of the research against the value of such advantages in the limited choice environment of the prison is impaired;

(3) the risks involved in the research are commensurate with risks that would be accepted by nonprisoner volunteers;

$\square$ (4) procedures for the selection of subjects within the prison are fair to all prisoners and immune from arbitrary intervention by prison authorities or prisoners. Unless the principal investigator provides to the Board justification in writing for following some other procedures, control subjects must be selected randomly from the group of available prisoners who meet the characteristics needed for that particular research project;

(5) the information is presented in language which is understandable to the subject population;

(6) adequate assurance exists that parole boards will not take into account a prisoner's participation in the research in making decisions regarding parole, and each prisoner is clearly informed in advance that participation in the research will have not effect on his or her parole; and

$\square$ (7) where the Board finds there may be a need for follow-up examinations or care of participants after the end of their participation, adequate provision has been made for such examination or care, taking into account the varying lengths of individual prisoners' sentences, and for informing participants of this fact.

Researcher's planning to include prisoners in research projects involving more than minimal risk must provide:

Provide protocol specific written justification for each of the seven statements above supporting inclusion that documents the benefits that are likely to accrue to a prisoner participating in this study. Justification must include protocol specific information that affirms the necessity for inclusion of this special population. 


\section{APPENDIX 5}

Recruitment Flyer

IRB No. 10.0305

July 19, 2010

University of Louisville School of Nursing

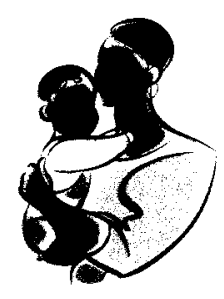

\section{Volunteers Wanted for a Motherhood Research Study Information Sessions will be held on ___ at ___.m.}

The purpose of this research study is to explore and describe the experience of mothering among incarcerated women

To be included in the study you must:

$\diamond$ have at least one living child

$\diamond$ Were the primary caretaker and lived with your children prior to incarceration

$\diamond \quad$ To be released from prison within 12 months

$\diamond$ Will be the primary caretaker of your children upon release

$\diamond \quad$ Understand and speak English

$\diamond$ Agree to participate in the study

This research study will include a short questionnaire, an interview, and a follow-up group discussion. These interviews will take place in the chapel and will be done by Vicki Hines-Martin and Barbara Jackson, a student at

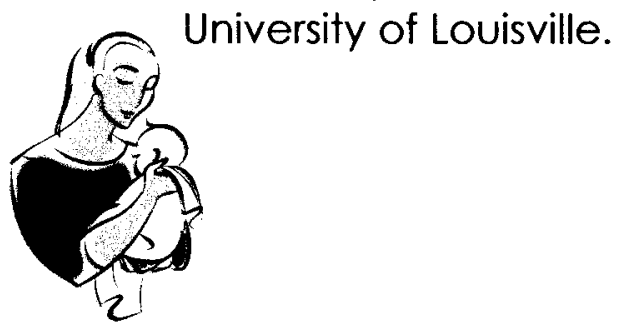


APPENDIX 6

Subject Informed Consent Document

IRB \# 10.0305

For IRB Approval Stamp

For IRB Approval Stamp

IRB 10.0305

\section{THE LIVED EXPERIENCE OF MOTHERING DURING INCARCERATION}

Investigator(s) name \& address: Vicki Hines-Martin, $\mathrm{PhD}, \mathrm{CNS}$, RN; Barbara Jackson, BSN, RN, School of Nursing, 555 S. Floyd Street, Louisville, KY 40202

Site(s) where study is to be conducted: Kentucky Correctional Institution for Women

Phone number for subjects to call for questions: 502-693-2474

\section{Introduction and Background Information}

You are invited to participate in a research study for incarcerated mothers. The study is being conducted by Vicki Hines-Martin, PhD, CNS, RN and Barbara Jackson, BSN, RN, Doctoral Student University of Louisville School of Nursing. The study is supported by the University of Louisville, School of Nursing. The study will take place at Kentucky Correctional Institution for Women. Approximately 20 women will be invited to participate.

\section{Purpose}

The purpose of this study is to find out what it means to be a mother while in prison.

You are being asked to be in the study because you have a child or children between the ages 1 and 12 years old. Your feelings about being a mother while in prison are important and the basis for this study.

\section{Procedures}

In this study, you will be asked to complete a survey which will give the researcher some basic and general information about you and your children. You will also be asked to talk about what it is like to be a mother. Only your first name will be used and as you talk the researcher will write the things you say and the conversation will be audio taped. The meeting will last for about 1 hour, depending upon how much you have to say about the mothering experience. Another meeting will be done with all mothers to make sure the researcher got the right meaning from what everyone said. Ideas the researcher got from talking to all mothers will be discussed but no mother will have exactly what she told the 
researcher shared. You have the right to ask, and have answered, any questions you may have about this study. If you have questions, or concerns, you should ask the researcher listed on the first page of this form.

You will be asked to take part in two meetings within 2 months. Each meeting will last approximately 1 hour.

\section{Potential Risks}

There are few risks such as emotional stress, thoughts about not being with the children causing sadness and possible discomfort in answering personal questions.

\section{Benefits}

The possible benefits of this study include helping the public by providing new knowledge. You may not be helped from being in this study. The information collected may not benefit you directly. The information learned in this study may be helpful to others.

\section{Payment}

You will not be paid for your time, inconvenience, or expenses for your participation in this study

\section{Privacy}

Total privacy cannot be guaranteed. Your privacy will be protected to the extent permitted by law. If the results from this study are published, your name will not be made public. While unlikely, the following may look at the study records: Government agencies, such as: Office for Human Research Protections (OHRP).All information gathered in the process of the research will be kept strictly confidential and kept locked and protected in a locked file cabinet in the researcher's office. The de-identified information will be kept for three years beyond the closure of the study.

\section{Voluntary Participation}

Taking part in this study is voluntary. You may choose not to take part at all. If you decide to be in this study you may stop taking part at any time.

\section{Research Subject's Rights, Questions, Concerns, and Complaints}

If you have any concerns or complaints about the study or the study staff, you have three options.

You may contact the principal investigator at (877) 816-8773 
If you have any questions about your rights as a study subject, questions, concerns or complaints, you may call the Human Subjects Protection Program Office (HSPPO) 1800-334-8635. You may talk about any questions about your rights as a subject, in secret, with a member of the Institutional Review Board (IRB) or the HSPPO staff. The IRB is an independent committee composed of members of the University community, staff of the institutions, as well as members of the community. The IRB has reviewed this study.

If you want to talk to a person outside the University, you may call 1-877-852-1167. You can talk about any questions, concerns or complaints in secret. This is a 24 hour hot line answered by people who do not work at the University.

This paper tells you what will happen during the study if you choose to take part. Your signature means that this study has been discussed with you, that your questions have been answered, and that you will take part in the study. This informed consent paper is not a contract. You are not giving up any legal rights by signing this paper. You will be given a signed copy of this paper to keep for your records.

Signature of Subject/Legal Representative

Date Signed

Signature of Person Explaining the Consent Form

(If other than the researcher)

Date Signed

Signature of researcher

Date Signed

\section{LIST OF INVESTIGATORS}

Vicki Hines-Martin

Barbara Jackson
PHONE NUMBERS

1-877-816-8773

1-877-816-8773 


\section{APPENDIX 7 \\ Department of Corrections \\ Research Consent Form}

I freely and voluntarily agree to participate in the research project entitled

I fully realize that my participation is of my own choosing and I agree not to hold the Department of Corrections responsible for any personal injury to myself and release any claim against the Department of Corrections pertaining to the research project. The project has been satisfactorily explained to me and all my questions have been satisfactorily answered.

Signature of Participant

Date

Signature of Staff Witness

Date 


\begin{abstract}
APPENDIX 8
Description of the Mothers

Below are descriptions of each mother and their experience of mothering.
\end{abstract}

Janet

Janet, a 20 year old Caucasian, high school educated mother, was the first participant in the study. She was the mother of a one year old daughter who was being cared for by Janet's mother during the incarceration. Janet appeared comfortable as she leaned back in the chair during the interview. She was relaxed and easy to talk. At the time of the interview she had served 7 months for second degree burglary and although she had slightly over four years left on her sentence, she was expecting to be paroled within the next two months. Janet had two previous incarcerations lasting a total of approximately two weeks. Since her mother lived four hours from the prison Janet had not been able to see her daughter since her incarceration. She was able to have contact with her daughter through letters which came about one time per week.

Janet wrote letters and poems and drew picture for her daughter and sent them to her. She also receives drawings from her daughter which she gives her joy:

My mom will send me a little drawn out scribbled pieces of paper and I cling to those for dear life. It's the only things I really get joy from. Or right now I mean I love her and she's my daughter, she makes me happy but it's not the physical part, the not being with her, it's scribbled pieces of paper that don't mean nothing to nobody else. They're priceless to me. I think about it all of the time.

Since her only contact with her daughter is through letters and she has to wait for those to come to get updates on her daughter she says,

It's hard. You never know from day one to day two if she's breathing, if she's living, if she's yelling, if she's learning new things. You're not there to teach her that's the worst part about it. It's my responsibility to teach 
her how to walk, how to talk, how to draw. I mean it's really, really hard. There aren't the words to describe the pain of it.

Farrah

Farrah, a 24 year old, Caucasian, high school educated mother of a three year old son, was the next interviewee. She was timid and cried a lot during the interview. During the interview, she would speak very quiet and seemed at a loss for words at times. Farrah became very emotional when talking about her son especially when discussing her contact with him. She writes letters to her son and had been able to make two or three phone calls a month to her mother and son but during those phone calls her son was not told who he was talking to. As she was crying, Farrah talked about what her relationship was like with her son:

Not much of one. Um, when I do talk to him, he's two so he doesn't really say much and they don't tell him who he's talking to....they say 'come talk to Farrah' He doesn't know it's his mom

Because she was afraid her mother wouldn't allow any more phone calls, she chose not to tell him she was his mother. She indicated that she did not have any opportunities to visit with her son but when she was asked about what gave her good feelings about her son she said,

Just seeing a smile on his face. Just watching him play. Him learning new things and seeing it. Shocking me that he could do what he did at that age. Just him being excited about seeing me. It sounds horrible but the fact that he would get upset because I would leave would make me happy, it showed he cared.

Farrah was incarcerated for trafficking drugs and had been sentenced to five years and had served one year at the time of the interview. Farrah reported that she had two previous incarcerations lasting a total of 55 days. She was expecting to be released from this incarceration within 24 months but had a parole hearing 2 weeks after our interview 
and she was planning living with her mother and son after her release and "proving" herself and getting custody of her son.

Wendy

Wendy was a 22 year old mother of a four year old daughter. She was a high school graduate despite giving birth to her daughter during her junior year of high school. The father of this little girl was caring for her while Wendy was incarcerated for manufacturing, tampering and possessing a controlled substance. Wendy was also pregnant and set to deliver a child the month after our meeting and as of our interview time, had not been sentenced for her crimes. She had spent five months in prison and was in this facility without being sentenced because of her pregnancy. All pregnant women who are charged or sentenced for a crime are sent to this facility where they receive their prenatal care.

Wendy was emotional and cried during the interview when describing what it was like to be incarcerated and have children:

It's hard, I can't do this like I want to. I get to talk to her. It's hard, um, it feels like I want to....she started her first day of school without me, missed her birthday, um, I'm still the mom but I don't feel like I should be. It's hard.

She didn't make eye contact frequently but she was very open when describing her life before being in prison and spoke of many happy memories as a child except when she spent time in foster care. When talking about her father, she openly laughed:

...oh goodness, she's a great mom, um, she got into a bad relationship when I was younger so therefore I was put into state custody and I was raised in a foster home for three and a half years... it took my dad a year to get me out of there..all my friends loved him, he was awesome, pick up my friends, of course he embarrassed me all the time, he was a good dad. 
Regina

Regina, a 22 year old Caucasian, mother of a two year old son, who was incarcerated for contraband and was sentenced to one year in prison. At the time of the interview she had served three and a half months and was set to be released after another four months. She was pregnant and was due to deliver three months after our interview. She had a less than high school education and appeared and sounded young during the interview. Her son was living with her grandmother while Regina was incarcerated and she had no opportunities to have contact with her son.

As she described being a mother, Regina smiled a lot when talking about her son. She was relaxed and made good eye contact. Regina appeared to fight back crying but on one occasion she openly cried:

He doesn't know where I am, but I think he's frustrated. I think he's, they say he's having like, I guess depression...I don't know what you would call it, but that he's acting out since I haven't been around.

When asked how that made her feel, she cried when she said,

It just tears my heart up. It kills me, it makes me feel, it makes me feel really worthless and I know that I'm not supposed to feel that way. So I don't know, but I can't help- but feel that way because I feel like I've let him down. You know, cuz, he loves me like, he love me a lot and I can only imagine.

Regina talked about wanting to have more contact with her son and that it would "make it a little better."

Jordan

Jordan was a Caucasian, 38 year old trade school graduate, who was the married mother to a son and a daughter, 18 years and five years, respectively. She was incarcerated on contraband charges and had been sentenced to 20 years. When we met 
she had two weeks remaining and had served one year. Jordan had no prior incarcerations. She received visits from her adult son but her only contact with her daughter had been when she sent letters. She had not received any contact from the foster family caring for her daughter until about one week before our interview when she received a letter. The foster mother was gracious in her letter and let Jordan know that her daughter was doing well and that they, the foster family, hoped that Jordan was well also:

...she's been everywhere, the little thing, she's a traveler....as soon as she grows more, 'I'll send you more pictures, We love and pray for you' I can't ask for more, I can't as for no more....

It also gave Jordan the motivation to improve herself:

"...my goal is to make something out of myself so when it comes time to be with her, I'll be worth seeing again, yeah."

Jordan was soft spoken but made good eye contact during the interview. She was easy to smile when talking about her children and when talking about what their future would be like when they were reunited. She cried when she talked about how she imagined her daughter was feeling and when she talked about what events and milestones she was missing.

Lydia

Lydia, a 28 year old mother of four, had a high school education and was incarcerated for the first time. She had been in prison for close to 3 years for a list of charges including burglary, escape, credit card fraud, and possession of a controlled substance. Her children were living in different homes while she was incarcerated, with her oldest daughter living with the girl's father, her sons living with her mother, and her 
youngest daughter living with a foster organization. She received four visits a month with her youngest daughter, and calls and letters with the other three children.

Lydia was very talkative and talked fast during the interview. She made some eye contact but was fidgety in her seat and her eyes danced around the room for the entire hour. She spoke of being especially frightened for her oldest daughter to follow in her footsteps. She recognized the similarities that the two of them shared and was afraid for her future. With nervous laughter she said,

I'm scared she's gonna be like me. It kills me because she looks just like me, acts just like me...I'm scared, terrified of things. I'm afraid somebody's gonna hurt her. I don't want her to get a boyfriend, cuz I don't want them to make her feel bad. I'm scared that she's gonna feel like I did, that she's not gonna feel good about herself. I think she should, she's great.

She described prison affecting how she would care for her children as:

I'll be more grateful. I'll definitely be more grateful. I'll spend more time with them. I think I'll be more grateful for what we have, I'll be more eager, and I want to be more active in their lives. I want to be better than I was when I left.

She then described how she had learned things about herself, about how to "deal" with things, and what kind of parent she wants to be. She talked about learning everything she could to be a better parent and be a better person. Her ideal day would be for her and the children to "just be together" and because she has never seen all of her children in one place, she wanted to go to the park and feed the ducks even though it was 40 miles from her home.

Susan

Susan was a 25 year old Caucasian mother of a three year old son and a two year old daughter. She had a less than high school education and was serving a three year 
sentence for possession of a controlled substance. She was unable to estimate the total amount of time that she had been served in her previous estimated 20 plus incarcerations. She reported that she had 10 months left to serve but that she had a parole hearing 3 days after our interview and that was anxious to be released but also scared.

Susan had received no contact from her children or from her mother who was caring for the children for the 13 months of her incarceration. She became extremely emotional when talking about her children and how much she missed them. The interview began with her making no eye contact at all and looking down towards the floor. She appeared to be a lost little girl and acted scared. Her answers seemed sincere though and by the end of the interview, Susan was holding eye contact when answering the questions.

As she described what it was like being an incarcerated mother she said,

It's really hard, cuz like, I don't get to see my kids, I don't get to talk to em, just anything like that." Through tears she continued, "It's been really hard this last few months. Just not getting to see em, or hold em, or talk, just to talk to them, would just satisfy me.

She didn't want her children to be in foster care but was worried about her mother caring for them:

...my mom struggles with a drug addiction too. So I know that they're not always in the best, you know, situation but I think it would be selfish of me to have them removed. But I still have this hope that I'm gonna get out soon and I don't want them to have to go, they wouldn't have to go to foster care...

She has strong ideas about wanting to be a family and has begun to realize that the family may not include having a father for the children but instead she needed to make it 
"okay" for her and that the kids would be happy that way. She spoke of seeing families together doing family things and wanting that for herself.

Renee

Renee was a mixed race, mother of three boys and one girl. She answered the questions, quick and to the point at the beginning of the interview. She seemed standoffish and appeared weathered and older than her 36 years. She was tattooed with many designs on her hands, arms and neck. Renee made good eye contact and during the course of the interview seemed to soften and become more descriptive. She was not very emotional but did cry when talking about her oldest son, who was also a recovering addict, who had died in a car accident 10 months prior to our interview. She was distressed that their parting words were hurtful and that she was incarcerated at the time of his death:

....there's a lot of hateful words said to each other, the last words he heard me say to him was 'I hate you and I wish you were dead' He died a month later and I...but I think he knew that I loved him, at least I hope he knows did.

From that experience, Renee has recognized that she could be a better mother and that being incarcerated was her "rock bottom." When her son died she made a commitment to being available for her children and improving herself. She realized all that she was missing and that she doesn't want "to miss another thing. I want out"

Renee was serving a 10 year sentence for second degree forgery and had served 20 months. She had served four months in her one prior incarceration. Prior to this incarceration, Renee had been in cosmetology school and planned to return there after her release. The children were living with her husband of 17 years and she was able to 
maintain contact with them through letters and four visits a month. She acknowledged the abusiveness of her husband and stated that they were separated. She talked about the difficulty of know her children were living in an abusive situation and hearing from them that they wanted her to rescue them from that home:

I'm so powerless in here. You know, they tell me 'mom, you know dad is doing this, daddy's doing that, you know, why aren't you here to help us? Why aren't you here to save us, why?' I just tell them to hold on, you know... all I can do is do the best that I can, and that's encourage them every time I write, every time I talk to them...I'm trapped now and I can't come out of these walls until they say I can...that's all I can do and that's more than I did before, before I didn't even care. I'll do my best, that's all I can do.

\section{Khloe}

Khloe was a single, Caucasian, 35 year old mother of two boys, aged 12 and 15. She stated that she had some college experience and worked in the food industry prior to prison. Khloe had an estimated 22 prior incarcerations where she reportedly served one day to six months. She was in prison for credit card fraud and had been sentenced to 15 years of which she had served two years. She stated that she had one year left to serve. As she talked about what she wanted other people to know about being a mother in prison she described the stigma that is attached to she and women like her:

I think that, even I, before I ever came to prison, women in prison, moms, anybody in prison, it's like bad person, you know, we're in prison stabbing each other, you know what I mean, movie image. It's not like that, like most of us are moms here, most of us, I guess, all of us, I don't know, love our kids, miss our children. We're all in the same boat, it's hard for us, it's not easy. We didn't come here because was actually wanted to, it's just the way the cards fell.

Khloe did not cry during the interview and would sometimes frown and furrow her brow when considering how to answer the questions. She seemed sincere and 
smiled easily when talking about her children. The interview started with her being soft spoken but as she became more comfortable, her answers were very open and the frown disappeared. Khloe's children were living with her father while she was incarcerated and she was able to contact her children by phone three times a month but stated she only got to visit with them one time every six months. She talked about taking her children for granted before her incarceration. She described wanting to take care of them, spend time with them, and she stated that "Prison's been a great teacher of gratitude." She spoke of not taking any of those moments for granted anymore.

\section{Francis}

Francis was a Caucasian, mother of German descent, of four girls and a boy. Their ages ranged from eight years to 19 years of age. This 38 year old high school graduate was serving 12 years for unlawful access to a computer and escape. She had served four years at the time of our interview and was set to be released in six months. The children were living with their respective fathers which meant they were living in three different homes. Francis was distressed by the fact that her children had not gotten to see or communicate with each other during her incarceration and that she had limited contact with the children. She had received one to two visits a year by her 11 year old son and 14 year old daughter, letters from her 19 year old and eight year old daughters, and once a month visits with the eight year old daughter. She reported no contact or communications with the 17 year old daughter:

....all they knew was each other, and then to get ripped apart, I blame myself, that's what I get for messing up...if they have to suffer now cuz they have to be ripped apart they can't be with one family, and that's just sad. 
Francis made good eye contact and smiled a lot when talking about her children. She was very open and descriptive when discussing her life prior to prison and when talking about the things she had learned in prison. Because of her German descent she was unaware of the government programs that were available to her and her children. At the time her husband left her she had four children, with a high school education and no child support, she resorted to her crimes to support her family. She did express some anger at the United States for allowing her to become so destitute and making it difficult to apply and receive any financial aid:

...being married everything was fine financially, but after that he wouldn't pay no child support....I was trying to keep up with the way we used to live, not take that away from them. I worked at Subway and stuff like that, that don't pay the bills, so I mean it was horrible. I didn't know where to go for help. I heard little things about Section 8 stuff, they had a waiting list so long it was crazy. I didn't want to go to a homeless shelter, because it kinda scared me, um, I had food stamps eventually but no money to pay the bills, and welfare check, they say they can only pay $\$ 400$ and some dollars for five kids...

\section{Chelsea}

Chelsea entered the visiting room and before sitting down stated, "I'll bet you never expected someone like me to be here." This 31 year old Caucasian mother of three was a registered nurse with a bachelor's degree who had been sentenced to 11 years for committing fraud to obtain a controlled substance. Her two daughters and one son were being cared for by their father during her incarceration. At the time of our interview, she had served two years and seven months and was hoping to be released six months later. She received one visit a week with her children and mother, and was able to make approximately 12 phone calls a month. When talking about how she coped, she began to cry and said, 
I don't sometimes. Um, you would think it would get easier after all this time but it doesn't.... when they walk out of that door it kills me.

Chelsea was talkative, and easy to talk to. She cried often during the interview, especially when talking about her children and about not being able to care for them herself. She stated that she did not allow her children see her cry and was trying to shield them from the difficult feelings she experienced by being incarcerated. She also stated that she doesn't ask them how they are feeling because she doesn't want to make them feel bad. She talked about feeling fortunate that she was able to communicate so frequently with her children but that she worries about the day-to-day stuff that the children are going through:

I'm worried about my daughter starting her period, I don't know how my ex-husband is going to deal with that. I' $m$ worried about like, you know, when he goes to parent teacher conferences and stuff, and other kids are like, 'where's your mom?' And my eight year old has told me that the teacher says she doesn't have to talk about it, so I know it's been an issue already. I get worried because my four year old son, you know, he says I take bad people to jail, well that's where his mom is. So, he asks me 'did you rob a bank?' because that's their automatic, you know."

\section{Madeline}

Madeline is a married, Caucasian, 35 year old mother of 10 children. She had seven boys and three girls and their ages ranged from nine months to 17 years. She had two prior incarcerations for a total of two and a half years. The current incarceration was for writing bad checks and she had been sentenced to 11 years. At the time of the interview she had served four months and had nine months left to serve. She received three visits a month but wrote and received eight to ten letters a month.

Madeline smiled as she talked about her children and she stated that this incarceration would be her last one because she knew everything that she was missing 
with her children. She said that missing her youngest son take his first steps was a turning point for her and that she believed that this would be her last incarceration:

...the more I come, the more I see that I've lost, you know, man I'm so done with this, and I've never, never said it, until I seen my little baby at that bonding visit...it's like he stood up, you know and he took a couple of steps, and I mean, that just broke me down. I've never, out of all the time I've been in prison, say I'm done, but I'm done. I can honestly say this time, I'm done, I can't do it no more.

She spoke in a matter-of-fact tone and talked about her children not being bothered by her incarceration. She talked about how difficult it was for her to see her kids leave after visitation but that she could call them after two hours of them leaving. She believes that her incarceration is much more difficult for her than it is for them.

It don't bother them no more, and I hate to say that, but it doesn't. It used to, you know before when I was locked up the first time, like I said, they cried on visitation, it was always like, 'mom, when are you coming home?' ...this time they don't ask period. It's like 'okay, I'll see ya when ya come home'...God it makes me feel like dirt. I get emotionally beat down...it tears me up, yeah, it does.

Leslie

Leslie was open and talkative and made good eye contact during the interview. This 40 year old mother of three boys had attended some college and was divorced. She was incarcerated for possession of a controlled substance, wanton endangerment, and trafficking and was sentenced to 15 years. She was set to be released nine months after the interview and had served a little over two years. Leslie's children were living with her mother and she was able to received four visits, four calls, and four letters a month from them.

Leslie stated that her drug addiction started with smoking marijuana at 12 years of age and that after a back injury she had been taking prescription drugs. She blamed her 
friends for her arrest and took no responsibility for her complicity to traffic drugs charge although she admitted to selling some of her prescription pills.

It wasn't that we were doing anything else, it's because his friends, they'd gotten into making meth and he was around it and he had stored somebody's stuff at our house, and there had been a nark that come in.... and he lied on the stand and everything....I got 15 for something I didn't have anything to do with. I'd been going to the doctor cuz my backs been fractured and I was getting pain pills for that and uh, yeah I did sell some because he wasn't working and I couldn't make ends meet with the bills, and kids, food...as far as my crimes go it wasn't anything to do with my children. It was my ignorant choices, that got me here cuz it's the only time I've ever been in trouble.

Leslie talked about her children's lives being worth more than what they are having to live with during her incarceration. She said that she was worried about social services getting involved and that her biggest fear was that her children would go to foster care so she felt "lucky" that her mother was caring for the children. Leslie said that getting involved with drugs and getting into trouble wasn't worth being separated from her children. She stated that she missed the companionship of her children but that she didn't worry about them since her mother was caring for them during her incarceration:

It's rough. I don't worry about em because I know my mom's taking good care of them, but I miss em. I miss their companionship, their ups and downs, and what they do during the daytime and what all I'm missing out on, and it's hard to, you know to sit and think about it, and I do think about it a lot.

\section{Melinda}

Melinda was a 42 year old African American, divorced, high school graduate who had custody of her six grandchildren. She had three boys and three girls ranging in age from one month to eight years. She had been sentenced to 14 years and had served seven years at the time of the interview. She had four prior incarcerations and had served a total 
of three and a half years. She had been convicted of fraudulent use of a credit card and was set to be released in a year and a half although she believed it would be sooner since she was incarcerated this time for a parole violation.

Melinda showed very little emotion and hardly made any eye contact. She spent the entire interview looking around the room and only briefly smiled when talking about her "babies." Talking about her oldest grandson who was eight years old,

...not supposed to have favorites but he's the one that was born first, and been around for three years with no other children. I got to do more with him than the others because I started getting locked up...when they accomplish something, anything, I mean anything they do good...

When she spoke about the lack of emotional connection that she had with her mother, she would look down to the floor. She explained how she had been raped at 10 years of age and that she harbored a lot of anger at her mother for leaving her to be raised by her grandmother and that her mother did not return to help her through the emotional pain she experienced. It wasn't until she was 15 years old that Melinda was told that she was the product of a rape from her grandmother's boyfriend and that was the reason her mother left her to be raised by her grandmother.

My grandmother practically raised me and um I had got raped when I was 10 , my mom, was already I California. I was very upset with my mother because she did not come back to deal with it but I also didn't realize that she also had been raped and I' $m$ the product of it....I was so angry with her because I just didn't understand... how was I supposed to deal with it...

She described having a better relationship with her mother but that her mother didn't want to talk about the past. Melinda avoided talking about the past with her mother and she talked about not getting any support from other incarcerated women. She copes 
with her situation by reading her bible and taking her post traumatic stress disorder (PTSD) medications.

Randi

Randi was a 30 year old, widowed, Caucasian mother, with a less than high school education. She spoke of the level of drug addiction that she has been surrounded with for her entire life. Her mother was addicted to drugs and was also in prison, although at a different facility. Randi had also experienced her husband dying from a drug overdose three years prior to our interview. When talking about how she took care of her children compared to how her mother cared for her she said,

I've pretty much followed her path...pretty much doing the same thing she done with us, picking drugs and alcohol over my kids, even though I thought they were being took care of and getting what they needed. I remember my mom would stay up all night partying and stuff and let us run up and down the hallway and stuff. That's what I done with my kids, let them do whatever they wanted to do....I thought that's what you were supposed to do, let your kids do whatever they wanted to do.

She had no previous incarcerations and had been sentenced to seven years for trafficking pills. She had served two years and was set to be released 45 days after our interview. Randi was the mother of two boys, ages seven and three and one girl, aged five years. She was able to talk to the children four times a month by telephone and received four letters a month. Her children were being cared for by her husband's aunt.

Randi did not appear to understand most questions the first time they were asked. She had a flat affect and would blankly stare after a question was asked. Randi did not smile and showed no emotion during the interview and provided short answers. Although she showed little emotion, when asked about her children and what worried her about them, her words were very descriptive: 
...um, them turning out like I have. Them being disgusted and mad because of what I've done. And maybe them holding resentments against me for their dad overdosing. Maybe them not wanting to come back and live with me when I get out...

\section{Tammy}

Tammy was a 32 year old African American, mother of a 15 year old son and a nine year old daughter. She had a less than high school education and was serving a seven year sentence for trafficking cocaine. She had served a little over one year and had seven prior incarcerations averaging three months each. Her children were living with her uncle and she received one letter a week and two visits per year. She smiled a lot when talking about her children saying,

...just knowing that they love me, even though I did wrong. And that they forgive me for being away from them. And that I'll make it right when I get the chance.

During the interview she made a little eye contact but her eyes flitted around the room the majority of the time. Tammy teared up when talking about her mother's terminal medical condition:

As far as the things I wanted in life, I wasn't able to get it from her. She was always an alcoholic...then she got real sick, I think it was hepatitis or something, they had to pump her stomach and stuff. I just know her as an alcoholic. I hold my past against her, and I keep throwing that up in her face. And uh, her condition now, just uh, makes me regret treating her the way that I did, but I still hold a grudge against her.

Talking about her future, she stated that she had been trying to be in nursing and that because of her incarceration she wouldn't be able to go back. She stated that she would live with her uncle when she was released and would probably get a factory job for work. She was looking forward to being back with her children and "taking care of them like a real mother should be." 
Jackie

Jackie was a 34 year old, Caucasian, divorced mother of two. She had been a nurse by profession and was serving a seven and a half year sentence for prescription fraud. Her charges stemmed from crimes in three counties and because of her conviction her nursing licensed was revoked. At the time of the interview, she had served a little over two years and had six months left to serve. She had one prior incarceration in which she served 11 months. Her 12 year old son and 15 year old daughter lived with their respective fathers. Although they lived in different homes, the fathers took the children to visit with each other and they would each take a turn at bringing both children to the prison for a visit with their mother. She talked about how she took care of her children differently than her mother took care of her and her sister:

My mother was not nurturing at all, she wasn't around a lot, she was a single parent, my mother was very abusive verbally and physically. She never, I can't remember one time that my mom ever told me that she loved me. I don't remember that. I always tell my kids how much I love them. I'm very affectionate with my kids. I've never been physically abusive with them, I just don't. I don't believe in that.

Jackie seemed happy and had good eye contact. She appeared content and humble. She was comfortable and relaxed and sat beside me at the table instead of across from me like all of the other participants had done. At the beginning of the interview, it seemed like Jackie was answering the questions like she thought they should be answered but very shortly she began to soften and open up and just talked. When she talked about how her children feel about her being in prison she stated,

Well, they don't like it, but they gotten used to it. They, you know my kids I think are my biggest supporters, because they'll say, 'you know mom, this is the best thing for you' and you know they can see that I've changed a lot, they really can....they can actually see changes in me. 
Betty

Betty was a 31 year old Caucasian, high school graduate. She was the mother of an eight year old daughter and two year old twins, a boy and a girl. She had two prior incarcerations where she served a total of seven years. She had been sentenced for 28 years for robbery and trafficking in a controlled substance and had served one year at the time of our interview. She stated that she had two years left to serve but that she was going up for shock probation the month after our meeting and would be requesting that she be able to return to a rehabilitation facility where she had previously gotten clean and sober:

...the best time of my life was at Chrysalis house with my daughter. I was sober for seven years then. It was the best time of my life. My daughter asks to go back to Chrysalis house because it was the best time, we was close. They was good memories for my daughter.

Betty got extremely soft spoken and made little eye contact. She appeared to disappear into her own thoughts at times and seemed to have fragmented thoughts. She spoke of being scared for most of her life and talked about being forced into selling drugs for her father when she was 12 years old:

I never stood a chance. I had to sell his dope when I was a kid. I started doing drugs when I was 12. My dad would hold a gun to my head and tell me to go sell his dope or he would kill me. He was mean. Everyone was afraid of him.

Her drug addiction started in childhood as a way to escape her home life according to her description of growing up. She described two incidents that her father held a gun to her head and threatened to kill her; the second incident was with her daughter present. She talked about her 12 siblings being "drug pushers" and that no one 
in her family would speak to her because she intended to not return to the town where she grew up:

They don't talk to me. It bothers me, they say I've changed and we don't have a relationship. I'm the baby of 12 and they all do drugs, they all deal.

She described that from the programs that she had attended while in prison, she had learned to be stronger and that she had to "work" her program. She talked about her ideal day after she is released and she said, "me and my babies, yeah, me and my babies." Kara

Kara was a 29 year old, eight-month pregnant, mother of an eight year old son. At the time of the interview she had not been sentenced for her crime of driving while intoxicated. She had served four months and had 10 prior incarcerations, all for alcohol related offenses. Although she was to have court ordered communication with her son, Kara had one contact with him since her incarceration which was distressing to her and she had received word that her ex-mother-in-law would be pursuing terminating her parental rights:

...his birthday, she accepted one call from me on his birthday. He turned eight and I talked to him and that was just once in four and a half months. And I said can I call back in a week and she said no, I can't afford it.

She attempted to make another phone call in the month prior to our meeting but did not get any answer and has not tried to call again. She recognized the ramifications this was having on her son and said,

My child doesn't deserve this, you know. Even if he had a great support system right now where he's at. I've got to keep in my mind that there is a future, you know. Keep the faith and hope and keep trying, you know. 
Kara appeared confused, wanted clarification for each questions, and had bouts of sobbing that would abruptly stop. She did smile on a couple of occasions as she talked about her son but appeared depressed during the rest of the interview. She planned on a future with her son but there was a disconnect in her conversation when she talked about her son. Her description about what identified her as a mother simply included recognizing him as her son:

The first time I got locked up, I was here for seven days, it about killed me because my little boy was three years old. He's just a part of me, he's my child, he's my son. I teach him things, you know, love him like nobody else can, he's my son. I'm proud of him, he's a beautiful son.

\section{Kaitlyn}

Kaitlyn was a 39 year old mother who was married and had a high school education, of a 12 year old son. She was convicted of tax fraud and was sentenced to 10 years. At the time of the interview she had served two years and three months and had eight months left to serve. Kaitlyn had no prior incarcerations. Kaitlyn was open with she talked but cried often and appeared scared at times. Her son was living with his father, who was not Kaitlyn's current husband, and her last contact with him was just after her incarceration, which began in 2008. Kaitlyn was pained by the lack of contact she had with her son:

Not knowing anything about him is the worst. I could serve every day of 10 years as long as I knew he was okay. I scan the obituaries looking for his name. I just pray that I don't see his name because that means he's okay but it's the only way that I have to even learn anything about him.

Kaitlyn's mother died when Kaitlyn was 10 years old. She had never known her mother healthy and felt that she took care of her mother rather than her mother taking care of her. She remembered being bounced around to the homes of different relatives as 
a child. Her father remarried 10 months after her mother's death and she didn't have a good relationship with her stepmother. She remembers her father calling her a worthless mother f---er and she stated strongly that her father never said he loved her nor was he nurturing. She stated that being a mother was the only thing she ever wanted and she now knows that she can survive without taking the Xanax that she had been taking. Talking about her experience of being in prison:

It's gut wrenching. I can't breathe thinking about what I've done. My current husband is angry with me. This family is all he ever wanted and now he's lost both of us.

Abby

Abby was a 34 year old mixed race, married mother of two girls and a boy. She was sentenced to eight years in prison for identity theft, forgery, theft by deception, and criminal possession. She had served three years and was set to be released three weeks after our interview. Her only contact is writing a letter each week to her oldest daughter. She has no contact with her younger two children as they live with their paternal grandmother and she is unable to contact them. When she talked about her younger children she talked about how they were when she knew them at seven and six years old because that was her last contact with them.

...my son, he was a momma's boy. He clung right to me all the time, I couldn't do nothing without him. But with (daughter) it was touch and go, cuz she did her own thing. She just had her own world, she was more of a daddy's girls. I still worry that they won't know who I am cuz its been so long, cuz I haven't seen them in, God, forever. I just worry that they'll forget me.

Abby smiled a lot but didn't give off a warm vibe. Instead she had a hard demeanor and was hard to read. She teared up twice when talking about her children but 
then forced herself to stop. When she talked about her future plans, she didn't talk about being with her children. She spoke of working and going to school but made no mention about her children in that response:

I'm gonna try to work and go to school. And I'm going to go get my nails done, and my toes done, that's first on the list (laughing). Focusing on me when I first get out so I can get myself together.

Marcie

Marcie was a 28 year old mother of a one year old son. She was sweet and talkative and elaborated a lot when talking about her son. She smiled easily when talking about him and what she experienced as his mother for the two months that she was with him before being incarcerated.

It was wonderful, it was amazing, it was the best experience of my life. He was with me every second. I never knew love like I knew love when I looked into his eyes for the first time. I knew that that was my purpose in life. I was put here on this earth to be his mother. It's like amazing.

At the time of our meeting, she had been incarcerated for one year of a six year sentence for receiving stolen property and was finishing her sentence two months after our interview. She had approximately 17 prior incarcerations and had served a total of two years.

She was able to write to her son and she received pictures every week from her mother. She had phone conversations with her father every week and she also received two visits a month from her mother and son. She described her relationship with her mother as good although that wasn't the case when she was a child. She spoke about her mother leaving her to be raised by her grandmother when she was four years old and not 
returning until she was in the fourth grade. She sees the situation of him living with her mother the same as she was raised by her grandmother. She worries about his future:

Seventy percent that have parents that have been incarcerated end up incarcerated. So I'm gonna do my best to make him not a part of that statistic. Now I know what I have to do in my life to never make the same mistakes again, and I don't think that if I hadn't come to prison this time, I don't think it would have sank in really.

Cathy

Cathy is a 31 year old mother of two sons, ages 13 and eight. She was serving a 24 year sentence for trafficking and had served three and a half years at the time of the interview. She had 10 months remaining to serve. Cathy had two prior incarcerations lasting a total of 20 months. Cathy's sons were being cared for by the father of her eight year old son and he brought them for visits every three to four months. She wrote letters to them every week but did not talk to them by telephone:

That's why I can't really fuss so much, you know, cuz he's taken responsibility of one that's not his. And I know they're taken care of, regardless if I have contact or not with them. But you know, I do my part as a mother, I write em, and try to call them when I can.

Cathy was uncomfortable and apprehensive at the beginning of the interview but then settled into the conversation and became talkative. She pulled at her hair a lot until she pulled it back. Cathy cried a lot and continuously wiped her eyes. She appeared sad for most of the interview. She stated that before she came to prison she was on disability for "mental issues" and a learning disability. Cathy worries about something happening to her sons but she talked about being happy when she thinks about how they are doing in school or some of the silly things they say. After she is released, her ideal day would be: 
...getting them ready for school, being there when they come home, and letting them know, that it's gonna be okay.

Kristin

The final participant in the study was Kristin, a 22 year old mother of three children, two boys and a girl. Two of her children, a boy and a girl are twins and all of her children live with her parents while she and her husband are both incarcerated. She was serving time for identity theft and was sentenced to 15 years. She had served two years and four months and was planning on being released eight months after the interview. Kristin has no prior incarcerations although she spoke about getting in trouble as a teenager for stealing and fighting. She said that she never got punished and that she thinks that contributed to her current incarceration:

I did a couple of things when I was younger with stealing and stuff, joy riding in people's cars and fighting and stuff like that...just for the thrill of it, because I seen how I got away with it at first... so then I started to do more and more and more of criminal acts.

Kristin talked about coming from a wealthy family where they financially supported her after her son was born when she was in high school and how they have continued to financially support her through her court case and as they prepare to secure her an apartment when she's released. Her main concern was for her children and their relationship with their father since he would be in prison for an extensive period of time. She believes that her criminal activity would have been worse if it wasn't for her four year old son. She said that because of her responsibility to him, she wasn't with her husband when he committed his crimes:

I think I probably would have done worse if he wasn't there. Because I know a lot of my crime was, (husband) got the IDs and credit cards, I just used them. And I think if my son wasn't there, I would have been there with him getting em, robbing people. I think if my son wasn't there I 
would have done worse. Who knows how much worser I would have done.

Kirstin said that being incarcerated would be easier if she didn't have children.

She said it would honestly be "a piece of cake" and:

...with the kids it makes it more stressful, more things to worry about other than yourself. And it's like you know, I wonder what they did today, I wonder what they felt today, it makes it really difficult. 


\section{APPENDIX 9}

Significant Statements

\begin{tabular}{|c|c|c|c|}
\hline $\begin{array}{l}\text { Significant Participant Statement } \\
\text { Exemplars }\end{array}$ & Categories & Sub Theme & Theme \\
\hline $\begin{array}{l}\text { "I didn't practice active parenting...I } \\
\text { wasn't always there and I wasn't you } \\
\text { know, the one that was there to pick them } \\
\text { up during the day when they fell down or } \\
\text { hurt themselves or when they felt bad } \\
\text { about something..." (Lydia, mother of } 4 \text { ) }\end{array}$ & $\begin{array}{l}\text { Should have } \\
\text { done a better } \\
\text { job }\end{array}$ & \multirow[b]{2}{*}{$\begin{array}{c}\text { Mistakes } \\
\text { were Made }\end{array}$} & \multirow{6}{*}{$\begin{array}{l}\text { Living in the } \\
\text { fire: The } \\
\text { Lived } \\
\text { Experience } \\
\text { of } \\
\text { Incarcerated } \\
\text { Mothers }\end{array}$} \\
\hline $\begin{array}{l}\text { "...you feel like you failed at being a } \\
\text { mother. I look around and I'm like, I } \\
\text { can't believe that I chose pills over my } \\
\text { kids. I should be out there protecting } \\
\text { them and making sure they're safe from } \\
\text { predators or just anybody, and teaching } \\
\text { them right from wrong." (Randi, mother } \\
\text { of } 3 \text { ) }\end{array}$ & $\begin{array}{l}\text { Let the } \\
\text { children down }\end{array}$ & & \\
\hline $\begin{array}{l}\text { "...just because I'm in prison that doesn't } \\
\text { make me a bad mom. I'm still a mom and } \\
\text { I still love my kids more than anything. I } \\
\text { just made bad decisions and bad } \\
\text { choices." (Lydia, mother of } 4 \text { ) }\end{array}$ & $\begin{array}{l}\text { Addressing the } \\
\text { stigma }\end{array}$ & \multirow{4}{*}{$\begin{array}{l}\text { The 'Here } \\
\text { and Now' } \\
\text { of it }\end{array}$} & \\
\hline $\begin{array}{l}\text { “...it makes you feel bad about yourself } \\
\text { cause you know you could have done } \\
\text { something to prevent it. It's not easy } \\
\text { knowing you got kids out there, they're } \\
\text { playing ball or like my daughter's on the } \\
\text { dance team and I've never seen her } \\
\text { dance. It's hard" (Abby, mother of } 3 \text { ) }\end{array}$ & Not worth it & & \\
\hline $\begin{array}{l}\text { "I think I took it for granted before being } \\
\text { able to take care of my kids...Prisons } \\
\text { been a great teacher of gratitude so I } \\
\text { know that when I get out, you know, I'm } \\
\text { not gonna take these moments for } \\
\text { granted anymore." (Khloe, mother of 2) }\end{array}$ & Gratitude & & \\
\hline $\begin{array}{l}\text { "I can put a smile on their face...they're } \\
\text { happy when I do something good. Just to } \\
\text { see them smile means I'm not a failure. } \\
\text { I'm always their hero." (Renee, mother } \\
\text { of 4) }\end{array}$ & $\begin{array}{l}\text { Still wanted, } \\
\text { Still loved }\end{array}$ & & \\
\hline $\begin{array}{l}\text { "I'm missing out on a lot of stuff; I mean } \\
\text { I can't give him the guidance. I can't } \\
\text { teach him the things that I want, that is }\end{array}$ & Missing out & $\begin{array}{l}\text { Motivated } \\
\text { to Change }\end{array}$ & $\begin{array}{l}\text { Emerging } \\
\text { from the } \\
\text { fire: }\end{array}$ \\
\hline
\end{tabular}




\begin{tabular}{|c|c|c|c|}
\hline $\begin{array}{l}\text { important to how his life will be in the } \\
\text { future." (Regina, mother of } 1 \text { ) }\end{array}$ & & & $\begin{array}{l}\text { Dreams for } \\
\text { the Future }\end{array}$ \\
\hline $\begin{array}{l}\text { "...the more I come here, the more I see } \\
\text { that I've lost. I'm so done with this...he } \\
\text { took a couple of steps and I mean, that } \\
\text { just broke me down. I can honestly say } \\
\text { this time I'm done, I can't do it not } \\
\text { more." (Madeline, mother of } 10 \text { ) }\end{array}$ & $\begin{array}{l}\text { Impetus for } \\
\text { change }\end{array}$ & & as Mothers \\
\hline $\begin{array}{l}\text { "...teach them more, everything I can } \\
\text { possibly think of, teach them. Show em } \\
\text { how the outside world can be, if you } \\
\text { make bad choices, uh what can actually } \\
\text { happen to your family. They're learning } \\
\text { that now with me. This is not your future } \\
\text { and you need to worry about getting } \\
\text { schoolwork, good grades." (Leslie, } \\
\text { mother of 3) }\end{array}$ & $\begin{array}{l}\text { Teaching them } \\
\text { the right way }\end{array}$ & & \\
\hline $\begin{array}{l}\text { "It will make me do right. I've been } \\
\text { locked up so long this time, taking } \\
\text { programs, it's made me want to do what I } \\
\text { have to do in order to stay from behind } \\
\text { these bars. Make sure that we are doing } \\
\text { things the positive way instead of doing } \\
\text { them the wrong way." (Tammy, mother } \\
\text { of } 2 \text { ) }\end{array}$ & $\begin{array}{l}\text { Self } \\
\text { improvement }\end{array}$ & \multirow{3}{*}{$\begin{array}{l}\text { Redefining } \\
\text { Themselves }\end{array}$} & \\
\hline $\begin{array}{l}\text { "I'll make it right when I get a chance. } \\
\text { Being back with them and taking care of } \\
\text { them like a real mother should be, } \\
\text { working, having a roof over their head, } \\
\text { clothes on their back, and being } \\
\text { interactive with them more often." } \\
\text { (Tammy, mother of } 2 \text { ) }\end{array}$ & $\begin{array}{l}\text { Vision of being } \\
\text { the ideal } \\
\text { mother }\end{array}$ & & \\
\hline $\begin{array}{l}\text { "I made a promise to him to never leave } \\
\text { him again, to make better decisions for } \\
\text { my life. I think about him every day and I } \\
\text { love him." (Marcie, mother of 1) }\end{array}$ & $\begin{array}{l}\text { Being a mom } \\
\text { the kids need }\end{array}$ & & \\
\hline
\end{tabular}


APPENDIX 10

Codes, Categories, Sub-Themes, Themes

\begin{tabular}{|c|c|c|c|c|c|}
\hline \multicolumn{2}{|c|}{ List of Codes/Responses } & $\begin{array}{l}\text { Most Common Codes/Responses } \\
\text { Rearranged by Categories }\end{array}$ & $\begin{array}{l}\text { Identified } \\
\text { Categories }\end{array}$ & Sub-Themes & Themes \\
\hline $\begin{array}{l}\text { Best thing } \\
\text { Born to be a mom } \\
\text { Kids are my life } \\
\text { Great } \\
\text { Hard/Difficult } \\
\text { Awesome } \\
\text { Love it } \\
\text { Missing Out } \\
\text { Milestones } \\
\text { No Contact }\end{array}$ & $\begin{array}{l}\text { Guilt/Shame } \\
\text { Stressful } \\
\text { Horrible } \\
\text { Not worth it/Think Twice } \\
\text { Don't make mistakes } \\
\text { Not a place to be a mom } \\
\text { Still their mom } \\
\text { Keep in touch } \\
\text { Not a bad person } \\
\text { Not a bad mom }\end{array}$ & $\begin{array}{l}\text { - Should have been there more } \\
\text { - Followed same path as my mom } \\
\text { - Would get high } \\
\text { - Drugs } \\
\text { - Got aggravated } \\
\text { - Not as involved }\end{array}$ & $\begin{array}{l}\text { - Should have done } \\
\text { a better job } \\
\text { - Let the Children } \\
\text { down }\end{array}$ & $\begin{array}{l}\text { Mistakes were } \\
\text { Made }\end{array}$ & \multirow{2}{*}{$\begin{array}{l}\text { Living in the Fire } \\
\text { The Lived } \\
\text { Experience of } \\
\text { Mothering }\end{array}$} \\
\hline $\begin{array}{l}\text { Took places } \\
\text { Active in } \\
\text { school/homework } \\
\text { Holidays/events } \\
\text { Play with the kids } \\
\text { Always with me/Be a } \\
\text { mom/Love them } \\
\text { Should have been } \\
\text { there more } \\
\text { My responsibility to } \\
\text { teach them }\end{array}$ & $\begin{array}{l}\text { Followed same path as } \\
\text { my mom } \\
\text { They're taken care of } \\
\text { Child happy to see } \\
\text { her/wants her/loves her } \\
\text { Seeing them } \\
\text { I was there/involved } \\
\text { Not as involved } \\
\text { Getting better } \\
\text { Taking every class I can }\end{array}$ & $\begin{array}{l}\text { - Not a bad person } \\
\text { - Not a bad mom } \\
\text { - What people think/say to child } \\
\text { - They support me/Love me } \\
\text { - Will be more grateful }\end{array}$ & $\begin{array}{l}\text { - Addressing the } \\
\text { Stigma } \\
\text { - Not worth it } \\
\text { - Gratitude } \\
\text { - Still wanted, still } \\
\text { loved }\end{array}$ & $\begin{array}{c}\text { The 'Here and } \\
\text { Now' of it }\end{array}$ & \\
\hline $\begin{array}{l}\text { Great } \\
\text { Good } \\
\text { They support me/Love } \\
\text { me } \\
\text { Tell them/Show them } \\
\text { love } \\
\text { Strained } \\
\text { Kids mad }\end{array}$ & $\begin{array}{l}\text { Walked away/Hid Stress } \\
\text { Got aggravated } \\
\text { Snapped/Yelled } \\
\text { Would get high } \\
\text { Drugs } \\
\text { Will be more grateful }\end{array}$ & $\begin{array}{l}\text { - Missing out } \\
\text { - Milestones } \\
\text { - Worry about something happening } \\
\text { to child } \\
\text { - My responsibility to teach them }\end{array}$ & $\begin{array}{l}\text { - Missing out } \\
\text { - Impetus for } \\
\text { Change } \\
\text { - Teaching them the } \\
\text { right way }\end{array}$ & $\begin{array}{l}\text { Motivated to } \\
\text { Change }\end{array}$ & \multirow{2}{*}{$\begin{array}{c}\text { Emerging from } \\
\text { the Fire: Dreams } \\
\text { for the Future as } \\
\text { Mothers }\end{array}$} \\
\hline $\begin{array}{l}\text { Grow up like me } \\
\text { Thinking I forgot them } \\
\text { Do drugs } \\
\text { Health/emotions } \\
\text { Worry about } \\
\text { something happening } \\
\text { to child } \\
\text { Go to prison } \\
\text { Sex }\end{array}$ & $\begin{array}{l}\text { Growing up } \\
\text { Forgetting mom } \\
\text { Long term effects } \\
\text { How they're taken care of } \\
\text { What people think/say to } \\
\text { child } \\
\text { Should be there }\end{array}$ & $\begin{array}{l}\text { - Born to be a mom } \\
\text { - Kids are my life } \\
\text { - Tell them/Show them love } \\
\text { - Taking every class I can } \\
\text { - Getting Better } \\
\text { - Always with me/Be a mom/Love } \\
\text { them } \\
\text { - Should be there } \\
\text { - Play with the kids }\end{array}$ & $\begin{array}{l}\text { - Self Improvement } \\
\text { - Visions of being an } \\
\text { Ideal Mother } \\
\text { - Being a mom the } \\
\text { kids need }\end{array}$ & $\begin{array}{l}\text { Redefining } \\
\text { Themselves }\end{array}$ & \\
\hline
\end{tabular}




\title{
CURRICULUM VITAE
}

\author{
Barbara Jackson, BSN, RN \\ 4017 Sheehan Drive \\ Buckner, KY 40010 \\ (H) $502-852-4868$ \\ (Fax) 502-852-8783 \\ bmjack01@louisville.edu
}

\section{A. Education}

\begin{tabular}{|c|c|}
\hline 2005 - Present & $\begin{array}{l}\text { University of Louisville } \\
\text { Louisville, KY }\end{array}$ \\
\hline $2002-2005$ & $\begin{array}{l}\text { Indiana University Southeast } \\
\text { New Albany, IN }\end{array}$ \\
\hline $1997-1998$ & $\begin{array}{l}\text { Alvin Community College } \\
\text { Alvin, TX }\end{array}$ \\
\hline $1983-1985$ & $\begin{array}{l}\text { Valencia Community College } \\
\text { Orlando, FL }\end{array}$ \\
\hline
\end{tabular}

\section{B. Employment}

\author{
PhD Nursing Program \\ Bachelor in Science Degree in Nursing \\ (GPA 3.61) \\ Completed 39 credits towards a Masters \\ Degree in Healthcare Administration \\ Associate of Science (Hospitality \\ Management/Business Management \\ (Dean's List)
}

$\begin{array}{ll}8 / 08- & \text { Instructor } \\ \text { Present } & \text { School of Nursing } \\ & \text { University of Louisville }\end{array}$

- Arrange activities related to clinical e.g. orientation, pre and post conferences, unit activities for undergraduate nursing students

- Supervise undergraduate nursing students in the delivery of patient care at Home of the Innocents; supervise undergraduate nursing students in their community activities at TAPP and JB Atkinson Elementary; act as patient advocate, student advocate; liaison with students, hospital staff and administration and University of Louisville School of Nursing 


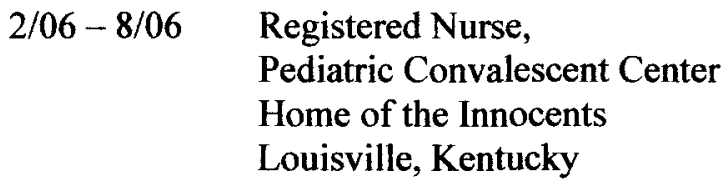

10/05 - 2/06 Registered Nurse Intensive Care Unit Baptist Hospital Northeast La Grange, Kentucky administration

- Prepare and deliver students midrotation and final evaluations; agency evaluation; preceptor evaluation

- Grade assignments and enter grades in online grade book using university Blackboard system

- Schedule, coordinate, and deliver patient care in the Pediatric Convalescent Center; act as patient advocate, assess patient status and notify physicians of clinical changes

- Educate patient's family members on health care status and health care needs

- Perform clinical tasks according to hospital policies

- Schedule, coordinate, and deliver patient care in the Intensive Care Unit for adults; act as patient advocate, assess patient status and notify physicians of clinical changes

- Educate patients and family members on health care status and health care needs

- Perform clinical tasks according to hospital policies

- Admit, transfer, and discharge patients to/from ICU to other nursing units or other facilities

- Surgical Intensive Care Unit

- Medical Intensive Care Unit $\begin{array}{ll}11 / 99-12 / 01 & \text { Adult Day Program } \\ & \text { Coordinator } \\ & \text { Cedar Lake Lodge } \\ & \text { LaGrange, Kentucky }\end{array}$
- Planned and developed Community Adult Day Program- providing services for adults living with severe and profound mental retardation and associated mental illnesses, including Policy and Procedure Manual for Community and In-House Adult Day Programs

- Managed Adult Day Program; providing active treatment and teaching daily 
$10 / 95-7 / 96$

$6 / 93-11 / 94$

$3 / 89-6 / 93$
Operations Assistant Gwinnett Medical Center Lawrenceville, Georgia

Quality Assessment Abstractor Florida Hospital Medical Center Orlando, Florida

Quality Assessment Analyst

Florida Hospital Medical Center

Orlando, Florida living skills to adults with severe and profound mental retardation, including direction, supervision, and evaluation of staff members

- Completed daily activity tracking data and monthly analysis reports, monitored monthly budget reports, prepared resident goals and objectives, analyzed resident goals monthly

- Prepared Departmental Budget, justified Monthly Budget (general ledger, budget distribution), completed price negotiation and item purchase (including capital equipment) for implementation of a new operating room, and organized product and equipment evaluation

- Maintained time and attendance records including paid time off, timecards, extended/workman's compensation leave forms, and biweekly personal statistics

- Participated in site visits with nursing leadership to hospitals and medical equipment manufacturing facilities in preparation for implementation of new operating room

- Implemented Medis Group System at Florida Hospital Kissimmee, one of the Central Florida hospitals in the Florida Hospital System.

- Developed and implemented a system-wide process for obtaining medical records for review

- Provided education and training for new staff

- Abstracted \& computed data and prepared committee and department reports for surgical, blood, mortality, and utilization review cases 


\author{
$10 / 87-3 / 89$ \\ Vital Statistics Coordinator \\ Florida Hospital Medical Center \\ Orlando, Florida
}

Graduate Assistantships

$\begin{array}{ll}\begin{array}{l}\text { 8/07- } \\ \text { present }\end{array} & \text { Graduate Research Assista } \\ \text { School of Nursing } & \text { University of Louisville } \\ & \text { Louisville, Kentucky } \\ & \\ 8 / 06-5 / 07 & \text { Graduate Teaching Assistant } \\ \text { School of Nursing } \\ \text { University of Louisville } \\ \text { Louisville, Kentucky }\end{array}$

- Processed Birth and Death records; maintained updated information and completed required statistics in accordance with Florida Law

- Note: During this time the Center for Women's Medicine was beginning an outpatient program for incontinence. I accepted the additional responsibility for designing and implementing the computer database and marketing for this new program

- Create patient database for Harambee Nursing Clinic

- Preparation and computer entry of Harambee Nursing Clinic patient fee tickets

- Assist faculty with IRB proposal submission, research instrument selection, data collection, etc.

- Develop conference posters for faculty members

- Assist with manuscript edits, literature reviews, powerpoint presentations for faculty members

- Assist Research Office Staff with various tasks such as biosketch creation, copying, scanning

- Create endnote or reference manager databases for faculty reference lists

- Arrange activities related to clinical e.g. orientation, pre and post conferences, unit activities for undergraduate nursing students

- Supervise undergraduate nursing students in the delivery of patient care at University Hospital; act as patient advocate, student advocate; liaison with students, hospital staff and administration and University of Louisville School of Nursing administration

- Prepare and deliver students midrotation and final evaluations; agency 
evaluation; preceptor evaluation

- Grade assignments and enter grades in online grade book using university Blackboard system

\section{Certifications \& Licensure}

Kentucky Registered Nurse, License \#1106616

\section{Professional Memberships and Activities}

Southern Nursing Research Society

American Nurses Association (Kentucky)

Student Nurses Association, IUS chapter, Secretary; Breakthrough to Nursing chairperson, 2002

\section{E. Honors and Awards}

- $1^{\text {st }}$ place, poster presentation, Adaptation of African American Women to Motherhood, $9^{\text {th }}$ International Family Nursing Conference, 2009

- Dr. Margaret S. Miles poster award, Parent/Child Research Interest Group, for Adaptation and Resiliency of African American Mothers, Southern Nursing Research Society Annual Convention, 2008

- $2^{\text {nd }}$ place, student poster session 2, for Adaptation and Resiliency of African American Mothers, Southern Nursing Research Society Annual Convention, 2008

- Ruth B. Craddock Fund (\$500), 2007

- Pinnacle National Honor Society, 2005

- Veteran's Administration Learning Opportunity Residency (VALOR) in the Surgical and Medical Intensive Care Units, 2004

- Mary Lou Kraus Jacobi Scholarship (competitive), 2003, 2004

- Alpha Chi National College Honor Scholarship Society, 2002

- Sigma Theta Tau International Honor Society of Nursing, 2004 - present

\section{F. Committees and Services}

School of Nursing:

2010 Curriculum Council, Chairperson

2009-present Undergraduate Program Committee, Member

2007-2008 Graduate Academic Affairs, $\mathrm{PhD}$ program representative

Community Service:

2003-2005

Center for Women and Families-provided childcare services to women and children in Kentucky and Indiana shelters 
2003 - present

2004 - present

2008,2009

\section{G. Teaching}

Undergraduate
St. Johns Day Shelter for Men-provided shower facilities, personal care items, reading materials, coffee, and other various day shelter services. Make shelter wish-list donations

Wayside Christian Mission - serve meals, assist with child care center needs. Make shelter wish-list donations

Harambee Nursing Clinic - assist with annual health fair activities including serving food, assist vendors, and assist community members

N 351 Adult Health Nursing, Clinical, Instructor, 2006 (20 students), 2007 (10 students)

N 451 Synthesis Complex Health, Clinical, Instructor, 2007 (10 students), 2009 (10 Students)

N 352 Pediatric Health, Instructor, 2008 (30 students)

N 441 Nursing Care of the Childbearing Family, Instructor, 2009 (20 students)

N 361 Community Health, Instructor, 2009 (20 students), 2010 (10 students)

N 464 Child Health Nursing, Instructor, 2009 (40 students), 2010 (40 students)

N 473 Community Leadership Practicum, 2010 (6 students)

\section{Graduate}

N 610 Nurse Educator Practicum, 2010 (2 students)

\section{H. Abstracts and Presentations}

Jackson, B. (2011). The Lived Experience of Mothering during Incarceration, Southern Nursing Research Society Annual Conference, Jacksonville, Florida.

Jackson, B., Kiehl, E. (2009) Adaptation of African American Women to Motherhood, $9^{\text {th }}$ International Family Nursing Conference, Reykjavik, Iceland.

Jackson, B., Kiehl, E. \& Armstrong, D. (2008). Adaptation and Resiliency of African American Mothers. Southern Nursing Research Society Annual Conference, Birmingham, Alabama.

Oral Presentations: National/International Meetings

Summer 2009 Adaptation of African American Women to Motherhood, $9^{\text {th }}$ International Family Nursing Conference, Reykjavik, Iceland (Competitively Selected)

\section{Poster Presentation: National/International Meetings}

Summer 2009 Adaptation of African American Women to Motherhood, $9^{\text {th }}$ International Family Nursing Conference, Reykjavik, Iceland (Competitively Selected) 


\section{Poster Presentation: Local/Regional Meetings}

Spring 2011

Spring 2008

Fall 2007
The Lived Experience of Mothering During Incarceration, Southern Nursing Research Society Annual Conference, Jacksonville, FL. (Competitively Selected)

Adaptation and Resiliency of African American Mothers, Southern Nursing Research Society Annual Conference, Birmingham, AL. (Competitively Selected)

Adaptation and Resiliency of African American Mothers, Research!Louisville annual celebration of health related research, Louisville, KY. (Competitively Selected) 